\title{
DOR EM RECÉM-NASCIDOS HOSPITALIZADOS EM UNIDADE DE TERAPIA INTENSIVA: ASPECTOS FISIOLÓGICOS, COMPORTAMENTAIS E ENDÓCRINOS
}

Versão corrigida da tese apresentada ao Programa de Pós-Graduação Interunidades de Doutoramento em Enfermagem, da Escola de Enfermagem da Universidade de São Paulo e Escola de Enfermagem de Ribeirão Preto, da Universidade de São Paulo, para obtenção do título de Doutor em Ciências.

Área de Concentração: Enfermagem

Linha de Pesquisa: Fundamentos Teóricos e Filosóficos do cuidar

Orientadora: Prof. ${ }^{a}$ Dr. ${ }^{a}$ Mariana Bueno

Coorientadora: Prof. ${ }^{\text {a }}$ Dr. ${ }^{\text {a }}$ Isília Aparecida Silva

\section{VERSÃO CORRIGIDA}

A versão original encontra-se disponível na Biblioteca da Escola de Enfermagem da Universidade de São Paulo e na Biblioteca Digital de Teses e Dissertações da Universidade de São Paulo.

\section{São Paulo}


AUTORIZO A REPRODUÇÃO TOTAL OU PARCIAL DESTE TRABALHO, POR QUALQUER MEIO CONVENCIONAL OU ELETRÔNICO, PARA FINS DE ESTUDO E PESQUISA, DESDE QUE CITADA A FONTE.

Assinatura:

Data:

1

Catalogação-na-publicação (CIP)

Biblioteca Wanda de Aguiar Horta

Escola de Enfermagem da Universidade de São Paulo

Rocha, Vanderlei Amadeu da

Dor em recém-nascidos hospitalizados em unidade de terapia

intensiva: aspectos fisiológicos, comportamentais e endócrinos. / Vanderlei

Amadeu da Rocha. São Paulo, 2020.

$160 \mathrm{p}$.

Tese (Doutorado) - Escola de Enfermagem da Universidade de São Paulo.

Orientador(a): Prof. ${ }^{a}$ Dr. ${ }^{\text {a }}$ Mariana Bueno

Coorientador(a):Prof. ${ }^{a}$ Dr. ${ }^{a}$ Isília Aparecida Silva

Área de concentração: Enfermagem.

1. Recém-Nascido. 2. Dor. 3. Avaliação da Dor. 4. Sinais Vitais. 5. Citocinas. I. Título

Ficha catalográfica automatizada.

Bibliotecária responsável: Fabiana Gulin Longhi (CRB-8: 7257) 
Nome: Vanderlei Amadeu da Rocha

Título: Dor em recém-nascidos hospitalizados em unidade de terapia intensiva: aspectos fisiológicos, comportamentais e endócrinos.

Tese apresentada ao Programa de Pós-Graduação Interunidades de Doutoramento em Enfermagem da Escola de Enfermagem, da Universidade de São Paulo e Escola de Enfermagem de Ribeirão Preto, da Universidade de São Paulo, para obtenção do título de Doutor em Ciências.

Aprovado em:

\section{Banca Examinadora}

Orientadora: Prof. ${ }^{\mathrm{a}}$ Dr. $^{\mathrm{a}}$

Instituição: Assinatura:

Coorientador: Prof. ${ }^{a}$ Dr. ${ }^{a}$

Instituição: Assinatura:

Prof. Dr. Instituição:

Julgamento: Assinatura:

Prof. Dr. Instituição:

Julgamento: Assinatura:

Prof. Dr. Instituição:

Julgamento: Assinatura: 
Dedico este estudo à minha filha,

Mariana Sayuri, por todo carinho e compreensão.

Luz da minha vida. 


\section{AGRADECIMENTOS}

Agradeço a Deus por iluminar meus caminhos e por me dar forças para continuar a enfrentar os obstáculos de cada dia.

Aos meus pais, Antonio e Delzuita, e ao meu irmão, Vanderson, pelo apoio constante e exemplo de luta, simplicidade, coragem e honestidade. À minha esposa, Paula, exemplo de dedicação e perseverança, pelo companheirismo, por entender inúmeras vezes minha ausência e por dividir comigo todas as conquistas e angústias. Agradeço também à minha filha, Mariana Sayuri, pelo carinho e amor incondicional.

Ao Prof. Dr. Sanseray pela amizade, conselhos, paciência, apoio, discussões e ajuda em todas as etapas. Serei eternamente grato.

À minha orientadora Prof. ${ }^{a}$ Dr. ${ }^{a}$ Mariana Bueno, pela amizade, por ouvir minhas ideias e por todas as oportunidades de aprendizagem que muito contribuíram para a minha formação.

À minha Coorientadora Prof. ${ }^{a}$ Dr. ${ }^{a}$ Isília Aparecida Silva, por acreditar em mim, pelo apoio e confiança.

Aos Professores Pedro Fernandes, Regina Pekelmann Markus e Zulma Felisbina da Silva Ferreira, pela amizade, acolhida e por abrirem as portas de seus laboratórios ao longo dos anos.

À Prof. ${ }^{a}$ Dr. ${ }^{a}$ Patrícia de Freitas pela amizade, apoio e por estar sempre disposta a ajudar.

Agradecimento mais que especial a toda de equipe de enfermagem da Unidade de Terapia Intensiva Pediátrica e Neonatal do Hospital Universitário da Universidade de São Paulo: Alda, Ana Beatriz, Ana Zélia, Anne, Camilla, Cleidevane, Cristiane, Daniela, Denise, Edilene L., Edilene P, Edson, Emilia, Fabiana L., Fabiana P., Fernanda, Ione, Juliana, Kátia, Keline, Késsia, Leandro, Luciana, Marcelo, Márcia, Maria Aparecida, Maria Emília, Maria 
Helena, Nair, Nanci, Neide, Nelaine, Pérola, Renata, Roberta, Rozilene, Silvia, Solange, Tatiana, Thamiris, Vanessa C., Vanessa R., Vera e Zenaide. Vocês foram fundamentais para o desenvolvimento deste trabalho.

Aos alunos de graduação em Enfermagem e da residência da Saúde da Criança e do Adolescente, da Escola de Enfermagem, da Universidade de São Paulo, pela colaboração.

Ao Programa de Pós-Graduação Interunidades de Doutoramento em Enfermagem da Escola de Enfermagem, da Universidade de São Paulo e Escola de Enfermagem de Ribeirão Preto, da Universidade de São Paulo.

Aos funcionários da Escola de Enfermagem, da Universidade de São Paulo, Hospital Universitário da Universidade de São Paulo e do Departamento de Fisiologia do Instituto de Biociências, da Universidade de São Paulo, pelo profissionalismo e competência nos serviços prestados.

Agradecimento especial a todos recém-nascidos e seus pais que, gentilmente, aceitaram participar desta pesquisa e sem os quais este trabalho não seria possível.

A todos aqueles que contribuíram de alguma maneira para a realização deste trabalho.

O presente trabalho foi realizado com apoio da Coordenação de Aperfeiçoamento de Pessoal de Nível Superior - Brasil (CAPES). 
O êxito da vida não se mede pelo caminho que você conquistou, mas sim pelas dificuldades que superou no caminho. 
ROCHA,V. A. Dor em recém-nascidos hospitalizados em unidade de terapia intensiva: aspectos fisiológicos, comportamentais e endócrinos [tese]. São Paulo: Escola de Enfermagem, Universidade de São Paulo; 2020.

\section{RESUMO}

Introdução: recém-nascidos $(\mathrm{RN})$, que passam semanas ou meses na Unidade de Terapia Intensiva Neonatal (UTIN), são submetidos a um número elevado de procedimentos dolorosos. Estes procedimentos podem desencadear uma resposta global, que inclui alterações fisiológicas, endócrinas e comportamentais. Apesar do grande número de escalas validadas nas últimas décadas, até o momento, não existe um método ideal para a avaliação da dor neonatal. Desta forma, outros parâmetros têm sido explorados, como por exemplo, as dosagens de mediadores inflamatórios. Objetivos: avaliar padrões físiológicos, comportamentais e endócrinos, relacionados a procedimentos dolorosos, nos primeiros três dias de vida em RN, hospitalizados em UTIN. Método: estudo clínico primário, observacional e prospectivo, desenvolvido na UTIN do Hospital Universitário, da Universidade de São Paulo. Foram coletados dados demográficos dos RN, bem como do número e o tipo de procedimentos dolorosos, medidas farmacológicas e não farmacológicas adotadas. Foram coletados ainda sinais vitais e escores de dor registrados em prontuário clínico. Finalmente, foram coletadas três amostras de saliva, por três dias consecutivos (1-3) para a dosagem de 11 citocinas (IFNg, IL1b, IL2, IL4, IL6, IL8, IL10, IL12, IL17, TNF e VEGF). Resultados: foram incluídos no estudo $90 \mathrm{RN}$, dos quais 53,33\% nasceram de parto cesárea; $62,22 \%$ do sexo masculino; $87,78 \%$ classificados como adequado para a idade gestacional (AIG); 48,88\% são pré-termo e 48,88\% de termo; idade gestacional média de 35 semanas; Escore de Apgar médio no $5^{\circ} \mathrm{min} 7,51 \quad(\mathrm{DP}=1,95)$; peso ao nascimento médio 2,56Kg $(\mathrm{DP}=1,0)$; o principal diagnóstico registrado foi desconforto respiratório precoce (60\%). Tempo médio de permanência na UTIN foi de 54,98 horas ( $\mathrm{DP}=30,61)$. Os RN foram submetidos ao total de 2.732 procedimentos dolorosos, foram empregadas 540 estratégias não farmacológicas e 216 medidas farmacológicas. Da admissão ao terceiro dia de internação, foram realizados, em média, 30,36 procedimentos dolorosos por RN, com média de 5,98 medidas não farmacológicas e 2,39 medidas farmacológicas. Nas primeiras 24 horas após a admissão, a média de procedimentos foi de 12,78 , no primeiro dia, a média foi de 8,1 , no segundo e terceiro dias, a média de procedimentos realizados foi de 5,36 e 3,84, respectivamente. $\mathrm{O}$ procedimento doloroso mais frequentemente realizado foi a glicemia capilar (20,96\%). Registrou-se média de 1,98 medidas não farmacológicas nas primeiras 24 horas após admissão, 1,73 no primeiro dia, sendo média de 1,23 e 0,97 no segundo e terceiro dias, respectivamente. A estratégia não farmacológica mais comumente registrada foi a redução de luminosidade $(28,33 \%)$. Com relação às medidas farmacológicas, foram adotadas, em média, 0,81 na admissão, 0,66 no primeiro dia, 0,544 no segundo dia e, 0,36 no terceiro dia, sendo o fentanil contínuo $(48,83 \%)$ a principal medida farmacológica documentada. $\mathrm{O}$ escore NIPS e os sinais vitais apresentam variabilidade da admissão ao terceiro dia de internação. Finalmente, observou-se oscilação do nível das 11 citocinas e, destaca-se a presença de correlação positiva das IL-1b $(r=0,52 ; p<0,05)$, IL-2 $(r=0,4 ; p<0,05)$, IL-6 $(r=$ $0,64 ; \mathrm{p}<0,05)$ e VEGF $(\mathrm{r}=0,44 ; \mathrm{p}<0,05)$ com o número de procedimentos dolorosos. Conclusões: evidencia-se que da admissão ao terceiro dia de internação na UTIN, os RN foram expostos a número elevado de procedimentos potencialmente dolorosos, sendo insuficiente o manejo da dor. As alterações fisiológicas e comportamentais não refletem necessariamente o número de intervenções nas quais os RN foram submetidos. Destaca-se ainda, que a dosagem dos mediadores inflamatórios nas amostras de saliva pode fornecer 
fundamentação científica para a avaliação da dor, que juntamente com os parâmetros fisiológicos e comportamentais, amplia as perspectivas para o desenvolvimento de novas pesquisas para investigar a associação entre dor e as citocinas inflamatórias e compreender melhor as características das condições dolorosas.

Palavras-chave: Recém-nascido. Dor. Avaliação da Dor. Sinais Vitais. Citocinas. 
ROCHA,V. A. Pain in newborns hospitalized in an intensive care unit: physiological, behavioral and endocrine aspects. [thesis]. São Paulo: Nursing School, University of São Paulo; 2020.

\begin{abstract}
Introduction: newborns (NB), who spend weeks or months in the Neonatal Intensive Care Unit (NICU), undergo a high number of painful procedures. These procedures can trigger a global response, which includes physiological, endocrine and behavioral changes. Despite the large number of scales validated in recent decades, so far, there is no ideal method for the assessment of neonatal pain. Thus, other parameters have been explored, such as, for example, the dosages of inflammatory mediators. Objectives:to evaluate physiological, behavioral and endocrine patterns, related to painful procedures, in the first three days of life in newborns hospitalized in the NICU. Method: primary, observational and prospective clinical study, developed at the NICU of the University Hospital of the University of São Paulo. Demographic data of newborns were collected, as well as the number and type of painful procedures, pharmacological and non-pharmacological measures adopted. Vital signs and pain scores recorded in clinical records were also collected. Finally, three saliva samples were collected for three consecutive days (1-3) for the measurement of 11 cytokines (IFNg, IL1b, IL2, IL4, IL6, IL8, IL10, IL12, IL17, TNF e VEGF). Results: 90 newborns were included in the study, of which $53.33 \%$ were born by cesarean delivery; $62.22 \%$ were male; $87.78 \%$ classified as adequate for gestational age (AGA);48.88\% are preterm and $48.88 \%$ term; average gestational age of 35 weeks; Mean Apgar score in the 5th min 7.51 (SD = 1.95); average birth weight $2.56 \mathrm{~kg}(\mathrm{SD}=1.0)$; the main diagnosis recorded was early respiratory distress $(60 \%)$. The average length of stay in the NICU was 54.98 hours (SD = 30.61). The newborns underwent a total of 2,732 painful procedures, 540 non-pharmacological strategies and 216 pharmacological measures were used. From admission to the third day of hospitalization, an average of 30.36 painful procedures per NB were performed,with an average of 5.98 non-pharmacological measures and 2.39 pharmacological measures. In the first 24 hours, after admission, the average of procedures was 12.78, on the first day, the average was 8.1, on the second and third days, the average of the procedures performed was 5.36 and 3.84, respectively. The most frequently performed painful procedure was capillary glycemia (20.96\%).An average of 1.98 non-pharmacological measures was recorded in the first 24 hours after admission, 1.73 on the first day, with an average of 1.23 and 0.97 on the second and third days, respectively.The most commonly registered non-pharmacological strategy was the reduction in brightness $(28.33 \%)$. Regarding pharmacological measures, an average of 0.81 was taken at admission, 0.66 on the first day, 0.544 on the second day and 0.36 on the third day, with continuous fentanyl (48.83\%) being the main pharmacological measure documented. The Neonatal Infant Pain Scale (NIPS) and vital signs show variability from admission to the third day of hospitalization. Finally, there was an oscillation in the level of the 11 cytokines and the presence of a positive correlation of IL- $1 \mathrm{~b}(\mathrm{r}=0.52 ; \mathrm{p}$ $<0.05)$, IL-2 ( $r=0.4 ; p<0.05)$, IL-6 $(r=0.64 ; p<0.05)$ and VEGF $(r=0.44 ; p<0.05)$, with the number of painful procedures. Conclusions: it is evident that from admission to the third day of hospitalization to the NICU,the NBs were exposed to a high number of potentially painful procedures, with insufficient pain management. Physiological and behavioral changes do not necessarily reflect the number of interventions to which newborns have undergone. It is also noteworthy that the dosage of inflammatory mediators in saliva samples can provide a scientific basis for pain assessment,which, together with the physiological and behavioral parameters, expands the perspectives for the development of new research to investigate the
\end{abstract}


association between pain and inflammatory cytokines and to better understand the characteristics of painful conditions.

Keywords: Newborn. Pain. Pain Assessment. Vital signs. Cytokines. 
Figura 1 - Dispositivo utilizado para coleta de amostra de saliva e armazenamento

Figura 2 - Caracterização dos RN incluídos no estudo quanto a (A) tipo de parto; (B) sexo; (C) classificação em relação ao peso e idade gestacional; (D) classificação em relação à idade gestacional ao nascimento; (E) via de parto em RN pré-termo, a termo e póstermo.

Figura 3 - Caracterização dos RN pré-termo, termo e pós-termo incluídos no estudo, de acordo com (A) idade gestacional; (B) Escore de Apgar e (C) peso ao nascimento (em kg)....

Figura 4 - Tempo de permanência dos RN pré-termo, termo e pós-termo incluídos no estudo na UTIN, durante o período de coleta em horas de internação, por grupo (pré-termo, termo e póstermo).

Figura 5 - (A) Número total de procedimentos potencialmente dolorosos, estratégias não farmacológicas e farmacológicas; (B) Número total de procedimentos potencialmente dolorosos por $\mathrm{RN}$, de acordo com a classificação em pré-termo, termo e pós-termo; (C) Número total de medidas não farmacológicas por $\mathrm{RN}$, de acordo com a classificação em pré-termo, termo e pós-termo; (D) Número total de medidas farmacológicas por $\mathrm{RN}$, de acordo com a classificação em pré-termo, termo e póstermo

Figura 6 - (A) Média do número de procedimentos potencialmente dolorosos, estratégias não farmacológicas e farmacológicas da admissão ao terceiro dia de internação na UTIN; (B) Procedimentos potencialmente dolorosos; (C) Estratégias não farmacológicas; (D) Estratégias farmacológicas

Figura 7 - (A) Média do número de procedimentos potencialmente dolorosos, estratégias não farmacológicas e farmacológicas da admissão ao terceiro dia de internação na UTIN; (B) Média do número de procedimentos potencialmente dolorosos, estratégias não farmacológicas e farmacológicas em RN prétermo; (C) Média do número de procedimentos potencialmente dolorosos, estratégias não farmacológicas e farmacológicas em RN a termo; (D) Média do número de procedimentos potencialmente dolorosos, estratégias não farmacológicas e farmacológicas em RN pós-termo; (E) Escore NIPS por RN; (F) Escore NIPS por grupo; (G-J) Porcentagem de RN com dor ao longo das horas; (K-N) Porcentagem de RN com dor por dia. 
Figura 8 - Média da temperatura axilar da admissão ao terceiro dia de internação na UTIN. Valores de referência: mínimo (linha azul) e máximo (linha vermelha)

Figura 9 - Média da frequência cardíaca da admissão ao terceiro dia de internação na UTIN. Valor de referência: máximo (linha vermelha)

Figura 10 - Média da frequência respiratória da admissão ao terceiro dia de internação na UTIN. Valor de referência: máximo (linha vermelha).

Figura 11 - Média da $\mathrm{SpO} 2$ da admissão ao terceiro dia de internação na UTIN. Valores de referência mínimo (linha azul) e máximo (linha vermelha)

Figura 12 - (A) Média da pressão sistólica; (B) Média da pressão diastólica; (C) Média da Pressão Média. Valores de referência mínimo (linha azul) e máximo (linha vermelha)

Figura 13 - Correlação de Spearman do número de procedimentos potencialmente dolorosos

Figura 14 - Mediadores inflamatórios avaliados nas amostras de saliva no primeiro e segundo dias.

Figura 15 - (A) Mediadores inflamatórios dosados; (B) Número de parâmetros correlacionados às citocinas; (C) Correlação IFNg e Saturação de Oxigênio; (D) Correlação IFNg e Número de Medidas não Farmacológicas; (E) Correlação IL1b e Temperatura Axilar; (F) Correlação IL1b e Frequência Respiratória; (G) Correlação IL1b e Pressão Diastólica; (H) Correlação IL1b e Pressão Média; (I) Correlação IL1b e Número de Procedimentos; (J) Correlação IL2 e Temperatura Axilar; (K) Correlação IL2 e Frequência Respiratória; (L) Correlação IL2 e Pressão Diastólica; (M) Correlação IL2 e Pressão Média; (N) Correlação IL2 e Número de Procedimentos; (O) Correlação IL4 e Frequência Respiratória; (P) Correlação IL4 e Saturação de Oxigênio 
Figura 16 - (A) Mediadores inflamatórios dosados; (B) Número de parâmetros correlacionados às citocinas; (C) Correlação IL6 e Temperatura Axilar; (D) Correlação IL6 e Frequência Respiratória; (E) Correlação IL6 e Número de Procedimentos; (F) Correlação IL6 e Número de Medidas não Farmacológicas; (G) Correlação IL8 e Número de Medidas não Farmacológicas; (H) Correlação IL10 e Temperatura Axilar; (I) Correlação IL10 e Frequência Respiratória; (J) Correlação IL10 e Número de Medidas Farmacológicas; (K) Correlação IL12 e Saturação de Oxigênio; (L) Correlação IL17 Frequência Respiratória; (M) Correlação IL17 e Pressão Diastólica.

Figura 17 - (A) Mediadores inflamatórios dosados; (B) Número de parâmetros correlacionados às citocinas; (C) Correlação TNF e Temperatura Axilar; (D) Correlação TNF e Frequência Respiratória; (E) Correlação TNF e Pressão Diastólica; (F) Correlação TNF e Pressão Média; (G) Correlação VEGF e Temperatura Axilar; (H) Correlação VEGF e Frequência Respiratória; (I) Correlação VEGF e Pressão Diastólica; (J) Correlação VEGF e Pressão Média; (K) Correlação VEGF e Número de Procedimentos; (L) Correlação VEGF e Número de Medidas não Farmacológicas.... 
Tabela 1 - Caracterização dos RN incluídos no estudo quanto à idade gestacional ao nascimento (em semanas), Escore de Apgar ( $1^{\circ}$, $5^{\circ}$ e $10^{\circ}$ minutos de vida) e peso ao nascimento (em $\mathrm{kg}$ )

Tabela 2 - Diagnósticos registrados nos prontuários clínicos dos RN incluídos no estudo, no momento da admissão.

Tabela 3 - Tempo de permanência (em horas) dos RN incluídos no estudo durante período de coleta.

Tabela 4 - Número total de procedimentos, medidas não farmacológicas e farmacológicas por RN realizadas da admissão ao terceiro dia de internação na UTIN.

Tabela 5 - $\quad$ Número de dispositivos utilizados nos RN ao longo de todo o período do estudo e de acordo com os dias de internação na UTIN.

Tabela 6 - Tipos de dispositivos utilizados nos RN da admissão ao terceiro dia de internação na UTIN.

Tabela 7 - Número de procedimentos potencialmente dolorosos, medidas não farmacológicas e farmacológicas realizadas da admissão ao terceiro dia de internação na UTIN

Tabela 8 - Escore NIPS da admissão ao terceiro dia de internação na UTIN

Tabela 9 - Temperatura axilar da admissão ao terceiro dia de internação na UTIN

Tabela 10 - Frequência cardíaca da admissão ao terceiro dia de internação na UTIN.

Tabela 11 - Frequência respiratória da admissão ao terceiro dia de internação na UTIN.

Tabela 12 - Saturação de oxigênio da admissão ao terceiro dia de internação na UTIN.

Tabela 13 - Pressão sistólica, diastólica e média.

Tabela 14 - Correlação de Spearman do número de procedimentos potencialmente dolorosos. 
Tabela 15 - Mediadores inflamatórios avaliados nas amostras de saliva, no primeiro e segundo dias. 


\section{LISTA DE ABREVIATURAS E SIGLAS}

AIG

CAAE Certificado de Apresentação de Apreciação Ética

CCIP Cateter Central de Inserção Periférica

$\mathrm{CO} \quad$ Centro Obstétrico

COT Cânula Endotraqueal

CPAP Continuous Positive Airway Pressure

DHEG Doença Hipertensiva Específica da Gravidez

DMG Diabetes Mellitus Gestacional

EEUSP Escola de Enfermagem da Universidade de São Paulo

FC Frequência Cardíaca

FM Filho de Mãe

FR

GIG

HU-USP Hospital Universitário da Universidade de São Paulo

IASP International Association for the Study of Pain

IFNg Interferon Gama

IL-10 Interleucina-10

IL12 Interleucina-12

IL-17 Interleucina-17

IL-1b Interleucina-1b

IL-2 Interleucina-2

IL-4 Interleucina-4

IL-6 Interleucina-6 


\begin{tabular}{|c|c|}
\hline IL-8 & Interleucina-8 \\
\hline ITU & Infecção do Trato Urinário \\
\hline IV & Terapia Intravenosa \\
\hline Max & Máximo \\
\hline Min & Mínimo \\
\hline NIPS & Neonatal Infant Pain Scale \\
\hline PA & Pressão Arterial \\
\hline PD & Pressão Diastólica \\
\hline PIG & Adequado para Idade Gestacional \\
\hline PIPP & Prematura Perfil Infant Pain \\
\hline PM & Pressão Média \\
\hline PS & Pressão Sistólica \\
\hline RN & Recém-Nascido \\
\hline SAM & Síndrome de Aspiração de Mecônial \\
\hline SNC & Sistema Nervoso Central \\
\hline $\mathrm{SpO} 2$ & Saturação Periférica de Oxigênio \\
\hline $\mathrm{T}$ & Temperatura \\
\hline TCLE & Termo de Consentimento Livre e Esclarecido \\
\hline $\mathrm{TNF}$ & Fator de Necrose Tumoral \\
\hline TPP & Trabalho de Parto Prematuro \\
\hline USP & Universidade de São Paulo \\
\hline UTIN & Unidade de Terapia Intensiva Neonatal \\
\hline VAS & Vias Aéreas Superiores \\
\hline VEGF & Fator de Crescimento Endotelial Vascular \\
\hline
\end{tabular}




\section{LISTA DE SÍMBOLOS}

\begin{tabular}{|c|c|}
\hline$\%$ & Porcentagem \\
\hline${ }^{\circ} \mathrm{C}$ & Graus Celsius \\
\hline bpm & Batimentos por minuto \\
\hline DP & Desvio Padrão \\
\hline $\mathrm{g}$ & Gramas \\
\hline $\mathrm{h}$ & Horas \\
\hline ipm & Inspirações por minuto \\
\hline $\mathrm{Kg}$ & Quilogramas \\
\hline $\min$ & Minutos \\
\hline $\mathrm{mL}$ & Mililitro \\
\hline $\mathrm{mmHg}$ & Milímetros de mercúrio \\
\hline $\mathrm{N}$ & Número de sujeitos \\
\hline $\mathrm{O} 2$ & Oxigênio \\
\hline $\mathrm{pg} / \mathrm{ml}$ & Picogramas por mililitro \\
\hline $\mathrm{rpm}$ & Rotações por minuto \\
\hline
\end{tabular}


1 INTRODUÇÃO

1.1 Justificativa do Estudo............................................................................ $\quad 35$

2 OBJETIVOS

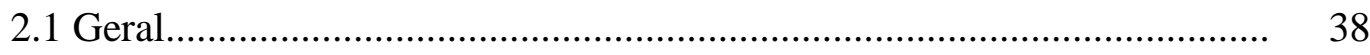

2.2 Específicos......................................................................... 38

3 MATERIAL E MÉTODOS................................................................................. 41

3.1 Desenho do Estudo........................................................................... 42

3.2 Local do Estudo...............................................................................

3.3 População e Amostra.............................................................................. 43

3.3.1 Critérios de Inclusão........................................................................

3.3.2 Critérios de Exclusão.........................................................................

3.4 Coleta de Dados..................................................................................

3.4.1 Consentimento..................................................................................

3.4.2 Instrumento de Coleta de Dados....................................................... 44

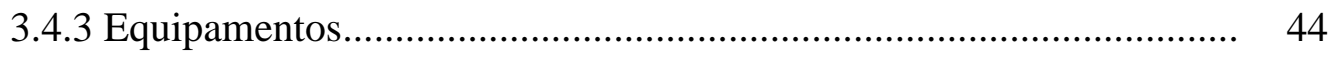

3.4.4 Procedimento de Coleta de Dados..................................................... 45

3.4.5 Coleta de saliva.............................................................................. 45

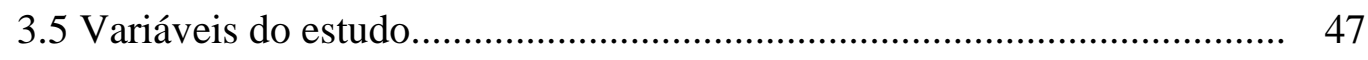

3.5.1 Caracterização dos RN................................................................. 47

3.5.2 Quantificação de procedimentos realizados........................................ 47

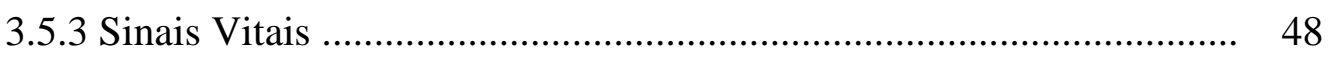

3.5.4 Escala de dor................................................................................ 48 
3.6 Análise estatística............................................................................ 49

3.7 Aspectos Éticos...................................................................... 49

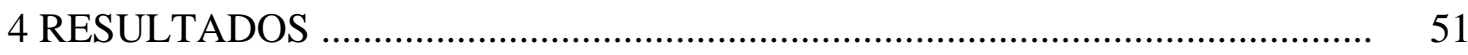

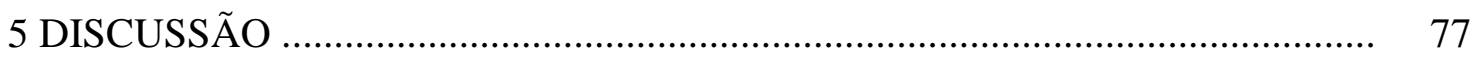

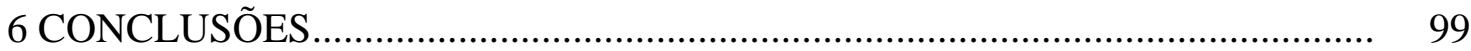

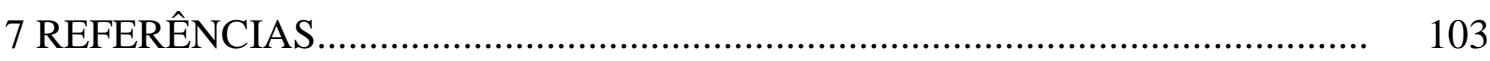

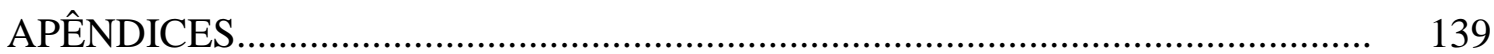

APÊNDICE A - Termo de Consentimento Livre e Esclarecido..................... 140

APÊNDICE B- Termo de Assentimento Livre e Esclarecido.......................... 143

APÊNDICE C - Instrumento de Coleta de Dados - Procedimentos dolorosos

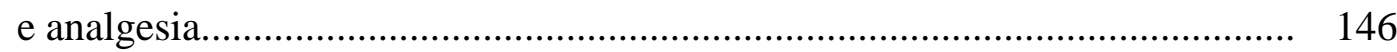

APÊNDICE D - Instrumento de Coleta de Dados - Caracterização dos

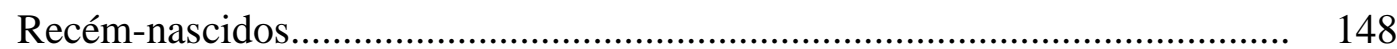

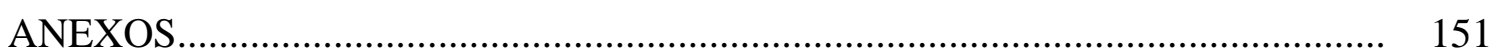

ANEXO 1 - Parecer consubstanciado do CEP EEUSP................................... 152

ANEXO 2 - Parecer consubstanciado do CEP HU - USP............................. 157 



\section{INTRODUÇÃO}

A neonatologia tem passado por profundas transformações nas últimas décadas, tanto do ponto de vista tecnológico, quanto da implementação de evidências científicas na prática clínica, o que tem proporcionado melhorias significativas no cuidado ao recém-nascido (RN) e sua família (Blencowe et al., 2012). Estes avanços têm resultado em diminuição na mortalidade dos RN que necessitam de internação em Unidade de Terapia Intensiva Neonatal (UTIN), em função de patologias ou anomalias congênitas, ou por eventos adversos durante a gestação ou parto (Maxwell et al., 2013). A mortalidade infantil diminuiu de forma acentuada nas três últimas décadas, em grande parte do mundo (Liu et al., 2015; Hug et al., 2019), ainda assim, aponta-se que no Brasil, a taxa de mortalidade neonatal persiste elevada, com 11,5 óbitos a cada 1.000 nascidos vivos, em 2019 (de Souza, Duim e Nampo, 2019).

A UTIN é, certamente, um ambiente estressante onde predominam situações que podem contribuir para o desarranjo da homeostasia do RN. Dentre elas, destacam-se o ambiente com luminosidade e temperatura artificiais, os ruídos constantes e estressantes e, ainda, a quantidade elevada de manipulações realizadas, em geral, dolorosas e estressantes (Jordão et al., 2016). Este ambiente contrasta muito com a calma e a proteção uterina, expondo assim estes $\mathrm{RN}$ a constantes experiências que podem impactar negativamente em seu crescimento e desenvolvimento.

Um RN pré-termo, que passa uma média 25 dias hospitalizado numa UTIN, por exemplo, recebe cerca de 130 a 234 manipulações em 24 horas (Santos et al., 2012). Muitas destas manipulações resultam da instabilidade clínica e da necessidade de procedimentos invasivos terapêuticos e diagnósticos, como intubação traqueal, aspiração traqueal e de vias aéreas, coleta de sangue, inserção de cateteres venosos e arteriais, entre outros (Cruz, Fernandes e Oliveira, 2016; Ganguly et al., 2020; Orovec et al., 2019).

A primeira semana de vida é, em geral, considerada crítica, por isso se observa a realização de elevado número de procedimentos dolorosos (Chen et al., 2012). Em geral, observa-se correlação entre o número de procedimentos e variáveis como a idade pós-natal, ao peso de nascimento e a gravidade da doença (Simons et al, 2003; Stevens et al, 2003; Johnston et al, 2011; Brito et al., 2014). Estudos apontam que o número médio de procedimentos dolorosos, realizados durante a estadia na UTIN varia entre 7,5 e 17,3 procedimentos por dia (Courtois et al., 2016; Cruz, Fernandes e Oliveira, 2016).

Assim, a dor é uma experiência sensorial e emocional desagradável, associada ou semelhante à associada a um dano tecidual real ou potencial (International Association for the 
Study of Pain - IASP, 2020). Dor e estresse prolongado são comuns na hospitalização em UTIN e podem impactar na qualidade de vida e no desenvolvimento neuropsicomotor do RN, em curto e longo prazo (Santos et al., 2012; Ranger e Grunau, 2014). Vale ressaltar que a alteração do processamento doloroso e o aumento da resposta à dor são os efeitos mais comuns em longo prazo, após os procedimentos dolorosos (Grunau et al., 2001; Taddio et al., 2002; Walker et al., 2018) e, que estes efeitos podem persistir até a adolescência (Buskila et al., 2003; Jaekel, Eryigit-Madzwamuse e Wolke, 2016; Linsell et al., 2018; Olsen et al., 2018).

Em 2015, um estudo envolvendo $10 \mathrm{RN}$ a termos saudáveis, com idade gestacional média no momento do estudo de 40,6 semanas, encontrou evidências de que estes experimentam dor de maneira semelhante aos adultos, ao comparar-se as respostas cerebrais de ambos por ressonância magnética funcional, após estímulo agudo no calcanhar (Goksan et al., 2015). Os resultados revelaram que 18, das 20 regiões cerebrais ativadas em adultos com dor aguda, também eram ativas em RN (Goksan et al., 2015). Embora se tenha acreditado previamente que o sistema sensorial do RN era incapaz de responder a estímulos nocivos, atualmente sabe-se que após 24 semanas de gestação os RN exibem atividade cortical evocada (Bartocci et al., 2006; Slater et al., 2006), robusta secreção de hormônios do estresse (Anand et al., 1987), e elevação da frequência cardíaca e atividade facial (Grunau et al., 2005; Grunau et al., 2010), em resposta a estímulos dolorosos (Perry et al., 2018).

Desta forma, entende-se que as vias nociceptivas são funcionais após o nascimento e a dor produz respostas fisiológicas e comportamentais significativas em neonatos prematuros e a termo (Walker et al., 2013). Evidências sugerem que os prematuros podem ter uma maior sensibilidade à dor do que os neonatos a termo ou crianças mais velhas (Fitzgerald e Beggs, 2001). Embora o sistema nervoso periférico esteja desenvolvido e funcional com 24 semanas gestacionais, as vias neurais ainda são imaturas e há mudanças neuroanatômicas substanciais que ocorrem no período pós-natal, na distribuição das fibras ascendentes não mielinizadas e mielinizadas (Fitzgerald e Walker, 2009; Hatfield, 2014).

Apesar do avanço na compreensão da experiência multidimensional da dor, muitos aspectos permanecem inexplorados, particularmente na população neonatal. Durante o desenvolvimento neonatal, os RN apresentam alto grau de neuroplasticidade e são muito vulneráveis aos efeitos moduladores de estímulos nocivos (Schwaller e Fitzgerald, 2014; Beggs, 2015), principalmente se estes estímulos forem de natureza repetitiva. É amplamente aceito que os neonatos percebem e respondem à dor e que procedimentos invasivos, dolorosos e repetitivos ocasionam repercussões negativas em curto e longo prazo, incluindo respostas 
fisiológicas agudas deletérias e possível neuromodulação, que levam à alteração das respostas aos estímulos nocivos (Anand et al., 1987; Bosenberg e Flick, 2013; Bouza, 2009; Taddio et al., 1995; Taddio e Katz, 2005; Walker, 2013).

Portanto, estudos têm demonstrado que estímulos dolorosos repetidos podem resultar em déficits de memória de curto prazo (Nuseir et al., 2015) e podem ter maior importância biológica e clínica para prematuros (Anand, 1998; Valeri, Holsti e Linhares, 2015), já que estes apresentam maior sensibilidade a estímulos táteis e, por conseguinte, maior sensibilidade à dor (Vinall et al., 2012).

De fato, a dor ativa mecanismos compensatórios do sistema nervoso autônomo e produz uma gama de respostas comportamentais, fisiológicas e hormonais que podem ser utilizadas como ferramentas de avaliação clínica da dor, inclusive em RN (Grunau et al., 2007; Hatfield e Ely, 2015). A partir de alguns destes parâmetros, mais de 46 instrumentos de medida foram desenvolvidos para avaliar a dor em RN, muitos destes compostos por parâmetros fisiológicos, comportamentais e contextuais para a avaliação, em especial, da dor procedural (Walden e Gibbins, 2008).

Nesse sentido, a avaliação das respostas comportamentais à dor em RN apresenta desafios únicos. Por um lado, em comparação com um $\mathrm{RN}$ a termo, a resposta comportamental de um prematuro à dor é generalizada, inespecífica e, comumente, de curta duração. Além disso, as respostas à dor procedural são diferentes daquelas à dor pósoperatória, especialmente entre os prematuros, que não conseguem sustentar uma resposta comportamental à dor (Hatfield e Ely, 2015). Observa-se que os parâmetros comportamentais, como a atividade facial (Grunau e Craig, 1987; Stevens et al, 2000), choro (Lemos et al., 2010), movimentos corporais (Holsti e Grunau, 2007) e estados de sono-vigília (Grunau et al., 2004) são considerados mais específicos que os parâmetros fisiológicos para o reconhecimento da dor neonatal (Lemos et al., 2010; Hatfield e Ely, 2015).

As respostas comportamentais mais amplamente documentadas e válidas incluem expressão facial, choro e movimento corporal (Gibbins, Stevens e Asztalos, 2003; Stevens et al., 2007). Salienta-se que a atividade facial é um indicador específico, válido e confiável para a dor neonatal e que RN a termo são mais propensos a mostrar expressões faciais do que os prematuros (Ramelet et al., 2006). Aponta-se, ainda, que a principal dificuldade em usar o choro como uma medida de dor é que os neonatos são capazes de produzir um choro robusto por outras razões que não à exposição a um estímulo nocivo. Por outro lado, um RN pode não conseguir chorar devido à interferência mecânica (por exemplo, intubação traqueal) ou gravidade da doença (Hatfield e Ely, 2015). É reconhecido, por exemplo, que crianças 
extremamente doentes não apresentam o mesmo grau de resposta comportamental à dor, em comparação com crianças mais saudáveis (Franck et al., 2000; Gibbins et al., 2008; Slater et al., 2009).

Logo, a capacidade de avaliar indicadores comportamentais pode ser influenciada por fatores como a idade gestacional, uso de ventilação mecânica, a gravidade da doença e o uso de intervenções farmacológicas (Brummelte et al., 2012).

Haja vista que os indicadores fisiológicos, comumente mensurados para a avaliação da dor neonatal, são medidas relativamente não-invasivas. Estes incluem frequência cardíaca (FC) (Gibbins e Stevens, 2003; Gibbins et al., 2008; Mainous e Looney, 2007), frequência respiratória (FR) (Faye et al., 2010; Mainous \& Looney, 2007), pressão arterial (PA) e saturação periférica de oxigênio (SpO2) (Mainous e Looney, 2007; Gibbins et al., 2008), entre outros.

Desse modo, a FC é um indicador fisiológico frequentemente utilizado na avaliação da dor, no qual se observa elevação e/ou variabilidade em neonatos durante procedimentos dolorosos (Gibbins et al., 2008; De Jonckheere et al., 2011). Vários estudos também relatam aumento da FR acompanhada da diminuição da $\mathrm{SpO} 2$, durante procedimento doloroso (Raeside, 2011; de Jesus et al., 2011). Faye et al., (2010) relataram diminuição da variabilidade da FR em RN a termo e prematuros com dor pós-operatória, por exemplo.

Então, o uso isolado destes indicadores tem se demonstrado ineficaz devido à incapacidade dos RN em apresentar uma resposta autonômica sustentada na presença da dor; adicionalmente, outros fatores, tais como ventilação mecânica e intervenções farmacológicas podem interferir nas medidas destes parâmetros (de Jesus et al., 2011; Hatfield e Ely, 2015; Field, 2017). Embora variáveis fisiológicas sejam valiosas no fornecimento de medidas objetivas da dor, elas têm baixa especificidade e podem ser alteradas por outros estímulos como fadiga, fome e estresse (Raeside, 2011; Hatfield e Ely, 2015). Além disso, o processo de obtenção de medidas fisiológicas pode ocasionar desconforto no RN, alterando as respostas comportamentais associadas à dor (Hatfield e Ely, 2015).

Reconhece-se que a avaliação da dor em RN na UTIN é de importância vital devido à alta prevalência de dor nesta população. Salienta-se ainda que esta avaliação pode ser realizada por instrumentos padronizados específicos, sendo que todos os métodos têm vantagens e limitações (Bueno et al., 2007). Devido à complexidade da avaliação da dor no período neonatal, a maioria das escalas utilizadas é multidimensional, visto que elas avaliam tanto parâmetros fisiológicos, como comportamentais e contextuais, o que aumenta a sua especificidade (Ranger, Johnston e Anand, 2007). 
Em revisão sistemática, realizada por Giordano et al., (2019), foram identificadas 65 escalas para a avaliação da dor e/ou sedação. Das 65 escalas incluídas, 57 escalas (88\%) são empregadas para a avaliação da dor, 13 escalas (20\%) para a avaliação da sedação e quatro escalas (6\%) avaliam as duas condições. Nesta revisão, das 65 escalas, 32 (49\%) foram validadas para avaliar a dor aguda, 14 (22\%) para avaliar a dor prolongada e 18 (28\%) para avaliar a dor no pós-operatório. Ainda, de acordo com os resultados desta revisão sistemática, das 65 escalas, 42 (65\%) são escalas comportamentais e 23 (35\%) escalas multidimensionais, que devem ser aplicadas de acordo com a população avaliada. Os autores destacaram as seguintes escalas: COMFORT (Blauer e Gerstmann, 1998), Échelle Douleur Inconfort Nouveau-Né (EDIN) (Debillon et al., 2001), Behavioral Pain Scale (EVENDOL) (FournierCharrière et al., 2012), the Neonatal Facial Coding System (NFCS) (Grunau e Craig, 1987), Neonatal Pain, Agitation, and Sedation Scale (N-PASS) (Hummel et al., 2008) e Premature Perfil Infant Pain (PIPP) (Stevens et al., 1996). A despeito do elevado número de instrumentos, nenhum deles é considerado ideal, o que confirma os desafios relacionados à avaliação da dor neonatal.

Em relação à variedade de escalas para avaliação da dor neonatal e do número elevado de procedimentos potencialmente dolorosos realizados em $\mathrm{RN}$, diversos estudos indicam que a avaliação da dor não é realizada sistematicamente nas UTIN (Akuma e Jordan, 2011; Franck, 2002). O estudo de Ozawa e Yokoo (2013) mostrou que mais de 60\% das UTIN no Japão não utilizam quaisquer escalas de dor, por exemplo. Em um levantamento realizado por Foster et al. (2013), em hospitais em toda a Austrália, observou-se apenas um ligeiro aumento de $6 \%$ para $11 \%$ no uso de ferramentas de avaliação da dor procedural, nas unidades neonatais em relação à pesquisa realizada em 2004. Aponta-se que, apesar do grande número de instrumentos disponíveis, estes não são usados rotineiramente e avaliação da dor permanece controversa (Foster et al., 2013).

Dessa forma, trabalhos nacionais evidenciam que ainda existem lacunas com relação ao conhecimento dos profissionais de enfermagem quanto à avaliação e ao manejo da dor neonatal no Brasil (Soares et al., 2016; Christoffel et al., 2017). Adicionalmente, constata-se que a implementação das medidas analgésicas disponíveis é inadequada e insuficiente em unidades neonatais (Capellini et al., 2014; Bonutti et al., 2017; Christoffel et al., 2017; Maciel et al., 2019). Em estudo retrospectivo transversal, desenvolvido por Sposito et al, (2017), que teve como objetivos determinar a frequência de dor e verificar as medidas realizadas para seu alívio, durante os sete primeiros dias de internação na UTIN, bem como identificar o tipo e frequência de procedimentos invasivos aos quais os RN foram submetidos, 
evidenciou-se, por exemplo, subutilização da escala NIPS como ferramenta para pautar o cuidado de enfermagem no alívio da dor, bem como o subtratamento da dor. Além disso, o estudo de caráter descritivo, realizado com 57 profissionais de saúde por Capellini et al. (2014), cujo objetivo foi analisar o conhecimento e as atitudes quanto à avaliação e ao manejo da dor aguda de RN em UTIN, observou que os profissionais avaliam a dor do RN, porém não conhecem escalas para a avaliação da dor neonatal. Muitos fatores influenciam a prática para o manejo da dor neonatal, tal como a falta de conhecimento, atitude, sobrecarga de trabalho, experiência profissional e pessoal (Capellini et al., 2014). Esta incapacidade de integrar a avaliação da dor com estratégias no manejo da dor, pode ser a razão para o baixo uso de instrumentos de avaliação da dor na prática clínica (Franck, 2002; Harrison et al., 2006).

Entende-se que, embora a maioria dos procedimentos seja dolorosa, a dor neonatal é muitas vezes subestimada e/ou subtratada e, a analgesia ou anestesia é utilizada em apenas 2$21 \%$ dos procedimentos invasivos realizados na UTIN (Simons et al., 2003; Prestes et al., 2005; Carbajal et al., 2008).

Durante a hospitalização em UTIN, os RN são submetidos a inúmeros e repetidos procedimentos dolorosos e estressantes, como destacado anteriormente. O estresse precoce é conhecido por afetar permanentemente os sistemas fisiológicos (Heim e Nemeroff, 2002), neurobiológicos e hormonais (Brummelte et al., 2015). A exposição precoce pós-natal a procedimentos invasivos é estressante, especialmente quando repetidas várias vezes, diariamente ao longo de um período de imaturidade fisiológica (Brummelte et al., 2015).

Assim sendo, as evidências das alterações no neurodesenvolvimento de pré-termos, expostos a procedimentos dolorosos, têm sido um desafio e, consequentemente, a importância do controle da dor nesta população tem sido cada vez mais reconhecida (Bouza, 2009; Dahl e Kamper, 2006; Lago et al., 2009; Peterson et al., 2000). Além disso, há uma relutância em prescrever analgésicos para RN devido aos diversos efeitos adversos, tolerância e dependência de drogas e, as orientações de dosagem e dados farmacocinéticos sobre drogas comuns, para recém-nascidos de diferentes idades gestacionais e peso, muitas vezes não existem (Bellu et al., 2008). Intervenções comportamentais e ambientais, comumente chamadas de estratégias não farmacológicas, tais como o uso de amamentação, sacarose, e contato pele a pele, têm sido amplamente estudadas e utilizadas (Lago et al., 2009; Stevens et al., 2011; Stevens et al., 2013)

Nesse ínterim, muitas pesquisas foram realizadas na última década sobre a eficácia das intervenções não farmacológicas, tais como a sacarose (Stevens et al., 2016), sucção não 
nutritiva (Harrison et al., 2016), contato pele a pele (Johnston et al., 2017) e sobre o método canguru (Meek e Huertas, 2012). Entre elas, o emprego da sacarose foi extensivamente recomendado (Stevens et al., 2010) e atualmente é a prática padrão em muitas UTIN no mundo todo. No entanto, pouco se sabe sobre o mecanismo desta terapia em seres humanos e, sobre os efeitos a longo prazo de uma exposição repetida sobre o desenvolvimento, em especial em prematuros extremos (Harrison et al., 2012; Holsti et al., 2010; Slater et al., 2010). Até o momento, apenas um estudo avaliou os efeitos da administração repetida de sacarose no desenvolvimento neurológico em bebês muito prematuros e mostrou que a maior exposição (> 10 doses em 24 horas) foi associada com prejuízos na atenção e na habilidade motora entre 36 e 40 semanas de idade pós-conceptual (Johnston et al., 2002).

Portanto, avaliar a dor de modo preciso e confiável no RN consiste em tarefa desafiadora, visto que as alterações comportamentais e fisiológicas não devem ser empregadas como indicadores isolados da avaliação da dor. A ausência de uma medida objetiva e fidedigna para avaliação da dor neonatal faz com que seja nescessário que outros parâmetros sejam explorados, de modo a complementar o conhecimento atual sobre avaliação da dor neonatal. Esses parâmetros incluem medidas autonômicas, como a variabilidade da frequência cardíaca (Roué et al., 2018), condutância da pele (Roué et al., 2018) e eletroencefalograma (Benoit et al., 2017). Além disso, os marcadores hormonais de estresse como o cortisol e parâmetros de estresse oxidativo no plasma (Maxwell et al., 2013), cortisol salivar (Peña-Bautista et al., 2019) e alfa-amilase salivar ( $\alpha$-amilase) têm sido avaliados (Jenkins et al., 2018).

Assim, observa-se inúmeras vantagens no emprego das dosagens salivares, uma vez que as amostras de saliva são obtidas por procedimento simples, não invasivos, que ocasiona manipulação mínima e livres de estresse (Vining et al., 1983; le Roux et al., 2002; De Palo et al., 2009). É um exame alternativo e mais sensível quando comparado às técnicas plasmática e urinária (Castro e Moreira, 2003; Fogaça et al., 2005), já que os procedimentos para coleta de sangue e de urina apresentam aspectos potencialmente negativos, como a necessidade de punção venosa e a dificuldade de coleta de urina sem perdas, durante 24 horas, especialmente nos neonatos e lactentes do sexo feminino (Castro et al., 1999).

O desenvolvimento de novos biomarcadores constitui-se, assim, como um campo em constante evolução e a avaliação de indicadores biológicos salivares têm sido usadas experimentalmente. A análise de conteúdo salivar tem sido crescentemente utilizada, por exemplo, como método diagnóstico, uma vez que a saliva contém: enzimas, sais minerais, 
eletrólitos, tampões, inibidores de enzimas, fatores de crescimento, imunoglobulinas e citocinas (Schafer et al., 2014; Wittwer et al., 2016)

Adicionalmente, as citocinas ocupam lugar de destaque no mecanismo da dor. De maneira geral, as citocinas podem ser definidas como uma família de hormônios polipeptídicos ou peptídeos regulatórios, secretados por leucócitos (macrófagos, células dendríticas, linfócitos e mastócitos) e por diversas outras células do organismo, em resposta a diferentes estímulos inflamatórios, lesão tecidual e de estruturas nervosas, e também em resposta a outras citocinas (Pinho-Ribeiro, Verri e Chiu, 2017). São liberadas em sequência por vários tipos de células, sendo responsáveis pela produção de mediadores envolvidos na indução de sinais e sintomas de inflamação e da dor (Baral, Udit e Chiu, 2019; Gonçalves Dos Santos et al., 2020).

Inserido nesse panorama, estudos realizados em modelos animais mostraram que as citocinas agem através de diferentes mecanismos em vários locais das vias de transmissão dolorosa. Dentre estes, via ativação das terminações nervosas periféricas, estimulação direta do gânglio da raiz dorsal, indução da produção de citocinas por células do sistema nervoso central (SNC), estimulação de células da glia e indução da síntese de importantes mediadores da dor, tais como prostaglandinas (Sachs et al., 2002; Cunha et al., 2005; Watkins e Maier, 2005).

Com isso, diversos estudos têm mostrado o papel que o sistema imunológico e as citocinas pró-inflamatórias desempenham nos estímulos dolorosos e na manutenção de dores crônicas (de Miguel, Kraychete e Meyer Nascimento, 2014; Pinho-Ribeiro, Verri e Chiu, 2017; Ridgley, Anderson e Pratt, 2018). A dor e o sistema imunológico influenciam-se mutuamente, o que torna difícil determinar se o bloqueio da nocicepção contribui para a redução da produção de citocinas pró-inflamatórias, ou vice-versa, com a redução da formação de citocinas pró-inflamatórias, resultando em dor menos intensa (Gonçalves Dos Santos et al., 2020). Essas interações neuroimunes desempenham papel crucial na modulação da dor e são responsáveis por: recrutar elementos neuronais locais para ajustar a resposta imune, participar na plasticidade das sinapses durante o desenvolvimento, bem como na plasticidade sináptica na idade adulta e, envolver o resto do corpo na luta contra a infecção por microorganismos patogênicos (Ren e Dubner, 2010; Grace et al., 2014; Dantzer, 2018).

Até porque a ideia tradicional do microambiente pós-trauma revela que a migração de leucócitos associados à inflamação é responsável por secretar mediadores químicos que produzem dor. Entretanto, evidências atuais sugerem que a função da resposta inflamatória na geração de dor não é limitada apenas a efeitos produzidos pela migração de leucócitos. 
Acredita-se que as citocinas pró-inflamatórias que participam do processo nóxico podem ter origem em células imunológicas, neuronais e gliais (micróglia e astrócitos), tanto no sistema nervoso periférico quanto no central, e que essas moléculas podem desencadear efeitos em curto e longo prazo, com eventual hiperexcitabilidade crônica e alterações na expressão fenotípica dos nociceptores, processamento anormal dos sinais nóxicos e exacerbação dos processos de dor (de Oliveira et al., 2011; Williams e Lascelles, 2020). Esses efeitos são causados diretamente pelas citocinas ou por mediadores formados sob seu controle (Totsch e Sorge, 2017; Vanderwall e Milligan, 2019).

Diferentemente dos hormônios clássicos, as citocinas não são armazenadas como moléculas pré-formadas nas células produtoras, ao contrário, é necessária nova síntese para secreção, e atuam especialmente por mecanismos parácrino (em células vizinhas) e autócrino (nas próprias células produtoras) (Lin, Calvano e Lowry, 2000; Sommer e White, 2010). Em revisão de literatura realizada por DeVon et al., (2014), cujo objetivo principal foi de determinar a associação entre biomarcadores inflamatórios e a dor autorreferida em indivíduos adultos, identificou-se alterações das citocinas na presença de dor e, apesar da associação da presença de dor e sua intensidade com alterações nos biomarcadores próinflamatórios e anti-inflamatórios, as evidências ainda são inconclusivas para apoiar o uso de citocinas como um biomarcador de dor. Além disso, em comparação com dados de adultos, sabe-se consideravelmente menos sobre a produção e liberação de citocinas no RN.

De fato, as citocinas podem ser pró-inflamatórias e anti-inflamatórias. Dentre as próinflamatórias, temos: interferon-gama (IFNg), interleucina-1b (IL-1b), interleucina-2 (IL-2), interleucina-6 (IL-6), interleucina-8 (IL-8), interleucina-12 (IL-12), interleucina-17 (IL-17) e fator de necrose tumoral (TNF). As anti-inflamatórias incluem: interleucina-4 (IL-4) e interleucina-10 (IL-10). As IL-6, IL-8 e TNF, e estão associadas à indução e manutenção de quadros de dor (Cunha et al., 2005; Zhang e An, 2007) e com a fisiopatologia das síndromes dolorosas (Oliveira et al., 2011). Outros estudos sugerem que a IL-17 desempenha papel importante na indução de dor inflamatória em modelos de artrite (Mens et al., 2018; Wigerblad et al., 2016).

A IL-6 é uma glicoproteína secretada por muitos tipos de células, como macrófagos, monócitos, eosinófilos, hepatócitos e pela glia (Oliveira et al., 2011). Essa interleucina configura-se como um dos mais precoces e importantes mediadores de indução e controle da síntese e liberação de proteínas de fase aguda pelos hepatócitos durante estímulos dolorosos, como trauma, infecção, cirurgias e queimaduras (Oliveira et al., 2011; Sesso et al., 2014). A IL-6 é considerada um importante mediador da resposta à dor (Zhou et al., 2016; Baral, Udit 
e Chiu, 2019). Após lesão, concentrações plasmáticas de IL-6 são detectáveis em 60 minutos, com pico entre 4 e 6 horas, podendo persistir por 10 dias. É considerado como o marcador mais relevante do grau de lesão tecidual durante um procedimento cirúrgico, em que o aumento excessivo e prolongado está associado a maior morbidade pós-operatória (Hong e Lim, 2008). A IL-6 também tem sido implicada como um fator-chave nos mecanismos de dor periférica, além disso, está bem estabelecido que a expressão de IL-6 é aumentada na artrite reumatoide, dor neuropática e dor inflamatória (Zhou et al., 2016; Krock, Jurczak e Svensson, 2018). Por fim, destaca-se ainda que a IL-6 tem papel pleiotrópico associado à dor e à inflamação (Gonçalves dos Santos et al., 2020).

Já a IL-8 é produzida principalmente por monócitos, macrófagos ativados e células mononucleares (Wuyts, 1998). Na indução da dor, a participação da IL-8 também tem sido demonstrada, embora os mecanismos ainda não estejam completamente descritos (Cunha et al., 1991). A IL-8 tem sido relacionada a diferentes fenótipos de dor, em estudo desenvolvido por Krock et al., (2019), verificou-se nível elevado de IL-8 no líquido cefalorraquidiano (LCR) em pacientes adultos com dor lombar crônica em comparação com indivíduos sem dor. Em outro trabalho, realizado por Barry et al., (2018) em pacientes adultos com dor orofacial, observou-se nível plasmático elevado de IL-8 em relação aos pacientes saudáveis.

O TNF é outra citocina que desempenha um papel fundamental e bem estabelecido em alguns modelos de dor (Zhang e An, 2007). É um dos mediadores mais precoces e potentes da resposta inflamatória e, geralmente, antecede a síntese da IL-6. Embora sua meia-vida plasmática seja de apenas 20 minutos, é suficiente para provocar mudanças metabólicas e hemodinâmicas importantes e ativar distalmente outras citocinas. Entre as ações do TNF estão: ativar a coagulação, estimular a expressão ou liberação de moléculas de adesão, fator ativador de plaquetas, glicocorticóides, e influenciar a apoptose celular (Curfs et al., 1997; Raeburn et al., 2002). Em estudo desenvolvido por Teodorczyk-Injeyan, Triano e Injeyan, (2019), por exemplo, verificou-se níveis elevados de TNF plasmático em pacientes com dor lombar crônica, em relação aos pacientes assintomáticos, níveis de TNF que inclusive foram correlacionados positivamente com os escores da Escala Visual Analógica (EVA).

Já a IL-4, citocina anti-inflamatória, é um importante regulador da imunidade, com diversos papéis em processos, como proliferação de células $\mathrm{T}$, estimulação de células $\mathrm{B}$ ativada, ativação de macrófagos, inflamação crônica e reparo de feridas (Busch-Dienstfertig e González-Rodríguez, 2013). A IL-4 é produzida principalmente por macrófagos, células T (principalmente células Th2), mastócitos, eosinófilos e basófilos (Gadani et al., 2012). 
Muitas vias biológicas sinalizam a sensação de dor no organismo. Neste contexto, o VEGF (Fator de Crescimento Endotelial Vascular), que é produzido por células tumorais, fibroblastos, entre outros, desempenha papel essencial no crescimento dos vasos sanguíneos e, têm sido relacionado a uma ampla variedade de patologias que podem ocorrer concomitantemente com a dor, como câncer e a artrite reumatóide (Hamilton et al., 2016). A maioria dos estudos experimentais parece sugerir um efeito pró-nociceptivo induzido pelo VEGF-A em diversos tipos de dor (Llorián-Salvador M e González-Rodríguez S, 2018).

Investigações acerca dos níveis séricos de citocinas e a associação com os desfechos clínicos em RN prematuros têm sido conduzidas com o objetivo de favorecer diagnósticos precoces, aumentar a sobrevida, minimizar morbidade e mortalidade, além de possibilitar a adoção de medidas preventivas e mudanças nas práticas assistenciais vigentes (Bose, Damman e Laughon, 2008; Lam et al., 2008; Silveira, Fortes Filho e Procianoy, 2011). Apesar da associação de vários mediadores imunológicos com sensibilização nociceptora e respostas à dor em estudos pré-clínicos, pouco desse conhecimento foi traduzido em terapias para alívio da dor (Baral, Udit e Chiu, 2019).

Entende-se que as citocinas desempenham importante papel na dor, agindo através de diferentes mecanismos em vários locais das vias de transmissão da dor. Logo, a avaliação/quantificação dos níveis das citocinas em RN, durante sua hospitalização em UTIN, onde são expostos a inúmeros procedimentos dolorosos, poderá fornecer subsídios para compreensão e manejo da dor neonatal. Para tanto, além de explorar citocinas comumente avaliadas na dor, como IL-6, IL-8 e TNF, a dosagem de outras citocinas pró e antiinflamatórias que incluem: IFNg, IL-1b, IL-2, IL-12 e IL-10, poderá auxiliar na caracterização dos RN, assim como, na contribuição, no entendimento e avaliação da dor.

Deste modo, o presente estudo busca explorar variáveis clínicas, comportamentais, fisiológicas e bioquímicas ao longo dos primeiros três dias de hospitalização de recémnascidos em UTIN. Para tanto, dados relacionados à condição clínica dos neonatos, procedimentos dolorosos, valores de indicadores fisiológicos, escores de dor e, finalmente, dosagem de mediadores inflamatórios, referentes aos primeiros três dias de hospitalização, serão avaliados de modo isolado e combinado, com vistas a estabelecer possíveis padrões de apresentação e relações. Por fim, este é um estudo que, além de possibilitar um melhor entendimento da dinâmica da dor neonatal, poderá embasar futuros estudos e direcionamentos clínicos para o manejo da dor neonatal. 


\subsection{Justificativa do Estudo}

O manejo da dor em RN hospitalizados em UTIN é de fundamental importância em função do elevado número de procedimentos dolorosos e estressantes a que esta população é exposta. Embora a compreensão da dor tenha avançado nas últimas décadas, muitos aspectos relacionados à avaliação e manejo da dor neonatal permanecem inexplorados. $\mathrm{O}$ desenvolvimento do presente estudo permitirá traçar um perfil dos $\mathrm{RN}$ hospitalizados em UTIN, no que se refere à caracterização clínica, aos procedimentos invasivos, dolorosos e estressantes, realizados nos primeiros três dias de hospitalização, bem como as intervenções farmacológicas e não farmacológicas empregadas no alívio da dor neonatal. Adicionalmente, este estudo possibilitará estabelecer o perfil de parâmetros fisiológicos, comportamentais e endócrinos neste período. A proposta que se justifica pelo ineditismo e apresenta relevância, pois fornece fundamentação científica e contribui para futuros estudos relacionados à avaliação e manejo da dor, bem como para o aprimoramento da assistência ao neonato, possibilitando análises futuras acerca dos impactos imediatos ou mesmo tardios, decorrentes da exposição do RN a procedimentos dolorosos. 


\section{OBJETIVOS}

\subsection{Geral}

Avaliar padrões fisiológicos, comportamentais e endócrinos relacionados à dor nos primeiros três dias de vida em recém-nascidos, hospitalizados em Unidade de Terapia Intensiva Neonatal.

\subsection{Específicos}

- Caracterizar o número e o tipo de procedimentos dolorosos realizados nos primeiros três dias de vida de recém-nascidos hospitalizados em Unidade de Terapia Intensiva Neonatal;

- Caracterizar os registros dos valores de frequência cardíaca, frequência respiratória, pressão arterial, temperatura e saturação periférica de oxigênio nos primeiros três dias de vida de recém-nascidos, hospitalizados em Unidade de Terapia Intensiva Neonatal;

- Caracterizar os registros de escores de dor, mensurados pela escala Neonatal Infant Pain Scale (NIPS) (Lawrence et al., 1993; Motta, Schardosim e Cunha, 2015) nos primeiros três dias de vida de recém-nascidos, hospitalizados em Unidade de Terapia Intensiva Neonatal;

- Caracterizar os registros de medidas farmacológicas e não farmacológicas de alívio da dor, nos primeiros três dias de vida de recém-nascidos, hospitalizados em Unidade de Terapia Intensiva Neonatal;

- Caracterizar os níveis de 11 mediadores inflamatórios (IFNg, IL1b, IL2, IL4, IL6, IL8, IL10, IL12, IL17, TNF e VEGF) na saliva primeiro e no segundo dia de vida de recém-nascidos, hospitalizados em Unidade de Terapia Intensiva Neonatal;

- Verificar a correlação entre indicadores fisiológicos, comportamentais e endócrinos com o número de procedimentos dolorosos, realizados nos primeiros três dias de vida de recém-nascidos, hospitalizados em Unidade de Terapia Intensiva Neonatal;

- Verificar a correlação entre os registros dos escores de dor e os indicadores fisiológicos (frequência cardíaca, frequência respiratória, pressão arterial, temperatura e saturação periférica de oxigênio) nos três primeiros dias de vida de recém-nascidos, hospitalizados em Unidade de Terapia Intensiva Neonatal; 
- Verificar a correlação entre medidas farmacológicas e não farmacológicas de alívio da dor e indicadores fisiológicos, comportamentais e endócrinos, nos três primeiros dias de vida de recém-nascidos, hospitalizados em Unidade de Terapia Intensiva Neonatal. 


\section{MATERIAL E MÉTODOS}

\subsection{Desenho do Estudo}

Este é um estudo clínico primário, observacional e prospectivo, em que os sujeitos de pesquisa elegíveis foram observados em relação a variáveis relacionadas à dor, sem intervenção ou modificação de qualquer aspecto pelo pesquisador, em relação a variáveis relacionadas à dor resultante de procedimentos.

\subsection{Local do Estudo}

O estudo foi desenvolvido na Unidade de Terapia Intensiva Pediátrica e Neonatal do Hospital Universitário, da Universidade de São Paulo (HU/USP), hospital secundário que tem como objetivos o ensino, a pesquisa e a assistência. Situado na zona oeste do Município de São Paulo, atende à população residente na área de abrangência do Distrito de Saúde do Butantã e de outras regiões da Grande São Paulo, além de docentes, discentes, funcionários da USP e seus dependentes.

A área materno-infantil do HU/USP conta com as unidades de Centro Obstétrico, Alojamento Conjunto, Unidade Neonatal, Pediatria, Unidade de Terapia Intensiva Pediátrica e Neonatal.

A Unidade de Terapia Intensiva Pediátrica e Neonatal do HU/USP é uma UTI mista, destina à assistência a pacientes pediátricos e RN. Porém, há separação física entre os ambientes de UTI Pediátrica e UTI Neonatal, sendo que a primeira dispõe de 10 leitos, destinados a atender crianças na faixa etária de 29 dias a 14 anos e, a segunda conta com seis leitos para atender RN (nascimento a 28 dias de vida).

A UTIN destina-se ao atendimento de RN criticamente doentes. Tem como objetivo prestar assistência humanizada, de maneira rápida, segura e eficaz, restabelecer a saúde, minimizar os traumas e as sequelas provocadas pelo tratamento intensivo. Os RN são admitidos na UTIN provenientes do Pronto Socorro Infantil, da Unidade de Cuidados Intermediários Neonatal, do alojamento Conjunto, do Centro Obstétrico, ou de outras instituições por intermédio da central de vagas da cidade de São Paulo.

A equipe de enfermagem atuante na unidade é composta por 12 enfermeiros(as) e 26 técnicos(as) de enfermagem; o número de profissionais que presta cuidados aos neonatos é proporcional ao número de pacientes e varia frente à dinâmica da unidade e ao longo do dia. Em média, cada profissional assiste a dois neonatos ao longo do plantão. A equipe também é 
composta por profissionais médicos, fisioterapeutas, fonoaudiólogos, residentes de medicina e fisioterapia.

$\mathrm{Na}$ unidade campo de estudo são instalados na admissão do RN e mantidos, durante toda a hospitalização, monitores de frequência cardíaca (FC), frequência respiratória (FR), pressão arterial (PA) e oximetria pulso (SpO2). A intensidade da iluminação e dos ruídos varia conforme a rotina assistencial. Apesar de não existir um protocolo de luminosidade e ruídos, a iluminação, assim como a manipulação dos neonatos, é reduzida de acordo com a dinâmica da unidade. No período noturno, a iluminação é reduzida a partir das 22 horas e mantida apenas durante a realização dos cuidados assistenciais.

Em relação à dor, esta é mensurada pela escala NIPS em intervalos de 4 horas (8:00h; 12:00h; 16:00h; 20:00h; 24:00h; 4:00h) e registrada em impresso próprio da UTIN, conforme protocolo institucional. Contudo, não há um protocolo para manejo da dor neonatal, sendo que as medidas não farmacológicas são realizadas de acordo com a avaliação da equipe de enfermagem e as estratégias farmacológicas são implementadas após avaliação em conjunto e discussão entre equipes médica e de enfermagem.

Assim, a maioria dos procedimentos rotineiros, como aferição de peso corporal, banho, coleta de sangue para exames laboratoriais, entre outros, é realizada pela equipe multiprofissional ao longo do dia.

De qualquer forma, os pais podem permanecer em tempo integral na UTIN e são incentivados a participar dos cuidados ao RN. Os demais familiares visitam os neonatos três vezes ao dia, por períodos de uma hora, sendo permitida a entrada de até duas pessoas por horário.

\subsection{População e Amostra}

A população foi constituída por $\mathrm{RN}$, independente da idade gestacional, provenientes do Centro Obstétrico (CO) que necessitaram de suporte da UTIN. Para o cálculo do tamanho da amostra foi utilizado o software nQuery Advisor, versão 7,0. Considerando-se o objetivo primário, foi estipulado o número de 84 sujeitos para nível de significância de $5 \%$ (erro Tipo I) e correlação igual ou maior que 0,3 com erro tipo II de 20\%. Em razão das possíveis perdas na obtenção dos dados e das amostras de saliva, acresceu-se 5\% à amostra calculada inicialmente, totalizando $90 \mathrm{RN}$. 


\subsubsection{Critérios de inclusão}

Foram considerados elegíveis neonatos provenientes do $\mathrm{CO}$ e admitidos na unidade de terapia intensiva neonatal.

\subsubsection{Critérios de exclusão}

Foram excluídos deste estudo RN portadores de malformação grave (estrutura, função ou metabolismo), hemorragia intraventricular grau III ou IV, hidrocefalia, microcefalia e síndromes genéticas.

\subsection{Coleta de Dados}

\subsubsection{Consentimento}

Os pais dos RN que atenderam aos critérios de inclusão foram abordados no momento da admissão pelo pesquisador responsável na unidade de campo de estudo (UTIN) ou na Unidade de Alojamento Conjunto. No caso de pais menores de idade, foi abordado o responsável legal pela mãe do RN.

Os responsáveis foram esclarecidos quanto a aspectos relevantes do estudo, como os objetivos, o caráter voluntário e anônimo da participação, os riscos e benefícios, entre outros, conforme a Resolução 466/2012. Aqueles que permitiram a participação do RN no estudo foram convidados a assinar o Termo de Consentimento Livre e Esclarecido (TCLE) e, no caso de pais menores de idade, o Termo de Assentimento (APÊNDICES A e B, respectivamente).

\subsubsection{Instrumento de Coleta de Dados}

Os instrumentos foram desenvolvidos com base nos objetivos do estudo, bem como nos formulários utilizados nos prontuários clínicos da unidade campo de estudo e, posteriormente, apresentados à equipe de enfermagem para eventuais adequações (APÊNDICES C e D).

\subsubsection{Equipamentos}

Para o registro de frequência cardíaca, frequência respiratória, pressão arterial e saturação periférica de oxigênio foram utilizados monitores multiparamétricos, modelos GE Solar 8000M e Dixtal DX 2021, disponíveis na UTIN do HU - USP, para monitorização dos neonatos. A temperatura axilar foi aferida com termômetro digital G-Tech®.

Para processamento das amostras de saliva foram utilizados equipamentos do Laboratório de Neuroimunoendocrinologia, do Departamento de Fisiologia do Instituto de 
Biociências, da Universidade de São Paulo, que incluem Pipetas Eppendorf, modelo Research plus e Centrífuga Eppendorf Refrigerada 5810/5810R.

\subsubsection{Procedimento de Coleta de Dados}

$\mathrm{O}$ treinamento da equipe de enfermagem foi realizado antes do início do estudo e abordou aspectos teóricos e práticos relacionados à avaliação da dor, preenchimento do impresso referente ao número e tipo de procedimentos dolorosos realizados e, sobre a técnica para coleta, identificação e armazenamento das amostras de saliva dos RN. Todo treinamento foi realizado pelo pesquisador responsável nos diferentes turnos de trabalho, de modo a informar e capacitar todos profissionais de enfermagem que atuam na UTIN.

Além disso, o número e o tipo de procedimentos realizados (o que incluiu tentativas sem sucesso) com os RN, assim como possíveis intervenções (estratégias não farmacológicas e/ou medidas de conforto e estratégias farmacológicas de analgesia e sedação) foram registradas pelo profissional de enfermagem, responsável pelos cuidados do $\mathrm{RN}$, em impresso que permaneceu no prontuário clínico de cada RN incluído no estudo (APÊNDICE C). Os dados referentes aos valores da frequência cardíaca, frequência respiratória, pressão arterial, temperatura axilar e saturação periférica de oxigênio foram registrados periodicamente a cada 4 horas nos prontuários clínicos de todos os $\mathrm{RN}$ internados na unidade, como parte dos cuidados de rotina, e foram posteriormente obtidos pelo pesquisador a partir da análise dos prontuários. Os escores de dor, avaliados por intermédio da escala NIPS a cada 4 horas, como parte dos cuidados de rotina, foram obtidos a partir de impresso específico da UTIN, que compõe o prontuário do RN.

Finalmente, as coletas de saliva foram realizadas por profissional de enfermagem responsável pelos cuidados do RN (procedimento descrito a seguir, no item 3.4.5), conforme treinamento oferecido. As dosagens da saliva foram realizadas pelo pesquisador responsável.

\subsubsection{Coleta de saliva}

A coleta de saliva é um procedimento simples, não-invasivo e livre de estresse que pode ser realizado durante os cuidados de rotina. As amostras de saliva foram obtidas em intervalos de aproximadamente 8 horas (8:00-9:00h, 16:00-17:00h e 23:00-24:00h), a partir do primeiro dia, por três dias consecutivos (1-3), de modo a caracterizar o perfil dos mediadores avaliados ao longo do dia. Vale ressaltar que a data da admissão na UTIN foi considerada como dia zero. As coletas foram feitas por profissional de enfermagem responsável pelos cuidados do $\mathrm{RN}$, devidamente treinado para tal pelo pesquisador 
responsável. Para o procedimento foi utilizado a esponja oftalmológica Merocel®, que foi posicionada no canto interno direito ou esquerdo da cavidade oral do RN e mantida por 5 minutos para obtenção de uma alíquota de 0,5 a $1 \mathrm{~mL}$ de saliva, a qual foi transferida para um tubo Eppendorff, identificado com os dados do RN (Mitchell et al., 2012; Freitas e Kimura, 2019) (Figura 1).

Figura 1 - Dispositivo utilizado para coleta de amostra de saliva e armazenamento. São Paulo, 2020.

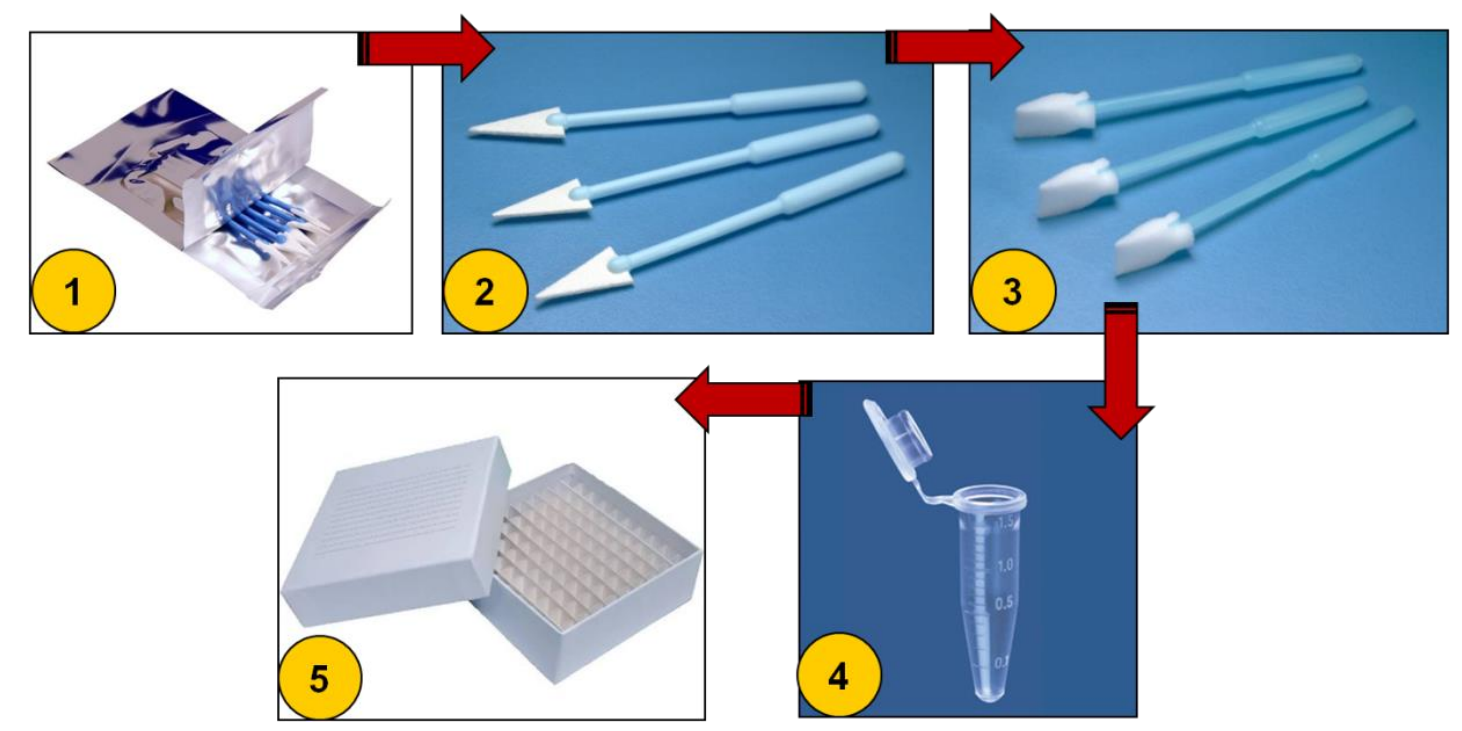

Desta forma, as amostras de saliva ficaram armazenadas a $4^{\circ} \mathrm{C}$ por no máximo 24 horas até serem transportadas para o Laboratório de Neuroimunoendocrinologia do Departamento de Fisiologia, do Instituto de Biociências, da Universidade de São Paulo. Para o transporte, as amostras foram acondicionadas em caixa para armazenagem e congelamento, com tampa e grade divisória, que foi colocada em caixa de isopor com gelo reutilizável rígido no fundo da caixa e nas laterais. A caixa de isopor foi devidamente tampada e lacrada com fita adesiva para garantir vedação e manutenção da temperatura.

$\mathrm{Na}$ chegada ao laboratório, as amostras foram acondicionadas em gelo triturado, centrifugadas a $4^{\circ} \mathrm{C}$, por 10 minutos a $3000 \mathrm{rpm}$, aliquotadas e armazenadas a $-80^{\circ} \mathrm{C}$ para posterior dosagem. Todas as amostras foram armazenadas e analisadas em colaboração com o Laboratório de Neuroimunoendocrinologia do Departamento de Fisiologia, do Instituto de Biociências, da Universidade de São Paulo. 


\subsection{Variáveis do estudo}

\subsubsection{Caracterização dos RN}

Os RN foram caracterizados de acordo com os seguintes dados obtidos do prontuário: tipo de parto (vaginal, fórceps e cesárea), sexo (masculino ou feminino), idade gestacional de nascimento em semanas (verificada por ultrassonografia - USG), escore de Apgar no $1^{\circ}, 5^{\circ}$ e $10^{\circ}$ minutos de vida, peso de nascimento ( em quilos - kg), diagnóstico(s) clínico(s) inicial(is) e tempo total (em horas) de permanência na UTIN. Todas estas informações foram registradas em instrumento previamente desenvolvido pelo pesquisador responsável (APÊNDICE D).

\subsubsection{Quantificação de procedimentos realizados}

Os procedimentos dolorosos e estressantes realizados com os $\mathrm{RN}$, incluindo tentativas sem sucesso, assim como possíveis intervenções de alívio da dor (estratégias não farmacológicas e/ou medidas de conforto e estratégias farmacológicas de analgesia e sedação) foram registrados pelo profissional de enfermagem, responsável pelos cuidados do RN, em instrumento previamente desenvolvido (APÊNDICE A). Os dados foram registrados da admissão (dia zero) até o $3^{\circ}$ dia de vida dos neonatos incluídos no estudo. Caso o RN tenha recebido alta antes deste período, a coleta foi finalizada no momento da transferência para a unidade de cuidados intermediários ou alojamento conjunto. Após levantamento dos principais procedimentos realizados na UTIN do local de estudo, antes do início da coleta de dados, os seguintes procedimentos foram considerados: punção venosa (terapia IV), punção venosa (coleta de sangue), punção capilar (glicemia), punção capilar (teste do Pezinho), punção arterial (coleta de sangue), punção intramuscular, intubação traqueal, extubação traqueal, ventilação mecânica, inserção de Continuous Positive Airway Pressure (CPAP), inserção de cateter nasal, aspiração de vias aéreas superiores (VAS) e/ou cânula, sondagem gástrica, passagem de Cateter Central de Inserção Periférica (PICC), passagem cateter umbilical, passagem cateter central, sondagem vesical, coleta de líquor, fisioterapia respiratória, realização de curativo e remoção de dispositivos.

Adicionalmente, também foi registrado o número e tipo de dispositivos que permaneceram em uso (como sonda orogástrica, sonda oroenteral, cânula orotraqueal, etc), (APÊNDICE B). Vale ressaltar que os formulários foram revisados diariamente com relação ao seu preenchimento e reforço periódico das orientações com a equipe de enfermagem. 


\subsubsection{Sinais Vitais}

Os dados referentes aos valores da frequência cardíaca (FC - bpm), frequência respiratória (FR - ipm), pressão arterial $(\mathrm{PA}-\mathrm{mmHg})$, temperatura axilar $\left(\mathrm{T}-{ }^{\circ} \mathrm{C}\right)$ e saturação periférica de oxigênio (SpO2 - \%) foram obtidos dos registros dos sinais vitais, do prontuário clínico de cada RN, em intervalos de 4 horas (8:00h; 12:00h; 16:00h; 20:00h; 24:00h; 4:00h), da admissão (dia zero) até o $3^{\circ}$ dia de vida. Os dados foram transcritos para instrumento desenvolvido para o presente estudo (APÊNDICE B).

\subsubsection{Escala de dor}

Os escores de dor foram mensurados pela escala NIPS, em intervalos de 4 horas (8:00h; 12:00h; 16:00h; 20:00h; 24:00; 4:00h), da admissão (dia zero) até o $3^{\circ}$ dia de vida dos $\mathrm{RN}$, internados na UTIN. Os registros diários foram realizados pelo profissional de enfermagem, responsável pelos cuidados do RN, em instrumento empregado diariamente na UTIN e transcrito para instrumento desenvolvido para o presente estudo.

A Neonatal Infant Pain Scale (NIPS) (Lawrence et al., 1993; Motta, Schardosim e Cunha, 2015) foi inicialmente desenvolvida por Lawrence e colaboradores em 1993 e, avalia cinco indicadores comportamentais (expressão facial, choro, movimento de braços, pernas e estado de alerta) e um indicador fisiológico (padrão respiratório). Recentemente, o instrumento foi traduzido, adaptado e validado para o português (Brasil) por Motta e colaboradores (2015). As pontuações de cada item variam de 0 ou 1, (exceto pelo choro, cuja pontuação varia entre 0 e 2). Cada item também contém uma breve definiçãa operacional. $\mathrm{O}$ escore total varia de 0 a 7 , pontuações maiores que 3 são indicativas de dor (Lawrence et al., 1993). De forma geral, a NIPS é facilmente compreendida e aplicada à beira leito, o que a torna uma ferramenta útil para os profissionais de saúde que trabalham com recém-nascidos expostos a estímulos dolorosos.

\subsubsection{Dosagens de mediadores inflamatórios}

A dosagem do conteúdo salivar de IFNg, IL1b, IL2, IL4, IL6, IL8, IL10, IL12, IL17, TNF e VEGF (pg/ml) foi realizada por imunoensaio com microesferas do tipo Multiplex (MILLIPLEX® MAP Human Cytokine/Chemokine Magnetic Bead Panel Kit, Millipore Corporation, Billerica, MA, USA), de acordo com as instruções do fabricante. Cada conjunto de microesferas, utilizadas na detecção das respectivas citocinas, é marcado com uma coloração específica, obtida pela combinação de dois fluoróforos. As microesferas são revestidas por anticorpos monoclonais específicos que se associam às citocinas que são alvo e 
estão presentes nas amostras. Após a incubação das amostras com as microesferas, adicionase uma mistura de anticorpos biotinilados que se ligam a citocinas humanas. Os anticorpos biotinilados são então detectados pelo conjugado ficoeritrina-estreptavidina. O ensaio é analisado com o sistema Luminex MAGPIX ${ }^{\circledR}$ (Millipore Corporation, Billerica, MA, USA) de detecção de fluorescência que emprega dois lasers: o primeiro feixe excita as microesferas, classificando-as pela coloração; o segundo feixe quantifica a fluorescência emitida pelas moléculas de ficoeritrina, associadas a cada microesfera. A concentração de citocinas nas amostras é estimada a partir de curvas padrão, construídas com o auxílio do software xPONENT 4.1 (Millipore Corporation, Billerica, MA, USA).

Nesse kit, os limites de detecção para as citocinas dosadas são: IFNg: 0,8pg/mL; IL1b: 0,8 pg/mL; IL2: 1,0pg/mL; IL4: 4,5pg/mL; IL6: 0,9pg/mL; IL8: 0,4pg/mL; IL10: 1,1pg/mL; IL12: 0,6pg/mL; IL17: 0,7pg/mL; TNF: 0,7pg/mL e VEGF: 26,3pg/mL.

Todas as dosagens foram realizadas em colaboração com o Laboratório de Neuroimunoendocrinologia do Departamento de Fisiologia, do Instituto de Biociências, da Universidade de São Paulo.

\subsection{Análise estatística}

Os dados foram armazenados em planilhas elaboradas no aplicativo Microsoft Excel for Windows (Enterprise/2007). Para análise estatística foi utilizado o programa Statistic Package for the social Sciences (SPSS inc., Chicago, IL, EUA), e o Software R (versão 2.15.2). A análise descritiva foi realizada por meio de valores de frequências absoluta e relativa para variáveis categóricas; para variáveis numéricas, foram utilizadas medidas de tendência central, como média e desvio padrão. Para as correlações utilizamos teste de Correlação de Spearman (Graph PadPrism, versão 6). O nível de significância estabelecido para todos os testes foi $\mathrm{p}<0.05$.

\subsection{Aspectos Éticos}

O estudo foi aprovado pelos Comitês de Ética em Pesquisa das instituições envolvidas no estudo (CAAE: 59994116.0.0000.5392 - EEUSP; CAAE: 59994116.0.3001.0076 - HUUSP) e conduzido conforme a resolução 466/2012 (ANEXOS 1 e 2). 


\section{RESULTADOS}

A coleta de dados foi realizada entre 13 de março de 2018 e 11 de junho de 2019, período em que $119 \mathrm{RN}$ foram admitidos na UTIN. Destes, $90 \mathrm{RN}$ foram incluídos neste estudo, os outros $29 \mathrm{RN}$ não foram considerados elegíveis, pois foram admitidos na UTIN provenientes do Pronto Socorro Infantil $(n=19)$ e da Unidade de Cuidados Intermediários ( $\mathrm{n}=10)$. Todas as famílias abordadas dos $\mathrm{RN}$ incluídos aceitaram participar do estudo.

A maioria dos $\mathrm{RN}$ nasceu de parto cesárea $(\mathrm{n}=48 ; 53,33 \%)$, seguidos por parto vaginal $(\mathrm{n}=33 ; 36,67 \%)$ e fórceps $(\mathrm{n}=9 ; 10 \%)$ (Figura 2A). Dos neonatos incluídos, $56(62,22 \%)$ foram do sexo masculino e $34(37,78 \%)$ do sexo feminino (Figura $2 B)$. Em relação ao peso e idade gestacional (IG), os RN foram majoritariamente classificados como adequado para idade gestacional (AIG) $(\mathrm{n}=79 ; 87,78 \%)$, seis $(6,67 \%)$ foram classificados como grande para idade gestacional (GIG) e cinco $(5,56 \%)$ como pequeno para idade gestacional (PIG) (Figura 2C). Com relação à idade gestacional ao nascimento, $44(48,88 \%)$ foram considerados como pré-termo, $44(48,88 \%)$ termo e apenas dois (2,22\%) pós-termo (Figura 2D). Metade dos RN pré-termo $(\mathrm{n}=22 ; 50 \%)$ nasceram de parto vaginal; já entre os $\mathrm{RN}$ de termo, a principal via de parto foi a cesárea $(n=24 ; 54,54 \%)$, seguida do parto vaginal $(n=11 ; 25,0 \%)$ e fórceps $(n=9$; 20,45\%); os RN pós-termo nasceram por parto cesárea (n=2; 100\%) (Figura 2E).

Figura 2 - Caracterização dos RN incluídos no estudo quanto a (A) tipo de parto; (B) sexo; (C) classificação em relação ao peso e idade gestacional; (D) classificação em relação à idade gestacional ao nascimento; (E) via de parto em RN pré-termo, a termo e pós-termo. São Paulo, 2020.

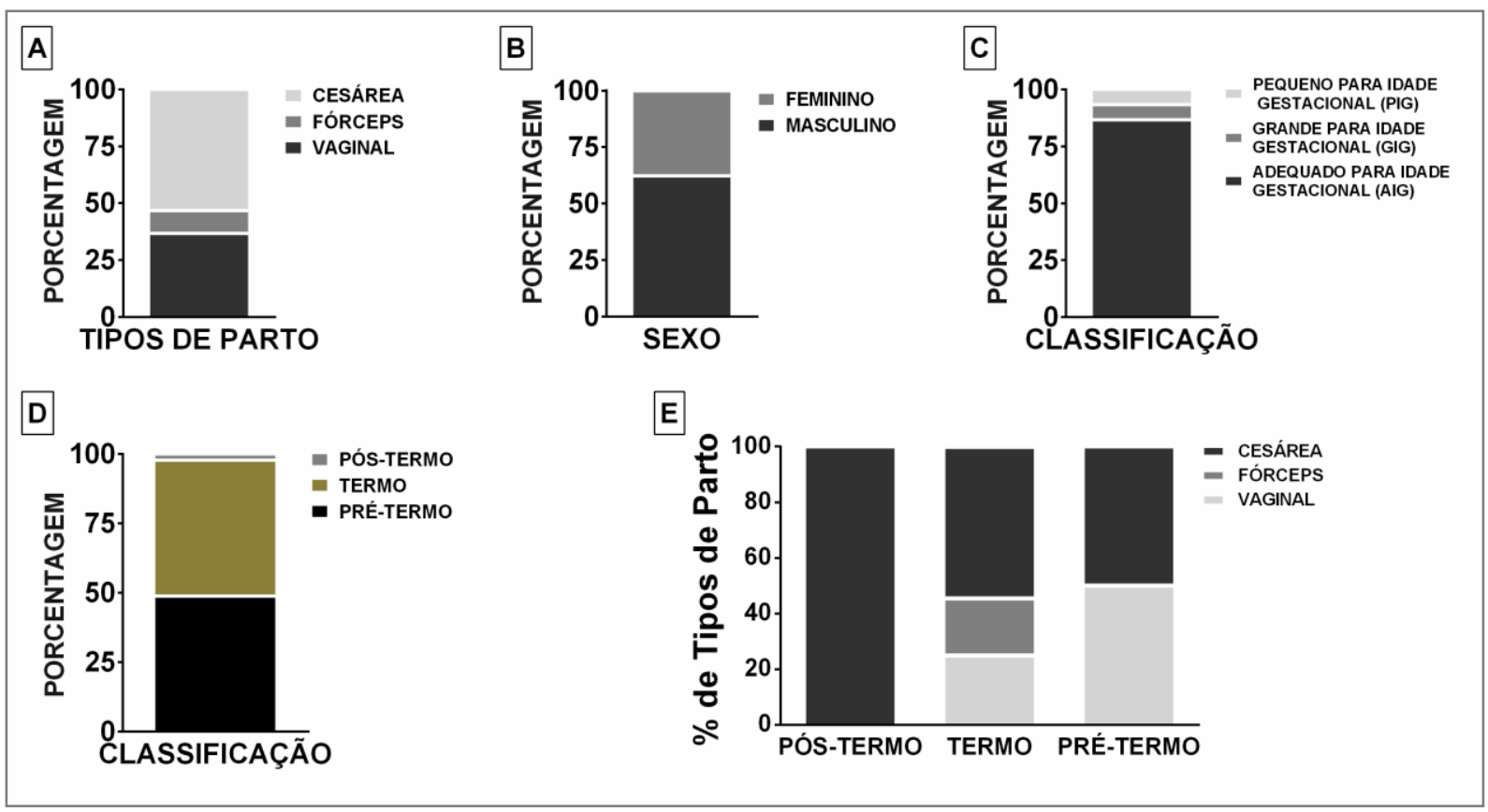


A idade gestacional ao nascimento foi de 35 semanas, em média (desvio-padrão $(D P)=5,00)$, sendo a idade gestacional mínima de 21 semanas e a máxima, 44 semanas (Tabela 1). Ao se agrupar os RN em pré-termo, termo e pós-termo, a IG média dos RN prétermo foi de 31 semanas ( $\mathrm{DP}=3,85)$, dos $\mathrm{RN}$ de termo, 39 semanas $(\mathrm{DP}=1,23)$ e do pós-termo, 43 semanas (DP=2,05) (Figura 3A).

O Escore de Apgar médio no $1^{\circ}$ minuto foi de $6,03(\mathrm{DP}=2,67)$, no $5^{\circ}$ minuto de vida de 7,51 ( $\mathrm{DP}=1,95)$ e no $10^{\circ}$ minuto, 8,63 ( $\left.\mathrm{DP}=1,49\right)$ (Tabela 1$)$. Ao se agrupar os RN em prétermo, termo e pós-termo, os pré-termo apresentaram Escore de Apgar de médio 6,14 $(\mathrm{DP}=2,74), 8,05(\mathrm{DP}=1,49)$ e $8,95(\mathrm{DP}=1,12)$, nos $1^{\circ}, 5^{\circ}$ e $10^{\circ}$ minutos de vida, respectivamente (Figura 3B). Já os RN de termo apresentaram Escore de Apgar médio de 6,07 $(\mathrm{DP}=2,61), 7,0 \quad(\mathrm{DP}=2,21)$ e $8,27 \quad(\mathrm{DP}=1,74)$, nos $1^{\circ}, 5^{\circ}$ e $10^{\circ}$ minutos de vida, respectivamente (Figura 3B). Finalmente, os RN pós-termo apresentaram Escore de Apgar médio de 3,0 $(\mathrm{DP}=0,0), 7,0(\mathrm{DP}=2,83)$ e $9,5(\mathrm{DP}=0,71)$, nos $1^{\circ}, 5^{\circ}$ e $10^{\circ}$ minutos de vida, respectivamente (Figura 3B).

Com relação ao peso, ao nascimento dos RN incluídos no estudo, a média foi de 2,56Kg (DP=1,0), sendo o valor mínimo 0,51Kg e o máximo 4,47Kg (Tabela 1). Ao agruparse os RN em pré-termo, termo e pós-termo, o peso médio de nascimento foi de $1,76 \mathrm{~kg}$ $(\mathrm{DP}=0,70), 3,32 \mathrm{Kg}(\mathrm{DP}=0,53)$ e $3,35 \mathrm{~kg}(\mathrm{DP}=0,49)$, respectivamente (Figura 3C).

Tabela 1- Caracterização dos RN incluídos no estudo quanto à idade gestacional ao nascimento (em semanas), Escore de Apgar $\left(1^{\circ}, 5^{\circ}\right.$ e $10^{\circ}$ minutos de vida) e peso ao nascimento (em kg). São Paulo, 2020.

\begin{tabular}{lcccccc}
\hline & N & Média & DP & Mín & Mediana & Máx \\
\hline Idade Gestacional & $85^{*}$ & 35,58 & 5,00 & 21,1 & 37,1 & 44,9 \\
APGAR $1^{\circ}$ min & 90 & 6,03 & 2,67 & 0 & 7 & 10 \\
APGAR $5^{\circ}$ min & 90 & 7,51 & 1,95 & 0 & 8 & 10 \\
APGAR $10^{\circ}$ min & 90 & 8,63 & 1,49 & 1 & 9 & 10 \\
Peso ao nascimento & 90 & 2,56 & 1 & 0,51 & 2,69 & 4,47 \\
\hline
\end{tabular}

*Não foi encontrado registro de Idade gestacional em cinco prontuários. 
Figura 3 - Caracterização dos RN pré-termo, termo e pós-termo incluídos no estudo, de acordo com (A) idade gestacional; (B) Escore de Apgar e (C) peso ao nascimento (em kg). São Paulo, 2020.

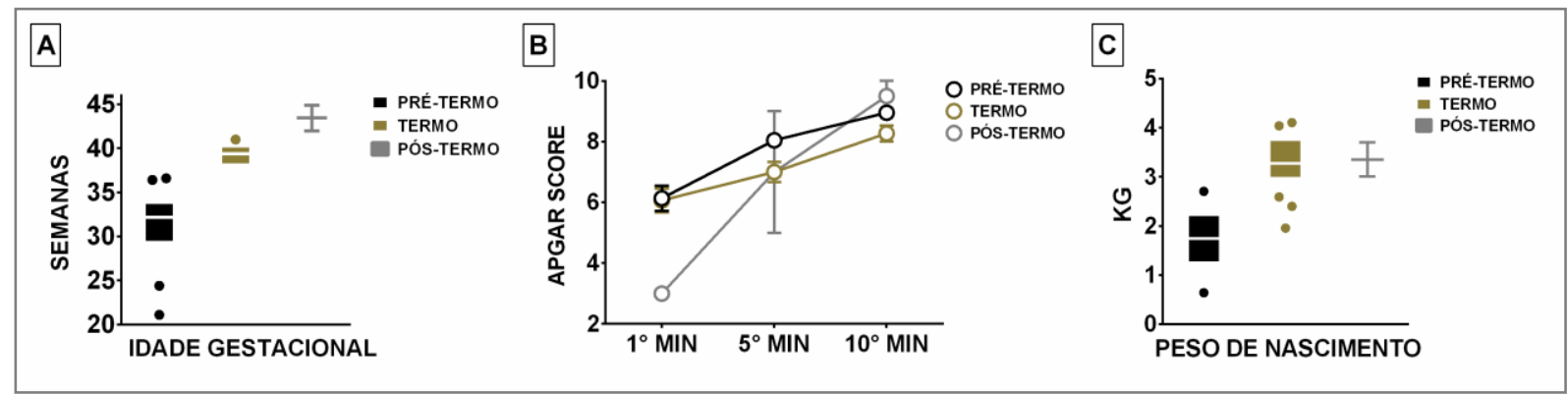

A seguir, a Tabela 2 apresenta os diagnósticos de admissão dos $\mathrm{RN}$ incluídos no estudo. Foram coletados até três diagnósticos por $\mathrm{RN}$, sendo os mais frequentemente registrados o desconforto respiratório precoce $(n=54 ; 60 \%)$, baixo peso $(n=16 ; 17,78 \%)$, risco de síndrome de aspiração meconial (SAM) $(n=15 ; 16,67 \%)$, risco infeccioso $(n=10 ; 11,11 \%)$, trabalho de parto prematuro $(\mathrm{n}=9 ; 10,0 \%)$ e $\mathrm{RN}$ de mães portadoras de diabetes gestacional $(n=9 ; 10,0 \%)$.

Tabela 2 - Diagnósticos registrados nos prontuários clínicos dos RN incluídos no estudo, no momento da admissão. São Paulo, 2020.

(Continua)

\begin{tabular}{|c|c|c|c|c|c|}
\hline Diagnóstico & Nível & $\mathbf{N}$ & Porcentagem & 95\% CI.lo & 95\% CI.hi \\
\hline \multirow{2}{*}{ Desconforto respiratório precoce } & Não & 36 & 40,00 & 30,49 & 50,33 \\
\hline & Sim & 54 & 60,00 & 49,67 & 69,51 \\
\hline \multirow{2}{*}{ Baixo peso } & Não & 74 & 82,22 & 73,06 & 88,75 \\
\hline & Sim & 16 & 17,78 & 11,25 & 26,94 \\
\hline \multirow{2}{*}{$\begin{array}{l}\text { Risco de síndrome de aspiração } \\
\text { mecônial (SAM) }\end{array}$} & Não & 75 & 83,33 & 74,31 & 89,63 \\
\hline & Sim & 15 & 16,67 & 10,37 & 25,69 \\
\hline \multirow{2}{*}{ Risco infeccioso } & Não & 80 & 88,89 & 80,74 & 93,85 \\
\hline & Sim & 10 & 11,11 & 6,15 & 19,26 \\
\hline \multirow{2}{*}{$\begin{array}{l}\text { Trabalho de parto prematuro } \\
\text { (TPP) }\end{array}$} & Não & 81 & 90,00 & 82,08 & 94,65 \\
\hline & Sim & 9 & 10,00 & 5,35 & 17,92 \\
\hline \multirow{2}{*}{$\begin{array}{l}\text { RN de mães portadoras de diabetes } \\
\text { gestacional }\end{array}$} & Não & 81 & 90,00 & 82,08 & 94,65 \\
\hline & Sim & 9 & 10,00 & 5,35 & 17,92 \\
\hline \multirow{2}{*}{ Filho de mãe (FM) corioamnionite } & Não & 82 & 91,11 & 83,43 & 95,43 \\
\hline & Sim & 8 & 8,89 & 4,57 & 16,57 \\
\hline \multirow{2}{*}{$\begin{array}{l}\text { FM com descolamento prematuro } \\
\text { da placenta }\end{array}$} & Não & 84 & 93,33 & 86,21 & 96,91 \\
\hline & Sim & 6 & 6,67 & 3,09 & 13,79 \\
\hline \multirow{2}{*}{ FM sem Pré-natal } & Não & 84 & 93,33 & 86,21 & 96,91 \\
\hline & Sim & 6 & 6,67 & 3,09 & 13,79 \\
\hline \multirow{2}{*}{ Asfixia neonatal } & Não & 84 & 93,33 & 86,21 & 96,91 \\
\hline & Sim & 6 & 6,67 & 3,09 & 13,79 \\
\hline \multirow{2}{*}{$\begin{array}{l}\text { FM com doença hipertensiva } \\
\text { específica da gravidez (DHEG) }\end{array}$} & Não & 85 & 94,44 & 87,65 & 97,60 \\
\hline & Sim & 5 & 5,56 & 2,40 & 12,35 \\
\hline
\end{tabular}


Tabela 2 - Diagnósticos registrados nos prontuários clínicos dos RN incluídos no estudo, no momento da admissão. São Paulo, 2020.

(Continuação)

\begin{tabular}{llcccc}
\hline Diagnóstico & Nível & N & Porcentagem & 95\% CI.lo & 95\% CI.hi \\
\hline FM com infecção do trato urinário & Não & 85 & 94,44 & 87,65 & 97,60 \\
(ITU) & Sim & 5 & 5,56 & 2,40 & 12,35 \\
FM com sífilis & Não & 87 & 96,67 & 90,65 & 98,86 \\
& Sim & 3 & 3,33 & 1,14 & 9,35 \\
Sepse neonatal & Não & 87 & 96,67 & 90,65 & 98,86 \\
& Sim & 3 & 3,33 & 1,14 & 9,35 \\
Sofrimento fetal agudo & Não & 88 & 97,78 & 92,26 & 99,39 \\
\multirow{2}{*}{ Hipotermia } & Sim & 2 & 2,22 & 0,61 & 7,75 \\
& Não & 88 & 97,78 & 92,26 & 99,39 \\
Epidermolise bolhosa & Sim & 2 & 2,22 & 0,61 & 7,75 \\
& Não & 89 & 98,89 & 93,97 & 99,80 \\
\multirow{2}{*}{ Atresia de esôfago } & Sim & 1 & 1,11 & 0,20 & 6,03 \\
\multirow{2}{*}{ Hérnia de hiato } & Não & 89 & 98,89 & 93,97 & 99,80 \\
& Sim & 1 & 1,11 & 0,20 & 6,03 \\
Anóxia neonatal & Não & 89 & 98,89 & 93,97 & 99,80 \\
& Sim & 1 & 1,11 & 0,20 & 6,03 \\
\hline \multirow{2}{*}{ Insuficiência respiratória aguda } & Não & 89 & 98,89 & 93,97 & 99,80 \\
& Sim & 1 & 1,11 & 0,20 & 6,03 \\
\hline & Sim & 89 & 98,89 & 93,97 & 99,80 \\
& & 1 & 1,11 & 0,20 & 6,03 \\
\hline
\end{tabular}

Em relação ao tempo de permanência na UTIN, nota-se que da admissão ao terceiro dia de internação na UTIN, período de coletada dos dados, os RN incluídos no estudo permaneceram, em média, por 55 horas $(\mathrm{DP}=30,61)$ na unidade, sendo o tempo mínimo de 9,33 horas e o máximo, de 101,3 (Tabela 3). Ao se agrupar os RN em pré-termo, termo e pós termo, observa-se que os RN pré-termo permanecem em média 67,63 horas ( $D P=26,84)$, mínimo de 18,42 e máximo de 101,3; os RN de termo permanecem, em média, 42,41 horas ( $\mathrm{DP}=28,52)$ internados, mínimo de 9,33 e máximo de 100,0; os RN pós-termo permanecem, em média, 59,54 (DP=57,93), mínimo de 18,58 e máximo de 100,5 horas (Tabela 3).

Nota-se ainda, em relação ao tempo de permanência, que a distribuição dos RN prétermo é superior à média e, que o grupo composto por RN de termo tende a permanecer por período inferior à média. Já em relação aos RN pós-termo, identifica-se disparidade no tempo de permanência, com um RN que permaneceu internado por período superior e outro inferior à média de 54,98h (Figura 4). Constatou-se três óbitos $(3,33 \%)$ ao longo do período de coleta, todos de RN pré-termo. 
Tabela 3 - Tempo de permanência (em horas) dos RN incluídos no estudo, durante período de coleta. São Paulo, 2020 .

\begin{tabular}{lcccccc}
\hline & N & Média & DP & Mín & Mediana & Máx \\
\hline Tempo de internação RN & 90 & 54,98 & 30,61 & 9,33 & 51,42 & 101,3 \\
RN pré-termo & 44 & 67,63 & 26,84 & 18,42 & 79,50 & 101,3 \\
RN termo & 44 & 42,41 & 28,52 & 9,33 & 29,17 & 100,0 \\
RN pós-termo & 2 & 59,54 & 57,93 & 18,58 & 59,54 & 100,5 \\
\hline
\end{tabular}

Figura 4 - Tempo de permanência dos RN pré-termo, termo e pós-termo incluídos no estudo na UTIN, durante o período de coleta em horas de internação, por grupo (pré-termo, termo e pós-termo). São Paulo, 2020 .

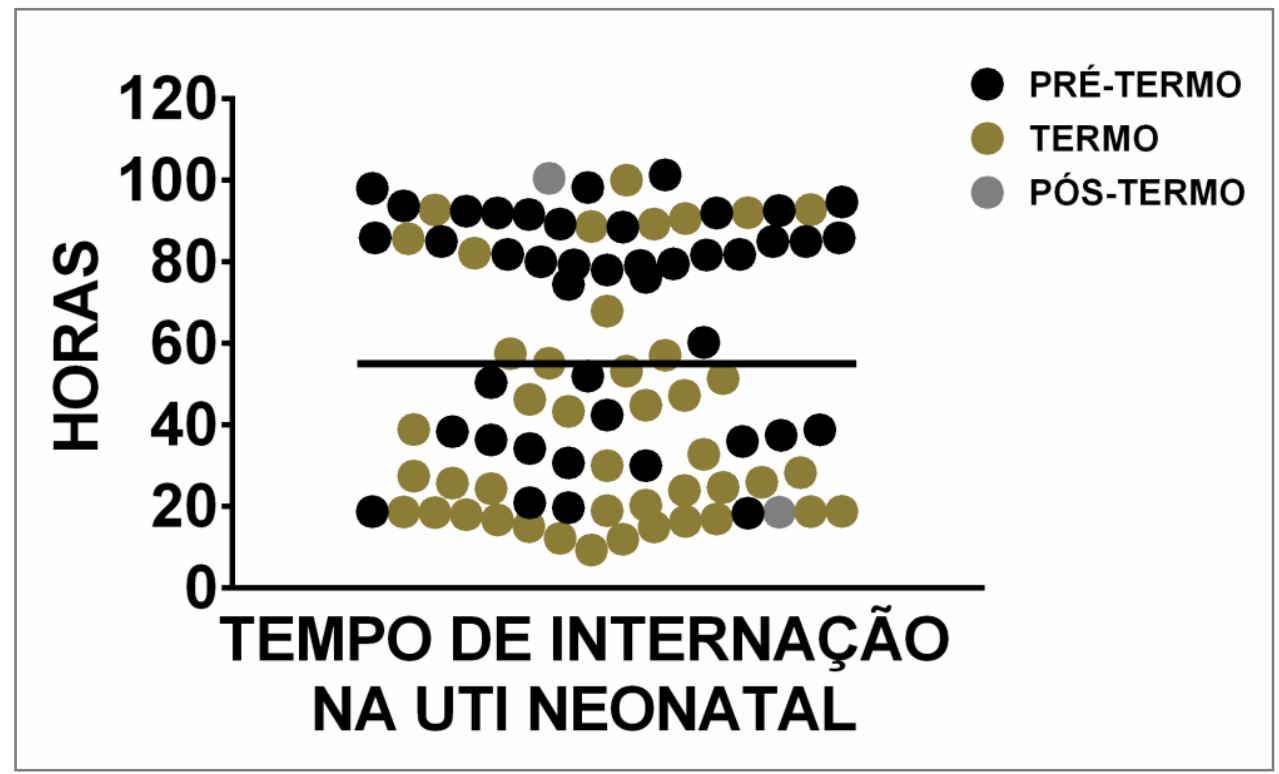

Entre a admissão (dia zero) e o terceiro dia de internação na UTIN, os 90 RN incluídos no estudo foram submetidos a um total de 2.732 procedimentos estressantes e potencialmente dolorosos, incluindo o número de tentativas com ou sem êxito na realização do procedimento. Foram empregadas 540 estratégias não farmacológicas e, 216 intervenções farmacológicas para o alívio da dor (Figura 5A). Considerando-se todo o período do estudo, os RN foram submetidos, em média, a 30,36 ( $\mathrm{DP}=20,47)$ procedimentos estressantes e potencialmente dolorosos. Observa-se que tanto os RN pré-termo quanto os pós-termo experienciaram maior número médio de procedimentos (Figura 5B; Tabela 4). Destaca-se que o maior número de procedimentos potencialmente dolorosos, realizados em um único $\mathrm{RN}$, ao longo do período de coleta dos dados, foi de 91; por outro lado, o número mínimo foi de quatro procedimentos (Figura 5B; Tabela 4). 
Percebe-se que da admissão ao terceiro dia de internação na UTIN, período de coletada dos dados, os RN receberam, em média, 5,98 (DP=5,11) medidas não farmacológicas. Destaca-se ainda que, em aproximadamente $50 \%$ da população estudada, as medidas não farmacológicas foram empregadas em frequência abaixo da média (Figura 5C; Tabela 4). Observou-se que um RN pré-termo recebeu 21 intervenções não farmacológicas e, que por outro lado, $19 \mathrm{RN}$ não receberam nenhum tipo de medida não farmacológica de alívio da dor, no período estudado (Figura 5C; Tabela 4). Quanto às medidas farmacológicas, os $\mathrm{RN}$ receberam uma média de 2,39 $(\mathrm{DP}=4,66)$ intervenções entre a admissão e o terceiro dia de internação na UTIN. Destaca-se, ainda, que um RN pré-termo recebeu 22 medidas farmacológicas durante o período avaliado. Além disso, observou-se que $80 \%$ dos RN incluídos não recebeu qualquer tipo de intervenções farmacológicas durante o período estudado (Figura 5D; Tabela 4).

Figura 5 - (A) Número total de procedimentos potencialmente dolorosos, estratégias não farmacológicas e farmacológicas; (B) Número total de procedimentos potencialmente dolorosos por RN, de acordo com a classificação em pré-termo, termo e pós-termo; (C) Número total de medidas não farmacológicas por RN, de acordo com a classificação em pré-termo, termo e pós-termo; (D) Número total de medidas farmacológicas por $\mathrm{RN}$, de acordo com a classificação em pré-termo, termo e pós-termo. São Paulo, 2020.

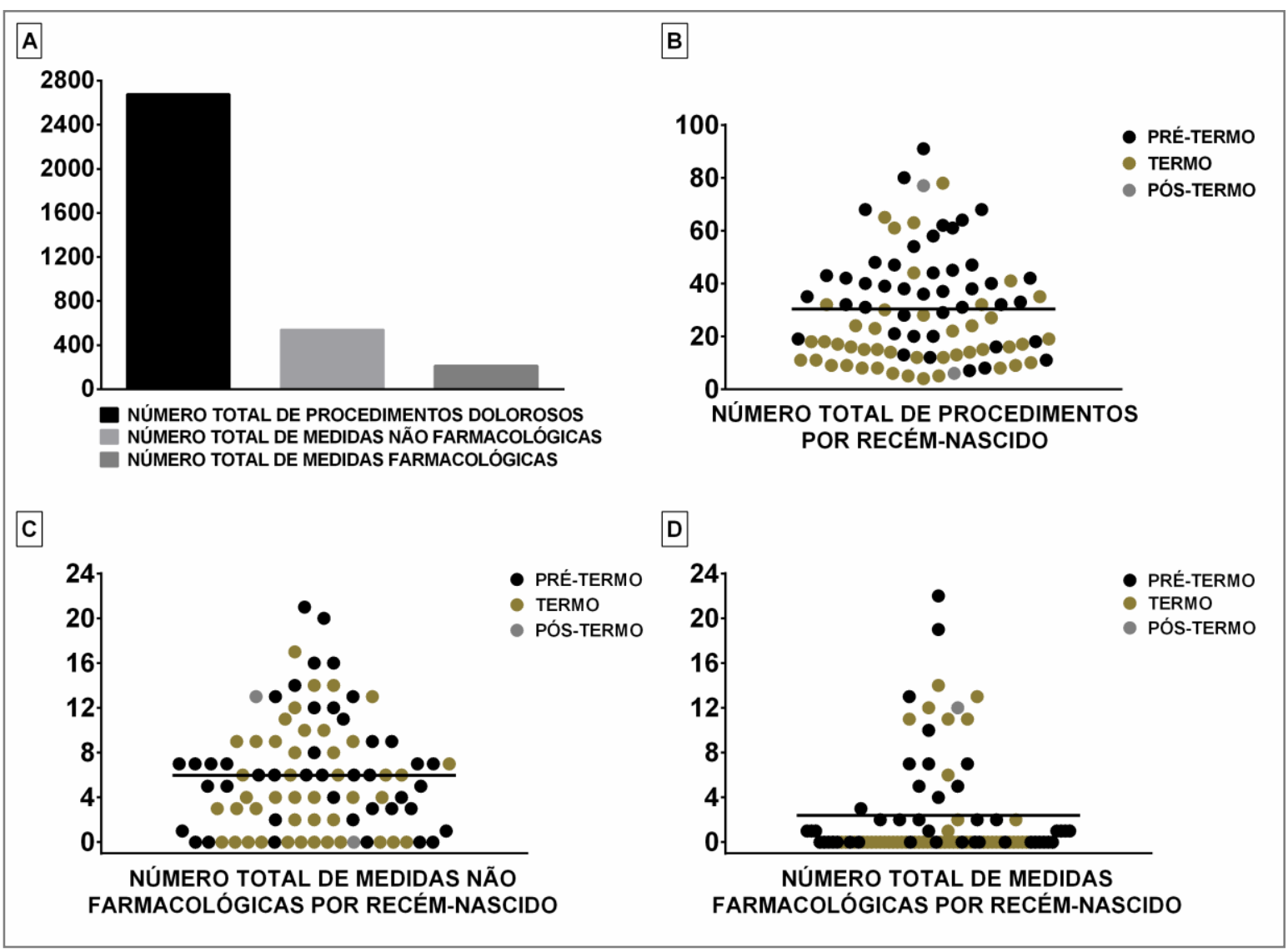


Tabela 4 - Número total de procedimentos, medidas não farmacológicas e farmacológicas por RN, realizados da admissão ao terceiro dia de internação na UTIN. São Paulo, 2020.

\begin{tabular}{llcccccc}
\hline Variável & & N & Média & DP & Mín & Mediana & Máx \\
\hline Número de & RN (total) & 2732 & 30,36 & 20,47 & 4 & 27,5 & 91 \\
procedimentos & RN pré-termo & 1686 & 38,32 & 19,32 & 7 & 38,0 & 91 \\
& RN termo & 963 & 21,89 & 17,32 & 4 & 16,0 & 78 \\
& RN pós-termo & 83 & 41,50 & 50,20 & 6 & 41,50 & 77 \\
Medidas não & RN (total) & 540 & 5,978 & 5,11 & 0 & 6 & 21 \\
farmacológicas & RN pré-termo & 298 & 6,77 & 5,39 & 0 & 6 & 21 \\
& RN termo & 229 & 5,20 & 4,67 & 0 & 4 & 17 \\
& RN pós-termo & 13 & 6,50 & 9,19 & 0 & 6,5 & 13 \\
Medidas & RN (total) & 216 & 2,39 & 4,66 & 0 & 0 & 22 \\
farmacológicas & RN pré-termo & 123 & 2,79 & 4,95 & 0 & 1 & 22 \\
& RN termo & 81 & 1,84 & 4,17 & 0 & 0 & 14 \\
& RN pós-termo & 12 & 6,0 & 8,48 & 0 & 6 & 12 \\
\hline
\end{tabular}

Após a realização dos procedimentos dolorosos, que inclui o número de tentativas com ou sem êxito, os RNs permaneceram, em média com 2,79 (DP=1,44) dispositivos no dia da admissão, 2,74 ( $\mathrm{DP}=1,62)$, em média, no primeiro dia, média de 2,67 ( $\mathrm{DP}=1,90)$ no segundo dia e, por fim, média de 2,48 ( $\mathrm{DP}=1,87)$ no terceiro dia (Tabela 5). Da admissão ao terceiro dia de internação, os principais dispositivos utilizados nos RN foram sonda orogástrica, acesso venoso periférico e CPAP nasal. Destaca-se, ainda, que durante todo o período de estudo foram utilizados em média 10,75 dispositivos distintos nos RNs (Tabela 6).

Tabela 5 - Número de dispositivos utilizados nos RN ao longo de todo o período do estudo e de acordo com os dias de internação na UTIN. São Paulo, 2020.

\begin{tabular}{lcccccc}
\hline & N & Média & DP & Mín & Mediana & Máx \\
\hline Total & 90 & 9,48 & 5,34 & 0 & 8,5 & 24 \\
Admissão & 90 & 2,79 & 1,44 & 0 & 3 & 6 \\
Dia 1 & 87 & 2,74 & 1,62 & 0 & 3 & 6 \\
Dia 2 & 58 & 2,67 & 1,90 & 0 & 3 & 6 \\
Dia 3 & 44 & 2,48 & 1,87 & 0 & 3 & 6 \\
\hline
\end{tabular}


Tabela 6 - Tipos de dispositivos utilizados nos RN da admissão ao terceiro dia de internação na UTIN. São Paulo, 2020.

\begin{tabular}{|c|c|c|c|c|c|c|c|c|c|}
\hline \multirow{2}{*}{ Variável } & & \multicolumn{2}{|c|}{ Admissão } & \multicolumn{2}{|c|}{ Dia 1} & \multicolumn{2}{|c|}{ Dia 2} & \multicolumn{2}{|c|}{ Dia 3} \\
\hline & & $\mathbf{N}$ & $\%$ & $\mathbf{N}$ & $\%$ & $\mathbf{N}$ & $\%$ & $\mathbf{N}$ & $\%$ \\
\hline \multirow{2}{*}{$\begin{array}{l}\text { Acesso venoso } \\
\text { periférico }\end{array}$} & Não & 25 & 28,09 & 19 & 22,09 & 12 & 22,22 & 10 & 26,32 \\
\hline & Sim & 64 & 71,91 & 67 & 77,91 & 42 & 77,78 & 28 & 73,68 \\
\hline \multirow{2}{*}{ Cânula endotraqueal } & Não & 71 & 79,78 & 67 & 77,91 & 37 & 68,52 & 26 & 68,42 \\
\hline & Sim & 18 & 20,22 & 19 & 22,09 & 17 & 31,48 & 12 & 31,58 \\
\hline \multirow{2}{*}{ Cateter central } & Não & 89 & 100,00 & 85 & 98,84 & 54 & 100,00 & 38 & 100,00 \\
\hline & Sim & 0 & 0,00 & 1 & 1,16 & 0 & 0,00 & 0 & 0,00 \\
\hline \multirow{2}{*}{$\begin{array}{l}\text { Cateter central de } \\
\text { inserção periférica }\end{array}$} & Não & 88 & 98,88 & 82 & 95,35 & 45 & 83,33 & 25 & 65,79 \\
\hline & Sim & 1 & 1,12 & 4 & 4,65 & 9 & 16,67 & 13 & 34,21 \\
\hline \multirow{2}{*}{ Cateter nasal } & Não & 84 & 94,38 & 77 & 89,54 & 49 & 90,74 & 36 & 94,74 \\
\hline & Sim & 5 & 5,62 & 9 & 10,47 & 5 & 9,26 & 2 & 5,26 \\
\hline \multirow{2}{*}{ Cateter umbilical } & Não & 73 & 82,02 & 71 & 82,56 & 41 & 75,93 & 28 & 73,68 \\
\hline & Sim & 16 & 17,98 & 15 & 17,44 & 13 & 24,07 & 10 & 26,32 \\
\hline \multirow{2}{*}{$\begin{array}{l}\text { Continuous positive } \\
\text { airway pressure } \\
\text { (CPAP) }\end{array}$} & Não & 22 & 24,72 & 42 & 48,84 & 35 & 64,81 & 23 & 60,53 \\
\hline & Sim & 67 & 75,28 & 44 & 51,16 & 19 & 35,19 & 15 & 39,47 \\
\hline \multirow{2}{*}{ Dreno de tórax } & Não & 87 & 97,75 & 82 & 95,35 & 50 & 92,59 & 35 & 92,11 \\
\hline & Sim & 2 & 2,25 & 4 & 4,65 & 4 & 7,41 & 3 & 7,90 \\
\hline \multirow{2}{*}{ Sonda nasogástrica } & Não & 88 & 98,88 & 85 & 98,84 & 53 & 98,15 & 38 & 100,00 \\
\hline & Sim & 1 & 1,12 & 1 & 1,16 & 1 & 1,85 & 0 & 0,00 \\
\hline \multirow{2}{*}{ Sonda orogástrica } & Não & 2 & 2,25 & 6 & 6,98 & 4 & 7,41 & 2 & 5,26 \\
\hline & Sim & 87 & 97,75 & 80 & 93,02 & 50 & 92,59 & 36 & 94,74 \\
\hline \multirow{2}{*}{$\begin{array}{l}\text { Sonda vesical de } \\
\text { demora }\end{array}$} & Não & 82 & 92,14 & 76 & 88,37 & 45 & 83,33 & 30 & 78,95 \\
\hline & Sim & 7 & 7,87 & 10 & 11,63 & 9 & 16,67 & 8 & 21,05 \\
\hline
\end{tabular}

Observa-se uma variação do número de procedimentos desde a admissão ao terceiro dia de internação na UTIN. Na admissão, a média de procedimentos foi de 12,78 (DP=6,02), no primeiro dia, 8,1 ( $\mathrm{DP}=6,38)$; no segundo dia, a média foi de 5,36 ( $\mathrm{DP}=6,095)$ e, no terceiro dia, 3,84 (DP= 5,55) (Tabela 7; Figura 6A). No período avaliado, em relação ao número de medidas não farmacológicas, registrou-se média de $1,98(\mathrm{DP}=2,39)$ na admissão, média de 1,73 ( $\mathrm{DP}=2,47)$ no primeiro dia, média de 1,23 ( $\mathrm{DP}=2,42)$ no segundo dia e, média de 0,97 $(\mathrm{DP}=2,11)$ no terceiro dia (Tabela 7; Figura 6A). Aponta-se ainda, adoção média de 0,81 $(\mathrm{DP}=2,04)$ medidas farmacológicas no dia da admissão, média de 0,66 ( $\mathrm{DP}=1,27)$ no primeiro dia, média de 0,544 ( $\mathrm{DP}=1,23)$ no segundo dia e, média de 0,36 ( $\mathrm{DP}=0,96)$ no terceiro dia (Tabela 7; Figura 6A).

Observou-se uma diferença estatisticamente significativa entre o número de procedimentos potencialmente dolorosos realizados ao longo dos dias de hospitalização (ANOVA one way), em relação aos procedimentos realizados na admissão e no $1^{\circ}$ dia $(\mathrm{p}<$ 
0,0001), na admissão e no $2^{\circ}$ dia ( $\left.p<0,0001\right)$, na admissão e no $3^{\circ}$ dia $(\mathrm{p}<0,0001)$, entre o $1^{\circ} \mathrm{e}$ o $2^{\circ}$ dia $(\mathrm{p}<0,05)$, entre o $1^{\circ}$ e o $3^{\circ}$ dia $(\mathrm{p}<0,0001)$. Além disso, observou-se uma diferença estatisticamente significativa somente entre o número de medidas não farmacológicas empregadas entre a admissão e o $3^{\circ}$ dia $(p<0,05)$. Não foi identificada uma diferença estatisticamente significativa em relação ao uso de medidas farmacológicas ao longo do período estudado.

Tabela 7 - Número de procedimentos potencialmente dolorosos, medidas não farmacológicas e farmacológicas, realizadas da admissão ao terceiro dia de internação na UTIN. São Paulo, 2020.

\begin{tabular}{|c|c|c|c|c|c|c|c|}
\hline & & $\mathbf{N}$ & Média & DP & Mín & Mediana & Máx \\
\hline \multirow[t]{3}{*}{ Admissão } & $\begin{array}{l}\text { Número de } \\
\text { Procedimentos }\end{array}$ & 1150 & 12,78 & 6,02 & 3 & 12 & 32 \\
\hline & $\begin{array}{l}\text { Medidas não } \\
\text { Farmacológicas }\end{array}$ & 178 & 1,98 & 2,39 & 0 & 1 & 10 \\
\hline & $\begin{array}{l}\text { Medidas } \\
\text { Farmacológicas }\end{array}$ & 76 & 0,81 & 2,04 & 0 & 0 & 9 \\
\hline \multirow[t]{3}{*}{$1^{\circ} \mathrm{DIA}$} & $\begin{array}{l}\text { Número de } \\
\text { Procedimentos }\end{array}$ & 754 & 8,1 & 6,38 & 0 & 7,5 & 29 \\
\hline & $\begin{array}{l}\text { Medidas não } \\
\text { Farmacológicas }\end{array}$ & 164 & 1,73 & 2,47 & 0 & 0 & 12 \\
\hline & $\begin{array}{l}\text { Medidas } \\
\text { Farmacológicas }\end{array}$ & 59 & 0,66 & 1,27 & 0 & 0 & 5 \\
\hline \multirow[t]{3}{*}{$2^{\circ}$ DIA } & $\begin{array}{l}\text { Número de } \\
\text { Procedimentos }\end{array}$ & 482 & 5,36 & 6,09 & 0 & 3 & 23 \\
\hline & $\begin{array}{l}\text { Medidas não } \\
\text { Farmacológicas }\end{array}$ & 111 & 1,23 & 2,42 & 0 & 0 & 11 \\
\hline & $\begin{array}{l}\text { Medidas } \\
\text { Farmacológicas }\end{array}$ & 49 & 0,54 & 1,23 & 0 & 0 & 6 \\
\hline \multirow[t]{3}{*}{$3^{\circ} \mathrm{DIA}$} & $\begin{array}{l}\text { Número de } \\
\text { Procedimentos }\end{array}$ & 346 & 3,84 & 5,55 & 0 & 0 & 18 \\
\hline & $\begin{array}{l}\text { Medidas não } \\
\text { Farmacológicas }\end{array}$ & 87 & 0,97 & 2,11 & 0 & 0 & 10 \\
\hline & $\begin{array}{l}\text { Medidas } \\
\text { Farmacológicas }\end{array}$ & 32 & 0,36 & 0,96 & 0 & 0 & 5 \\
\hline
\end{tabular}

Os principais procedimentos estressantes e potencialmente dolorosos realizados foram a glicemia capilar ( $\mathrm{n}=561 ; 20,96 \%)$, aspiração de vias aéreas superiores (VAS) e/ou cânula endotraqueal $(\mathrm{COT})(\mathrm{n}=387 ; 14,46 \%)$, fisioterapia respiratória $(\mathrm{n}=267 ; 9,97 \%)$, punção venosa para terapia IV ( $\mathrm{n}=198 ; 7,4 \%)$, remoção de dispositivos $(\mathrm{n}=190 ; 7,01 \%)$ e instalação de CPAP (n=175; 6,54\%) (Figura 6B).

Com relação às estratégias não farmacológicas de conforto e alívio da dor, foram registrados com maior frequência redução de luminosidade $(n=153 ; 28,33 \%)$, aconchego no 
leito/aninhamento ( $\mathrm{n}=141 ; 26,11 \%)$, manipulação mínima ( $\mathrm{n}=108 ; 26,11 \%)$, sucção não nutritiva $(\mathrm{n}=35 ; 6,48 \%)$ e solução adocicada $(\mathrm{n}=29 ; 5,37 \%)$ (Figura 6C). Destaca-se que as principais medidas farmacológicas empregadas foram fentanil contínuo ( $\mathrm{n}=104 ; 48,83 \%$ ), midazolam intermitente $(n=41 ; 19,25 \%)$, fentanil intermitente $(n=29 ; 13,61 \%)$ e morfina intermitente $(\mathrm{n}=19 ; 8,92 \%)$ (Figura 6D).

Figura 6 - (A) Média do número de procedimentos potencialmente dolorosos, estratégias não farmacológicas e farmacológicas da admissão ao terceiro dia de internação na UTIN; (B) Procedimentos potencialmente dolorosos; (C) Estratégias não farmacológicas; (D) Estratégias farmacológicas. São Paulo, 2020.

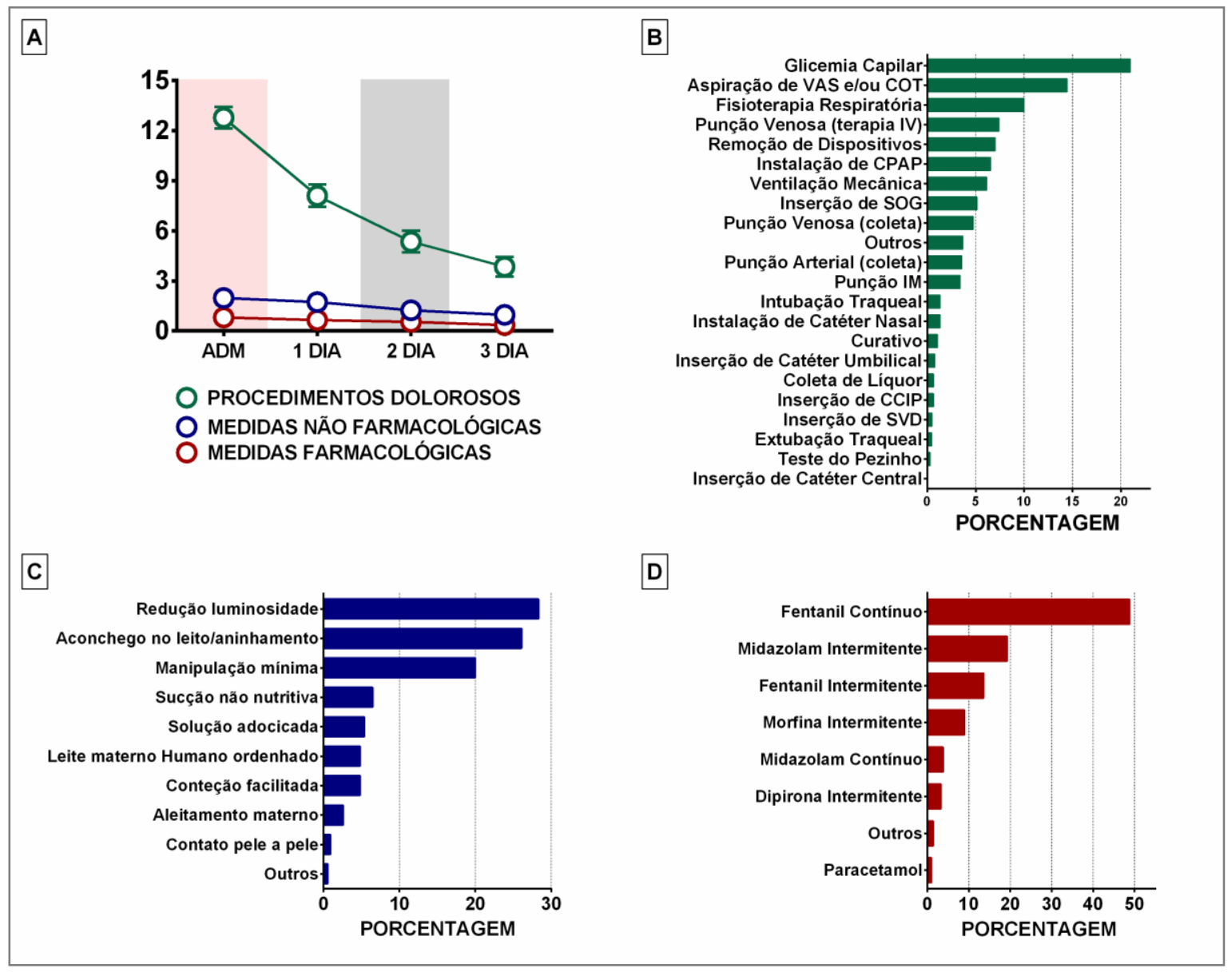

Em uma análise mais detalhada, nota-se uma variação no número de procedimentos potencialmente dolorosos, medidas não farmacológicas e farmacológicas ao longo de cada dia, nos períodos da manhã, tarde e noite (Figura 7A). Em relação ao número de procedimentos potencialmente dolorosos, na admissão foi realizada em média 7,42 (DP=3,41) procedimentos pela manhã, média de 5,44 $(\mathrm{DP}=4,16)$ à tarde e média de $6,13(\mathrm{DP}=3,36)$ à noite (Figura 7A). Variação similar ocorre em relação às medidas não farmacológicas e 
farmacológicas (Figura 7A). Ao se separar os RN entre pré-termo, termo e pós-termo, constata-se oscilação semelhante (Figura 7B-D).

Desse modo, percebe-se redução do escore NIPS durante o período (Figura 7E-F). A Tabela 8 apresenta os dados relacionados aos registros do escore NIPS, da admissão até o terceiro dia de hospitalização. Nos prontuários dos RN incluídos no estudo, foram encontrados um total de 356 registros de escores NIPS na admissão, 402 no $1^{\circ}$ dia, 286 registros no $2^{\circ}$ dia e 213 registros de escores de dor no $3^{\circ}$ dia. Nota-se que a porcentagem de RN com dor varia ao longo das horas e dos dias, observa-se que na admissão $20(5,61 \%)$ dos escores registrados correspondem à presença de dor, no primeiro dia, somente $10(2,49 \%)$ registros, no segundo dia, quatro $(1,14 \%)$ e no terceiro dia, três $(1,14 \%)$ (Figura $7 \mathrm{G}-\mathrm{J})$.

Figura 7 - (A) Média do número de procedimentos potencialmente dolorosos, estratégias não farmacológicas e farmacológicas da admissão ao terceiro dia de internação na UTIN; (B) Média do número de procedimentos potencialmente dolorosos, estratégias não farmacológicas e farmacológicas em $\mathrm{RN}$ pré-termo; (C) Média do número de procedimentos potencialmente dolorosos, estratégias não farmacológicas e farmacológicas em RN a termo; (D) Média do número de procedimentos potencialmente dolorosos, estratégias não farmacológicas e farmacológicas em RN pós-termo; (E) Escore NIPS por RN; (F) Escore NIPS por grupo; (G-J) Porcentagem de RN com dor ao longo das horas; (K-N) Porcentagem de RN com dor por dia. São Paulo, 2020.

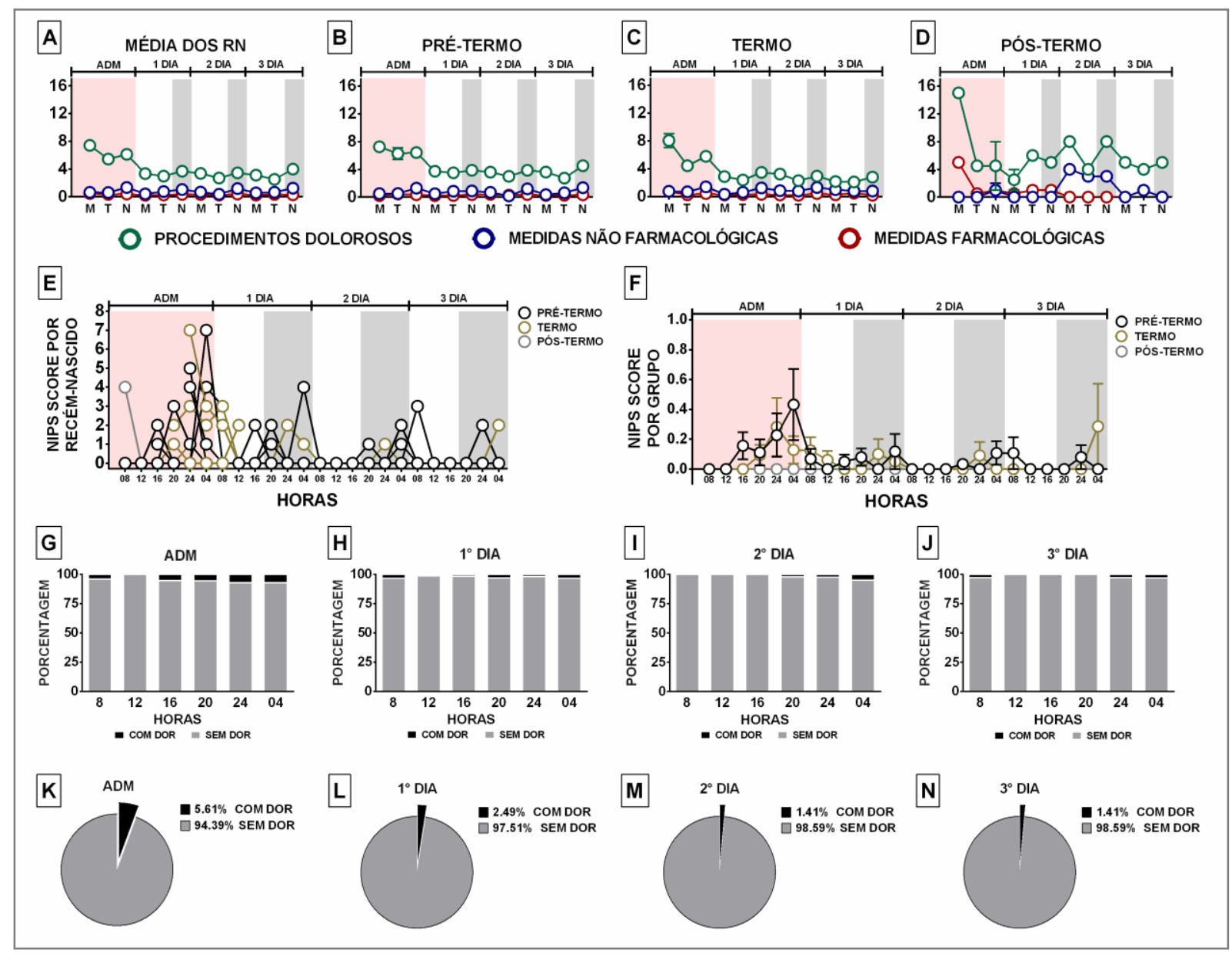


Tabela 8 - Escore NIPS da admissão ao terceiro dia de internação na UTIN. São Paulo, 2020.

\begin{tabular}{|c|c|c|c|c|c|c|c|c|}
\hline Variável & Dia & Horário & $\mathbf{N} *$ & Média & DP & Mín & Mediana & Máx \\
\hline \multirow[t]{24}{*}{ NIPS } & Admissão & $8 \mathrm{H}$ & 24 & 0,17 & 0,82 & 0 & 0 & 4 \\
\hline & & $12 \mathrm{H}$ & 34 & 0,00 & 0,00 & 0 & 0 & 0 \\
\hline & & $16 \mathrm{H}$ & 58 & 0,09 & 0,39 & 0 & 0 & 2 \\
\hline & & $20 \mathrm{H}$ & 70 & 0,10 & 0,46 & 0 & 0 & 3 \\
\hline & & $24 \mathrm{H}$ & 85 & 0,25 & 1,07 & 0 & 0 & 7 \\
\hline & & $4 \mathrm{H}$ & 85 & 0,28 & 1,20 & 0 & 0 & 7 \\
\hline & Dia 1 & $8 \mathrm{H}$ & 85 & 0,09 & 0,50 & 0 & 0 & 3 \\
\hline & & $12 \mathrm{H}$ & 77 & 0,03 & 0,23 & 0 & 0 & 2 \\
\hline & & $16 \mathrm{H}$ & 68 & 0,03 & 0,24 & 0 & 0 & 2 \\
\hline & & $20 \mathrm{H}$ & 62 & 0,05 & 0,28 & 0 & 0 & 2 \\
\hline & & $24 \mathrm{H}$ & 55 & 0,04 & 0,27 & 0 & 0 & 2 \\
\hline & & $4 \mathrm{H}$ & 55 & 0,09 & 0,55 & 0 & 0 & 4 \\
\hline & Dia 2 & $8 \mathrm{H}$ & 55 & 0,00 & 0,00 & 0 & 0 & 0 \\
\hline & & $12 \mathrm{H}$ & 53 & 0,00 & 0,00 & 0 & 0 & 0 \\
\hline & & $16 \mathrm{H}$ & 52 & 0,00 & 0,00 & 0 & 0 & 0 \\
\hline & & $20 \mathrm{H}$ & 46 & 0,02 & 0,15 & 0 & 0 & 1 \\
\hline & & $24 \mathrm{H}$ & 40 & 0,03 & 0,16 & 0 & 0 & 1 \\
\hline & & $4 \mathrm{H}$ & 40 & 0,08 & 0,35 & 0 & 0 & 2 \\
\hline & Dia 3 & $8 \mathrm{H}$ & 39 & 0,08 & 0,48 & 0 & 0 & 3 \\
\hline & & $12 \mathrm{H}$ & 38 & 0,00 & 0,00 & 0 & 0 & 0 \\
\hline & & $16 \mathrm{H}$ & 35 & 0,00 & 0,00 & 0 & 0 & 0 \\
\hline & & $20 \mathrm{H}$ & 34 & 0,00 & 0,00 & 0 & 0 & 0 \\
\hline & & $24 \mathrm{H}$ & 34 & 0,06 & 0,34 & 0 & 0 & 2 \\
\hline & & $4 \mathrm{H}$ & 33 & 0,06 & 0,35 & 0 & 0 & 2 \\
\hline
\end{tabular}

* Número de avaliações variou de acordo com a disponibilidade de registros nos prontuários

Em relação aos sinais vitais, verificou-se que a temperatura axilar média dos RN oscilou dentro da faixa de normalidade de 36,5 a $37,5{ }^{\circ} \mathrm{C}$, da admissão ao terceiro dia de permanência na UTIN (Figura 8; Tabela 9). No período avaliado, em relação à temperatura axilar, registrou-se na admissão valor médio de $36,4{ }^{\circ} \mathrm{C}(\mathrm{DP}=0,95)$; no primeiro dia, $36,5^{\circ} \mathrm{C}$ ( $\mathrm{DP}=0,83)$; média de $36,5^{\circ} \mathrm{C}(\mathrm{DP}=0,85)$ no segundo dia e, finalmente, média de $36,5^{\circ} \mathrm{C}$ $(\mathrm{DP}=0,63)$ no terceiro dia (Figura 8; Tabela 9). Os $\mathrm{RN}$ que apresentaram temperatura axilar abaixo dos valores normais foram aqueles submetidos à hipotermia terapêutica (Tabela 9). 
Figura 8 - Média da temperatura axilar da admissão ao terceiro dia de internação na UTIN. Valores de referência: mínimo (linha azul) e máximo (linha vermelha). São Paulo, 2020.

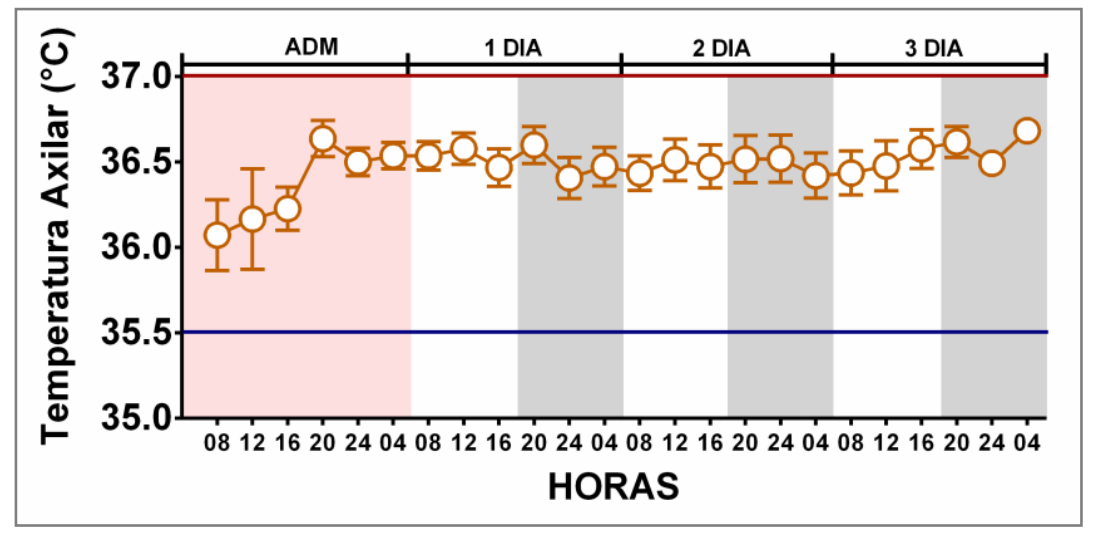

Tabela 9 - Temperatura axilar da admissão ao terceiro dia de internação na UTIN. São Paulo, 2020.

\begin{tabular}{lllccccc}
\hline Variável & Dia & N $^{*}$ & Média & DP & Mín & Mediana & Máx \\
\hline \multirow{2}{*}{ Temperatura } & Admissão & 349 & 36,43 & 0,95 & 28,5 & 36,6 & 37,8 \\
& Dia 1 & 395 & 36,52 & 0,83 & 32,2 & 36,7 & 38,1 \\
& Dia 2 & 279 & 36,48 & 0,85 & 32,6 & 36,6 & 37,7 \\
& Dia 3 & 207 & 36,54 & 0,63 & 32,5 & 36,6 & 37,9 \\
\hline
\end{tabular}

* Número corresponde à somatória de todos os registros encontrados nos prontuários de cada RN incluído no estudo, ao longo do período de estudo.

Averiguou-se que a frequência cardíaca média dos $\mathrm{RN}$ oscilou dentro da faixa de normalidade, ao longo dos dias de internação (Figura 9; Tabela 10). No período avaliado, registrou-se valor médio de $138 \mathrm{bpm}$ na admissão $(\mathrm{DP}=16,5)$; no primeiro dia, média de 137bpm ( $\mathrm{DP}=15,97)$; média de 141bpm ( $\mathrm{DP}=17,96)$ no segundo dia e média de 147bpm $(\mathrm{DP}=18,16)$ no terceiro dia (Figura 9; Tabela 10).

Figura 9 - Média da frequência cardíaca da admissão ao terceiro dia de internação na UTIN. Valor de referência: máximo (linha vermelha). São Paulo, 2020.

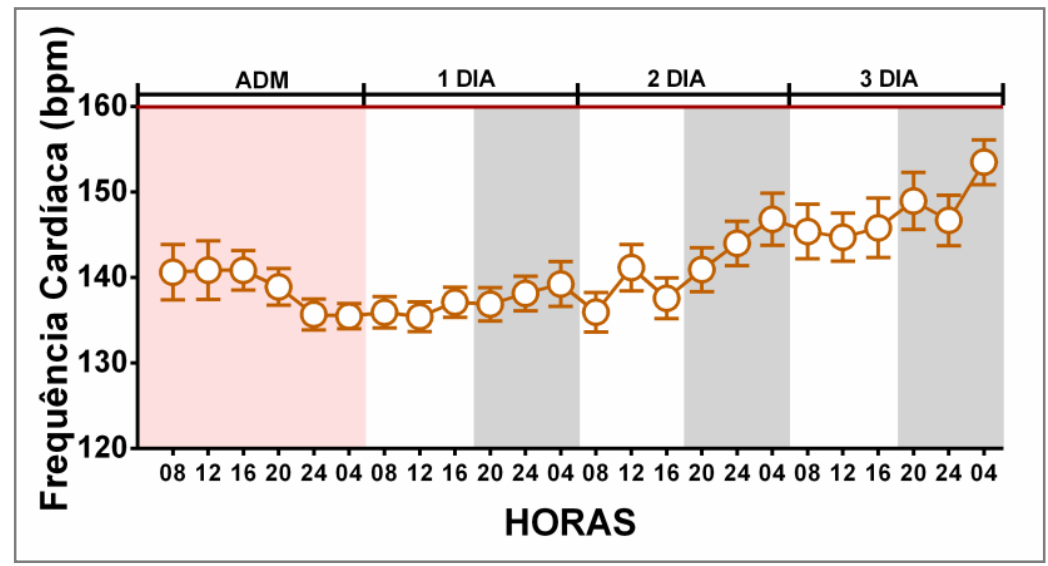


Tabela 10 - Frequência cardíaca da admissão ao terceiro dia de internação na UTIN. São Paulo, 2020.

\begin{tabular}{llcccccc}
\hline Variável & Dia & N $^{*}$ & Média & DP & Mín & Mediana & Máx \\
\hline Frequência & Admissão & 346 & 137,9 & 16,5 & 78 & 137,5 & 186 \\
cardíaca & Dia 1 & 396 & 136,9 & 15,97 & 80 & 137 & 195 \\
& Dia 2 & 280 & 140,7 & 17,96 & 96 & 140 & 199 \\
& Dia 3 & 207 & 147,4 & 18,16 & 93 & 150 & 184 \\
\hline
\end{tabular}

* Número corresponde à somatória de todos os registros encontrados nos prontuários de cada RN incluído no estudo, ao longo do período de estudo.

No período avaliado, em relação à frequência respiratória, registrou-se média de $55 \mathrm{ipm}(\mathrm{DP}=15,04)$ na admissão; no primeiro dia, 56ipm ( $\mathrm{DP}=14,81)$; média de 55ipm $(\mathrm{DP}=12,72)$ no segundo dia e, média de 52ipm $(\mathrm{DP}=13,51)$ no terceiro dia (Figura 10; Tabela 11).

Figura 10- Média da frequência respiratória da admissão ao terceiro dia de internação na UTIN. Valor de referência: máximo (linha vermelha). São Paulo, 2020.

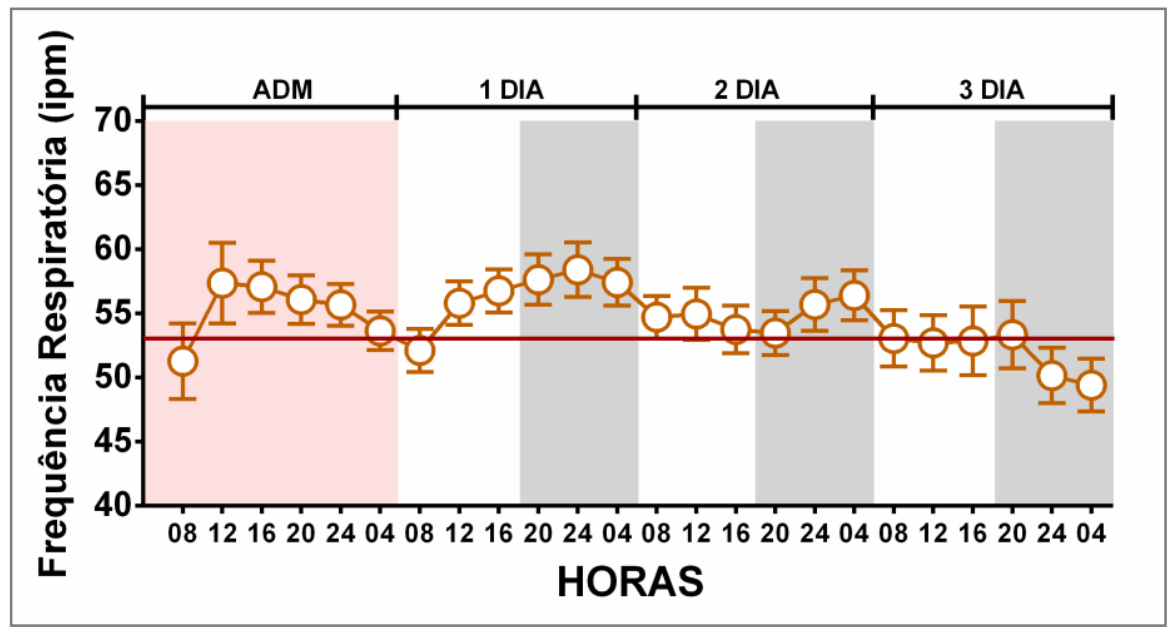

Tabela 11 - Frequência respiratória da admissão ao terceiro dia de internação na UTIN. São Paulo, 2020.

\begin{tabular}{lllccccc}
\hline Variável & Dia & N* & Média & DP & Mín & Mediana & Máx \\
\hline Frequência & Admissão & 345 & 55,37 & 15,04 & 22 & 54 & 114 \\
respiratória & Dia 1 & 395 & 56,05 & 14,81 & 22 & 54 & 104 \\
& Dia 2 & 279 & 54,75 & 12,72 & 29 & 54 & 100 \\
& Dia 3 & 206 & 51,97 & 13,51 & 27 & 52 & 96 \\
\hline
\end{tabular}

* Número corresponde à somatória de todos os registros encontrados nos prontuários de cada RN incluído no estudo, ao longo do período de estudo.

No período avaliado, em relação à saturação de oxigênio, registrou-se média de $96 \%$ $(\mathrm{DP}=5,11)$ no dia da admissão; no primeiro dia, média de 96\% ( $\mathrm{DP}=2,4) ; 96 \%(\mathrm{DP}=2,74)$ no segundo dia e $96 \%(\mathrm{DP}=3,14)$ no terceiro dia (Figura 11; Tabela 12). 
Figura 11 - Média da SpO2 da admissão ao terceiro dia de internação na UTIN. Valores de referência mínimo (linha azul) e máximo (linha vermelha). São Paulo, 2020.

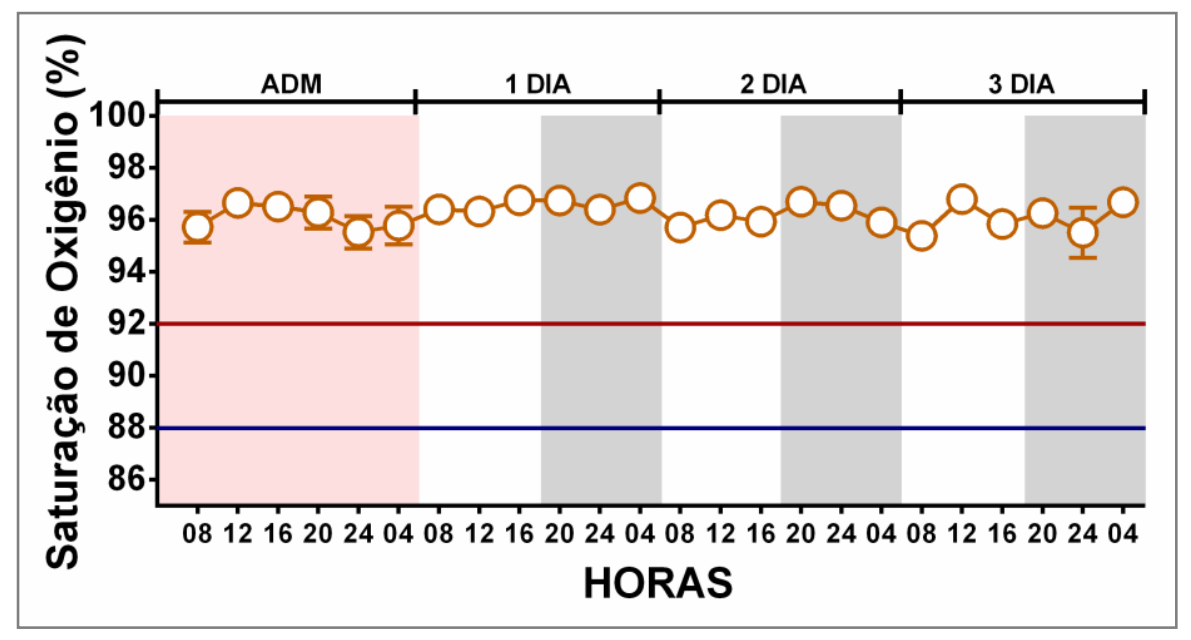

Tabela 12 - Saturação de oxigênio da admissão ao terceiro dia de internação na UTIN. São Paulo, 2020.

\begin{tabular}{lllccccc}
\hline Variável & Dia & N* $^{*}$ & Média & DP & Mín & Mediana & Máx \\
\hline \multirow{2}{*}{ Saturação } & Admissão & 341 & 96 & 5,11 & 46 & 97 & 100 \\
& Dia 1 & 391 & 96,55 & 2,40 & 85 & 97 & 100 \\
& Dia 2 & 277 & 96,13 & 2,74 & 83 & 97 & 100 \\
& Dia 3 & 196 & 96,06 & 3,14 & 69 & 97 & 100 \\
\hline
\end{tabular}

* Número corresponde à somatória de todos os registros encontrados nos prontuários de cada RN incluído no estudo, ao longo do período de estudo.

No período avaliado, registrou-se média de $59 \mathrm{mmHg}(\mathrm{DP}=11,72)$ da PS no dia da admissão; no primeiro dia, média de $58 \mathrm{mmHg}(\mathrm{DP}=10,83)$; valor médio de $61 \mathrm{mmHg}$ $(\mathrm{DP}=11,95)$ no segundo dia e, média de $64 \mathrm{mmHg}(\mathrm{DP}=13,09)$ no terceiro dia (Tabela 13; Figura 12A).

Em relação à $\mathrm{PD}$, registrou-se na admissão valor médio de $33 \mathrm{mmHg}(\mathrm{DP}=9,31)$; no primeiro dia, média de 33mmHg ( $\mathrm{DP}=8,43)$; média de $36 \mathrm{mmHg}(\mathrm{DP}=9,94)$ no segundo dia e, finalmente, média de $38 \mathrm{mmHg}(\mathrm{DP}=11,46)$ no terceiro dia (Tabela 13; Figura 12B).

No que diz respeito à pressão arterial média (PM), no período avaliado, registrou-se na admissão média de 43mmHg ( $\mathrm{DP}=8,71)$; no primeiro dia, média de $44 \mathrm{mmHg}(\mathrm{DP}=9,22)$; média de 46mmHg ( $\mathrm{DP}=10,63)$ no segundo dia e, média de 49mmHg $(\mathrm{DP}=11,68)$ no terceiro dia (Tabela 13; Figura 12C). 
Figura 12 - (A) Média da pressão sistólica; (B) Média da pressão diastólica; (C) Média da Pressão Média. Valores de referência mínimo (linha azul) e máximo (linha vermelha). São Paulo, 2020.

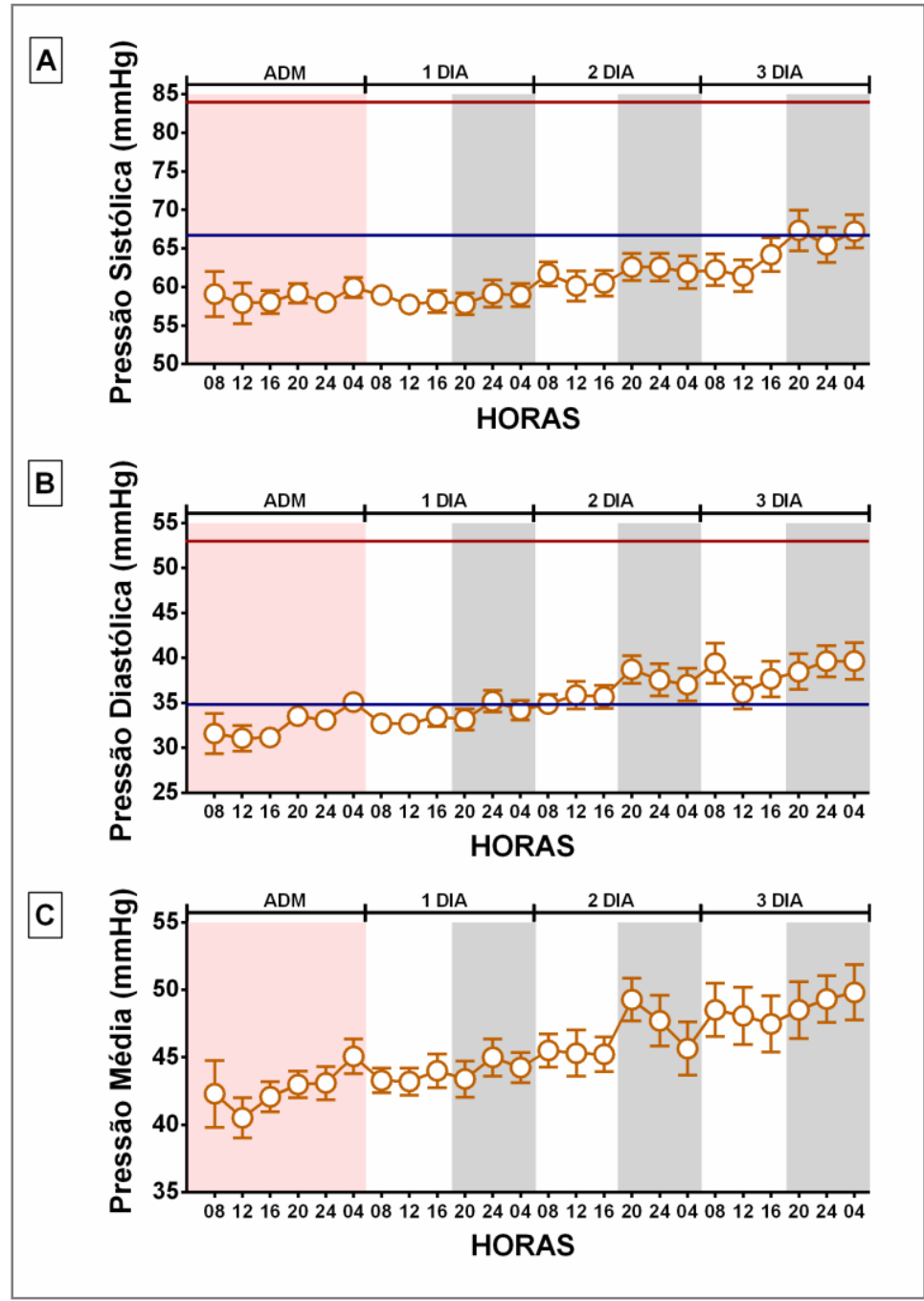

Tabela 13 - Pressão sistólica, diastólica e média. São Paulo, 2020

\begin{tabular}{lllccccc}
\hline Variável & Dia & N* & Média & DP & Mín & Mediana & Máx \\
\hline Pressão & Admissão & 341 & 58,76 & 11,72 & 23 & 58 & 114 \\
sistólica & Dia 1 & 387 & 58,44 & 10,83 & 27 & 58 & 91 \\
& Dia 2 & 269 & 61,51 & 11,95 & 24 & 61 & 104 \\
& Dia 3 & 206 & 64,53 & 13,09 & 34 & 64,5 & 105 \\
\hline \multirow{2}{*}{ Pressão } & Admissão & 340 & 33,24 & 9,31 & 12 & 32 & 98 \\
diastólica & Dia 1 & 387 & 33,45 & 8,43 & 8 & 33 & 65 \\
& Dia 2 & 270 & 36,49 & 9,94 & 10 & 35,5 & 72 \\
& Dia 3 & 206 & 38,46 & 11,46 & 12 & 37,5 & 76 \\
\hline \multirow{2}{*}{ Pressão } & Admissão & 334 & 42,63 & 8,71 & 17 & 42 & 70 \\
média & Dia 1 & 387 & 43,78 & 9,22 & 15 & 44 & 74 \\
& Dia 2 & 269 & 46,36 & 10,63 & 10 & 46 & 77 \\
& Dia 3 & 205 & 48,61 & 11,68 & 20 & 48 & 80 \\
\hline
\end{tabular}

* Número corresponde à somatória de todos os registros encontrados nos prontuários de cada RN incluído no estudo, ao longo do período de estudo. 
Foram avaliadas potenciais correlações entre o número de procedimentos estressantes e potencialmente dolorosos e as seguintes variáveis: idade gestacional, Apgar, tempo de internação (em horas), peso de nascimento, estratégias não farmacológicas e farmacológicas, NIPS, temperatura, frequência cardíaca, frequência respiratória, saturação, pressão sistólica, pressão diastólica e pressão média, utilizando-se o teste Correlação de Spearman. Constatouse correlação positiva $(\mathrm{r}=0,339 ; \mathrm{p}<0,001)$ somente entre o número de procedimentos e o emprego de medidas farmacológicas (Tabela 14; Figura 13).

Tabela 14 - Correlação de Spearman do número de procedimentos potencialmente dolorosos. São Paulo, 2020.

\begin{tabular}{|c|c|c|c|c|c|c|}
\hline $\mathbf{X}$ & $\mathbf{Y}$ & $\mathbf{N}$ & cor & 95\% CI.lo & 95\% CI.hi & p-value \\
\hline \multirow{16}{*}{$\begin{array}{l}\text { Procedimentos } \\
\text { potencialmente } \\
\text { dolorosos }\end{array}$} & $\mathrm{IG}$ & 1243 & $-0,086$ & $-0,141$ & $-0,031$ & 0,002 \\
\hline & APGAR 1min & 1334 & $-0,165$ & $-0,217$ & $-0,113$ & $<0.001$ \\
\hline & APGAR 5min & 1334 & $-0,145$ & $-0,197$ & $-0,092$ & $<0.001$ \\
\hline & APGAR 10min & 1334 & $-0,078$ & $-0,132$ & $-0,025$ & 0,004 \\
\hline & Tempo.internação & 1334 & 0,177 & 0,125 & 0,229 & $<0.001$ \\
\hline & Peso & 1332 & $-0,074$ & $-0,127$ & $-0,020$ & 0,007 \\
\hline & Temperatura & 1229 & $-0,151$ & $-0,205$ & $-0,096$ & $<0.001$ \\
\hline & $\mathrm{FC}$ & 1228 & 0,083 & 0,027 & 0,138 & 0,004 \\
\hline & FR & 1225 & $-0,027$ & $-0,083$ & 0,029 & 0,342 \\
\hline & Saturação & 1204 & $-0,095$ & $-0,151$ & $-0,039$ & $<0.001$ \\
\hline & PAS & 1202 & $-0,174$ & $-0,229$ & $-0,119$ & $<0.001$ \\
\hline & PAD & 1202 & $-0,089$ & $-0,145$ & $-0,033$ & 0,002 \\
\hline & PAM & 1197 & $-0,132$ & $-0,187$ & $-0,076$ & $<0.001$ \\
\hline & NIPS & 1232 & 0,118 & 0,062 & 0,172 & $<0.001$ \\
\hline & Estrat.não.farmac & 1334 & 0,114 & 0,061 & 0,167 & $<0.001$ \\
\hline & Estrat.farmac & 1334 & 0,339 & 0,291 & 0,386 & $<0.001$ \\
\hline
\end{tabular}


Figura 13 - Correlação de Spearman do número de procedimentos potencialmente dolorosos. São Paulo, 2020.

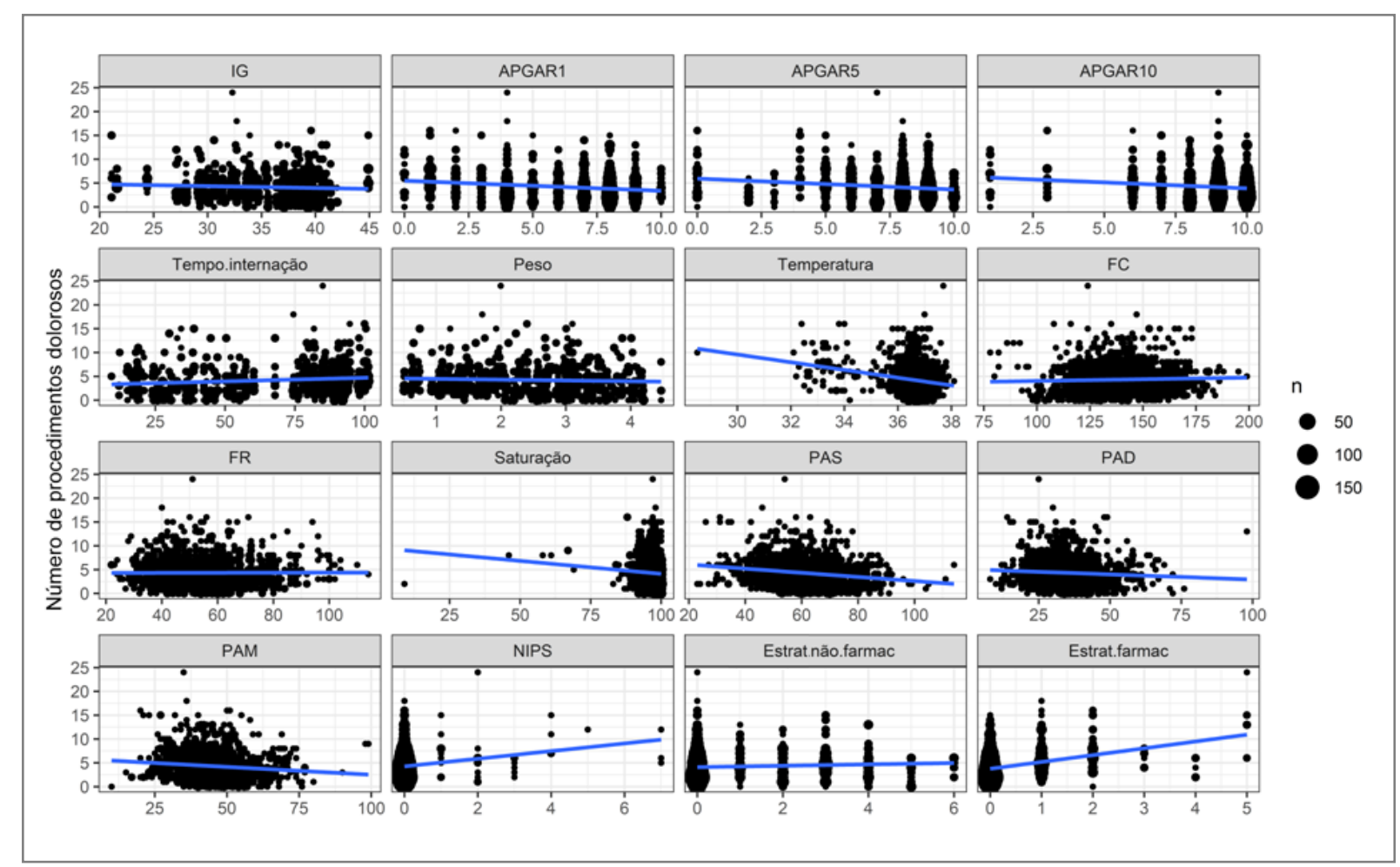

Desta forma, realizou-se a dosagem de 11 mediadores inflamatórios (IFNg, IL1b, IL2, IL4, IL6, IL8, IL10, IL12, IL17, TNF e VEGF) nas amostras de saliva de cinco RN, no primeiro e no segundo dia de internação na UTIN em cinco horários. Os dados da Tabela 15 mostram a estatística descritiva dessas dosagens (Tabela 15; Figura 14A-L). Não se observou diferença estatisticamente significativa entre os horários das citocinas avaliadas.

Observa-se, ainda, comportamento semelhante das diferentes citocinas ao longo dos horários, com decréscimo entre $8 \mathrm{~h}$ e $16 \mathrm{~h}$ do primeiro dia, seguido de um aumento entre às $16 \mathrm{~h}$ do primeiro dia e às 8 horas do segundo dia (Figura 14B-L). Passado este momento, observase três situações distintas entre 8 e $16 \mathrm{~h}$ do segundo dia: manutenção do volume das citocinas (IFNg, IL1b e IL2 - Figura 14B-D); aumento do volume de citocinas (IL4, IL10, IL17 e TNF - Figura 14E, H, J e K); redução do volume das citocinas (IL6, IL8, IL12 e VEGF - Figura 14F, G, I e L). 
Tabela 15 - Mediadores inflamatórios avaliados nas amostras de saliva no primeiro e segundo dias. São Paulo, 2020.

(Continua)

\begin{tabular}{|c|c|c|c|c|c|c|c|c|}
\hline Citocina & Dia & Horário & $\mathbf{N}$ & Média & DP & Mín & Mediana & Máx \\
\hline \multirow[t]{5}{*}{ IFNg } & \multirow[t]{3}{*}{ Dia 1} & $8 \mathrm{~h}$ & 5 & 30,16 & 9,592 & 15,99 & 29,88 & 40,1 \\
\hline & & $16 \mathrm{~h}$ & 5 & 22,65 & 20,81 & 1,792 & 22,26 & 44,27 \\
\hline & & $24 \mathrm{~h}$ & 5 & 24,66 & 22,19 & 3,501 & 22,71 & 47,76 \\
\hline & \multirow[t]{2}{*}{ Dia 2} & $8 \mathrm{~h}$ & 5 & 53,64 & 7,998 & 44,77 & 55,86 & 60,3 \\
\hline & & $16 \mathrm{~h}$ & 5 & 48,9 & 45,06 & 9,719 & 38,85 & 98,14 \\
\hline \multirow[t]{5}{*}{ IL1b } & \multirow[t]{3}{*}{ Dia 1} & $8 \mathrm{~h}$ & 5 & 24,08 & 21,77 & 6,516 & 19,01 & 51,79 \\
\hline & & $16 \mathrm{~h}$ & 5 & 15,94 & 14,28 & 7,238 & 8,163 & 32,41 \\
\hline & & $24 \mathrm{~h}$ & 5 & 27,61 & 14,05 & 11,83 & 32,26 & 38,75 \\
\hline & \multirow[t]{2}{*}{ Dia 2} & $8 \mathrm{~h}$ & 5 & 50,57 & 35,62 & 9,811 & 66,17 & 75,72 \\
\hline & & $16 \mathrm{~h}$ & 5 & 53,6 & 44,08 & 2,764 & 76,83 & 81,21 \\
\hline \multirow[t]{5}{*}{ IL2 } & \multirow[t]{3}{*}{ Dia 1} & $8 \mathrm{~h}$ & 5 & 30,58 & 26,18 & 1,984 & 40,33 & 54,65 \\
\hline & & $16 \mathrm{~h}$ & 5 & 28,42 & 27,22 & 3,058 & 27,99 & 54,65 \\
\hline & & $24 \mathrm{~h}$ & 5 & 20,6 & 25,8 & 4,559 & 6,87 & 50,36 \\
\hline & \multirow[t]{2}{*}{ Dia 2} & $8 \mathrm{~h}$ & 5 & 64,87 & 54,02 & 4,102 & 83,04 & 107,5 \\
\hline & & $16 \mathrm{~h}$ & 5 & 67,03 & 56,98 & 1,236 & 99,51 & 100,3 \\
\hline \multirow[t]{5}{*}{ IL4 } & \multirow[t]{3}{*}{ Dia 1} & $8 \mathrm{~h}$ & 5 & 113,2 & 71,9 & 38,96 & 76,16 & 212,8 \\
\hline & & $16 \mathrm{~h}$ & 5 & 53,04 & 48,58 & 3,2 & 49,77 & 109,4 \\
\hline & & $24 \mathrm{~h}$ & 5 & 45,58 & 41,5 & 3,2 & 47,41 & 86,14 \\
\hline & \multirow[t]{2}{*}{ Dia 2} & $8 \mathrm{~h}$ & 5 & 147,9 & 86,83 & 51,66 & 171,8 & 220,3 \\
\hline & & $16 \mathrm{~h}$ & 5 & 185,2 & 196,5 & 36,87 & 110,6 & 408,1 \\
\hline \multirow[t]{5}{*}{ IL6 } & \multirow[t]{3}{*}{ Dia 1} & $8 \mathrm{~h}$ & 5 & 12,57 & 16,23 & 3,2 & 3,2 & 31,31 \\
\hline & & $16 \mathrm{~h}$ & 5 & 2,38 & 1,42 & 0,741 & 3,2 & 3,2 \\
\hline & & $24 \mathrm{~h}$ & 5 & 3,2 & 0 & 3,2 & 3,2 & 3,2 \\
\hline & \multirow[t]{2}{*}{ Dia 2} & $8 \mathrm{~h}$ & 5 & 51,62 & 44,16 & 3,2 & 61,98 & 89,69 \\
\hline & & $16 \mathrm{~h}$ & 5 & 32,77 & 51,69 & 2,663 & 3,2 & 92,45 \\
\hline \multirow[t]{5}{*}{ IL8 } & \multirow[t]{3}{*}{ Dia 1} & $8 \mathrm{~h}$ & 5 & 164,1 & 84,53 & 67,81 & 198,6 & 226 \\
\hline & & $16 \mathrm{~h}$ & 5 & 13,47 & 9,736 & 3,2 & 14,65 & 22,57 \\
\hline & & $24 \mathrm{~h}$ & 5 & 263,8 & 402 & 9,485 & 54,63 & 727,2 \\
\hline & \multirow[t]{2}{*}{ Dia 2} & $8 \mathrm{~h}$ & 5 & 463,4 & 424,3 & 82,11 & 387,6 & 920,5 \\
\hline & & $16 \mathrm{~h}$ & 5 & 278 & 231 & 58,75 & 256 & 519,2 \\
\hline \multirow[t]{5}{*}{ IL10 } & \multirow[t]{3}{*}{ Dia 1} & $8 \mathrm{~h}$ & 5 & 64,2 & 76,75 & 6,314 & 34,16 & 190 \\
\hline & & $16 \mathrm{~h}$ & 5 & 6,731 & 6,115 & 3,2 & 3,2 & 13,79 \\
\hline & & $24 \mathrm{~h}$ & 5 & 23,13 & 26,16 & 3,2 & 13,42 & 52,76 \\
\hline & \multirow[t]{2}{*}{ Dia 2} & $8 \mathrm{~h}$ & 5 & 79,99 & 59,57 & 11,23 & 112,9 & 115,8 \\
\hline & & $16 \mathrm{~h}$ & 5 & 103,5 & 102,7 & 0,449 & 104,2 & 205,8 \\
\hline \multirow[t]{5}{*}{ IL12 } & \multirow[t]{3}{*}{ Dia 1} & $8 \mathrm{~h}$ & 5 & 45,13 & 20,79 & 21,47 & 47,89 & 72,09 \\
\hline & & $16 \mathrm{~h}$ & 5 & 22,97 & 34,24 & 3,2 & 3,2 & 62,51 \\
\hline & & $24 \mathrm{~h}$ & 5 & 44,98 & 63,89 & 3,2 & 13,2 & 118,5 \\
\hline & \multirow[t]{2}{*}{ Dia 2} & $8 \mathrm{~h}$ & 5 & 74,94 & 12,96 & 62,79 & 73,45 & 88,58 \\
\hline & & $16 \mathrm{~h}$ & 5 & 65,21 & 29,66 & 46,65 & 49,57 & 99,41 \\
\hline
\end{tabular}


Tabela 15 - Mediadores inflamatórios avaliados nas amostras de saliva no primeiro e segundo dias. São Paulo, 2020.

(Continuação)

\begin{tabular}{llllccccc}
\hline Citocina Dia & Horário & N & Média & DP & Mín & Mediana & Máx \\
\hline IL17 & Dia 1 & $8 \mathrm{~h}$ & 5 & 13,04 & 3,425 & 9,959 & 11,03 & 17,22 \\
& & $16 \mathrm{~h}$ & 5 & 9,662 & 8,311 & 1,281 & 8,655 & 20,06 \\
& & $24 \mathrm{~h}$ & 5 & 12,14 & 8,118 & 2,96 & 15,09 & 18,37 \\
& \multirow{2}{*}{ Dia 2 } & $8 \mathrm{~h}$ & 5 & 23,48 & 7,837 & 14,48 & 27,15 & 28,8 \\
& & $16 \mathrm{~h}$ & 5 & 25,03 & 16,05 & 7,929 & 27,38 & 39,76 \\
TNF & Dia 1 & $8 \mathrm{~h}$ & 5 & 43,94 & 36,77 & 12 & 42,77 & 78,19 \\
& & $16 \mathrm{~h}$ & 5 & 15,51 & 14,59 & 1,348 & 14,67 & 30,5 \\
& & $24 \mathrm{~h}$ & 5 & 26,09 & 21,82 & 8,328 & 19,49 & 50,44 \\
& \multirow{2}{*}{ Dia 2 } & $8 \mathrm{~h}$ & 5 & 89,89 & 61,64 & 18,95 & 120,3 & 130,4 \\
& & $16 \mathrm{~h}$ & 5 & 109,6 & 91 & 4,537 & 159 & 165,1 \\
VEGF & Dia 1 & $8 \mathrm{~h}$ & 5 & 253 & 97,12 & 156,3 & 245,5 & 364,6 \\
& & $16 \mathrm{~h}$ & 5 & 380,8 & 448,9 & 3,2 & 246,1 & 1028 \\
& & $24 \mathrm{~h}$ & 5 & 407,2 & 211,2 & 202,8 & 394 & 624,7 \\
& Dia 2 & $8 \mathrm{~h}$ & 5 & 691,2 & 455,6 & 179,5 & 841 & 1053 \\
& & $16 \mathrm{~h}$ & 5 & 590,9 & 465,6 & 100,1 & 646 & 1026 \\
\hline
\end{tabular}

Figura 14 - Mediadores inflamatórios avaliados nas amostras de saliva no primeiro e segundo dias. São Paulo, 2020.

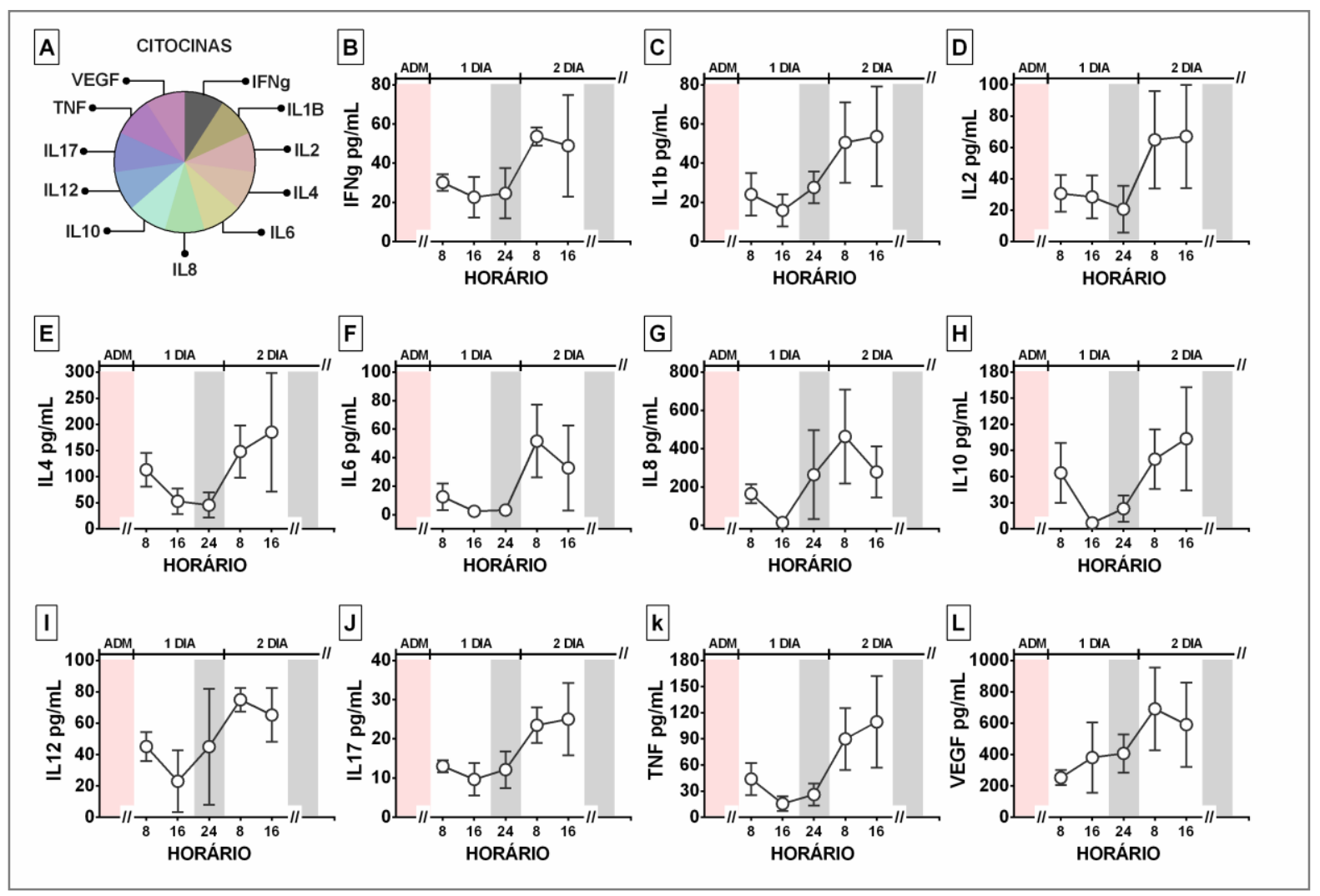


Foram analisadas as correlações entre as citocinas e as demais variáveis (idade gestacional, Apgar, tempo de internação, peso de nascimento, temperatura, frequência cardíaca, frequência respiratória, saturação, pressão sistólica, pressão diastólica, pressão média, NIPS, número de procedimentos, estratégias não farmacológicas e farmacológicas) utilizando o teste de Correlação de Spearman. Observou-se a correlação negativa do IFNg com a saturação de oxigênio $(r=-0,44 ; p<0,05)$ e correlação positiva com o número de mediadas não farmacológicas $(r=-0,44 ; p<0,05)$ (Figura 15A-D). Observou-se correlação negativa da IL1b com a temperatura axilar $(r=-0,71 ; p<0,05)$ e a frequência respiratória $(r=-$ $0,52 ; \mathrm{p}<0,05)$ e, correlação positiva com a pressão diastólica $(\mathrm{r}=0,69 ; \mathrm{p}<0,05)$, pressão média $(\mathrm{r}=0,55 ; \mathrm{p}<0,05)$ e número de procedimentos $(\mathrm{r}=0,52 ; \mathrm{p}<0,05)$ (Figura 15A, B, E-I). Também foi possível observar-se correlações negativas da IL2 com a temperatura axilar ( $\mathrm{r}=$ $0,67 ; \mathrm{p}<0,05)$, e com a frequência respiratória $(\mathrm{r}=-0,58 ; \mathrm{p}<0,05)$ e, correlação positiva com a pressão diastólica $(\mathrm{r}=0,66 ; \mathrm{p}<0,05)$, pressão média $(\mathrm{r}=0,58 ; \mathrm{p}<0,05)$ e número de procedimentos $(r=0,4 ; p<0,05)$ (Figura 15A, B, J-N). Aponta-se, ainda, a correlação negativa da IL4 com a frequência respiratória $(r=-0,65 ; p<0,05)$ e a saturação de oxigênio $(r$ $=-0,44 ; \mathrm{p}<0,05)$ (Figura 15A, B, O e P). 
Figura 15 - (A) Mediadores inflamatórios dosados; (B) Número de parâmetros correlacionados às citocinas; (C) Correlação IFNg e Saturação de Oxigênio; (D) Correlação IFNg e Número de Medidas não Farmacológicas; (E) Correlação IL1b e Temperatura Axilar; (F) Correlação IL1b e Frequência Respiratória; (G) Correlação IL1b e Pressão Diastólica; (H) Correlação IL1b e Pressão Média; (I) Correlação IL1b e Número de Procedimentos; (J) Correlação IL2 e Temperatura Axilar; (K) Correlação IL2 e Frequência Respiratória; (L) Correlação IL2 e Pressão Diastólica; (M) Correlação IL2 e Pressão Média; (N) Correlação IL2 e Número de Procedimentos; (O) Correlação IL4 e Frequência Respiratória; (P) Correlação IL4 e Saturação de Oxigênio.São Paulo, 2020.

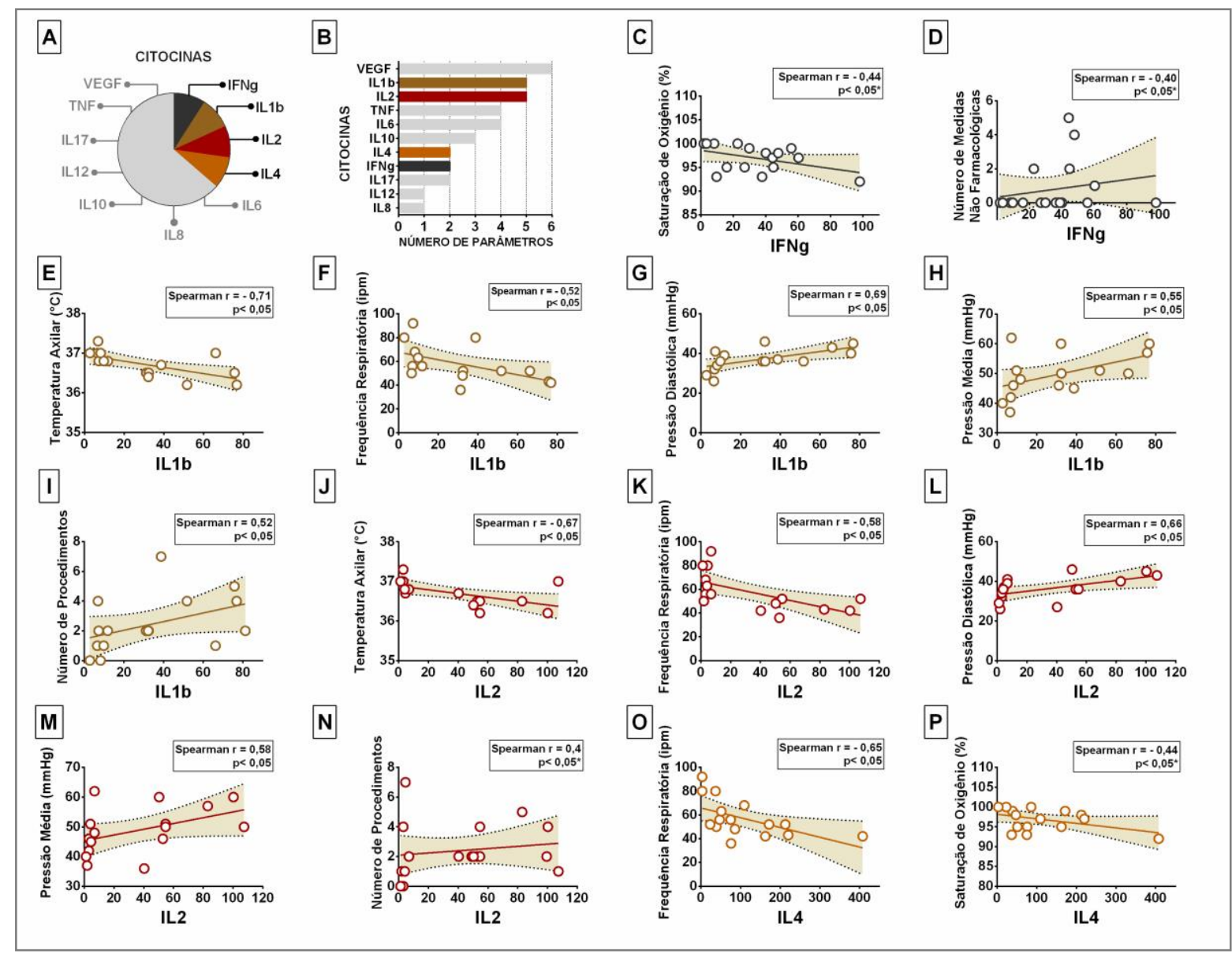

Em relação à IL6, observou-se correlação negativa com a temperatura axilar ( $\mathrm{r}=$ 0,58; $\mathrm{p}<0,05)$, frequência respiratória $(\mathrm{r}=-0,37 ; \mathrm{p}<0,05)$ e número de medidas não farmacológicas $(r=-0,37 ; p<0,05)$ e, correlação positiva com o número de procedimentos $(r=$ 0,64; $\mathrm{p}<0,05$ ) (Figura 16A-F). Além disso, observa-se a correlação negativa da IL8 com o número de medidas não farmacológicas ( $\mathrm{r}=-0,28$; $\mathrm{p}<0,05)$ (Figura 16A,B e G). Verificaramse também a correlação negativa da IL10 com temperatura axilar $(r=-0,45 ; p<0,05)$ e frequência respiratória $(r=-0,73 ; p<0,05)$ e, correlação positiva com número de medidas farmacológicas ( $\mathrm{r}=0,36 ; \mathrm{p}<0,05)$ (Figura 16A, B, H-J). A IL12 apresentou correlação negativa com saturação de oxigênio $(r=-0,61$; $\mathrm{p}<0,05)$ (Figura 16A, B e K). Por fim, evidenciou-se correlação negativa da IL17 com frequência respiratória $(r=-0,58$; $p<0,05)$ e correlação positiva com pressão diastólica $(r=0,47$; p<0,05) (Figura 16A, B, L e M). 
Figura 16 - (A) Mediadores inflamatórios dosados; (B) Número de parâmetros correlacionados às citocinas; (C) Correlação IL6 e Temperatura Axilar; (D) Correlação IL6 e Frequência Respiratória; (E) Correlação IL6 e Número de Procedimentos; (F) Correlação IL6 e Número de Medidas não Farmacológicas; (G) Correlação IL8 e Número de Medidas não Farmacológicas; (H) Correlação IL10 e Temperatura Axilar; (I) Correlação IL10 e Frequência Respiratória; (J) Correlação IL10 e Número de Medidas Farmacológicas; (K) Correlação IL12 e Saturação de Oxigênio; (L) Correlação IL17 Frequência Respiratória; (M) Correlação IL17 e Pressão Diastólica. São Paulo, 2020.

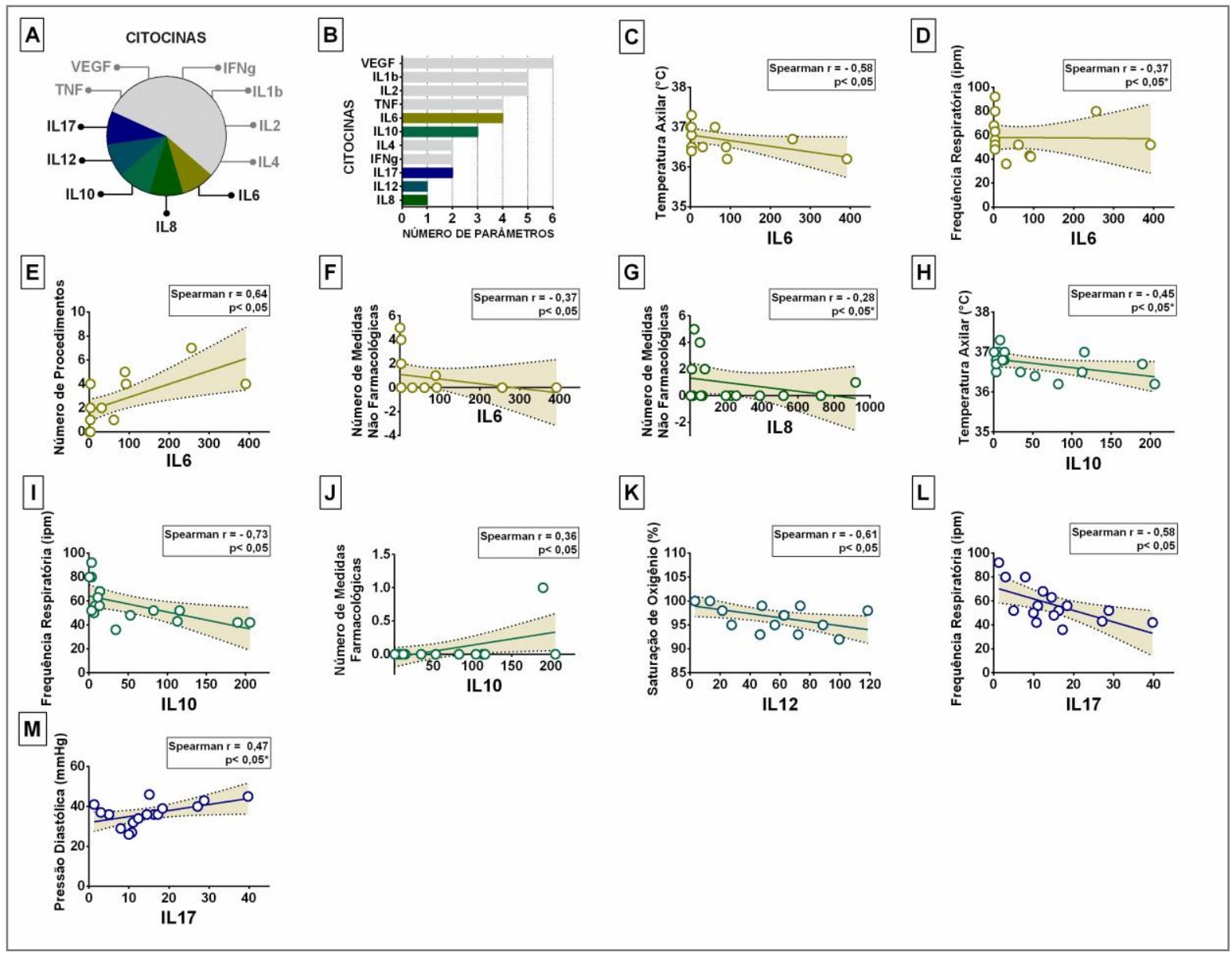

Além disso, observou-se a correlação negativa do TNF com temperatura axilar $(\mathrm{r}=$ 0,59; $\mathrm{p}<0,05)$ e frequência respiratória $(\mathrm{r}=-0,8 ; \mathrm{p}<0,05)$; por outro lado, observou-se, correlação positiva entre o TNF e pressão diastólica $(r=0,5 ; \mathrm{p}<0,05)$ e pressão média $(\mathrm{r}=$ 0,45; $\mathrm{p}<0,05)$ (Figura 17A-F). Finalmente, evidenciou-se a correlação negativa do VEGF com temperatura axilar $(r=-0,51 ; p<0,05)$, frequência respiratória $(r=-051 ; p<0,05)$ e número de medidas não farmacológicas $(r=-0,25 ; \mathrm{p}<0,05)$ e, correlação positiva com pressão diastólica $(\mathrm{r}=0,84 ; \mathrm{p}<0,05)$, pressão média $(\mathrm{r}=0,44 ; \mathrm{p}<0,05)$ e número de procedimentos $(\mathrm{r}=0,44$; $\mathrm{p}<0,05)$ e (Figura 17A, B, G-L). 
Figura 17 - (A) Mediadores inflamatórios dosados; (B) Número de parâmetros correlacionados às citocinas; (C) Correlação TNF e Temperatura Axilar; (D) Correlação TNF e Frequência Respiratória; (E) Correlação TNF e Pressão Diastólica; (F) Correlação TNF e Pressão Média; (G) Correlação VEGF e Temperatura Axilar; (H) Correlação VEGF e Frequência Respiratória; (I) Correlação VEGF e Pressão Diastólica; (J) Correlação VEGF e Pressão Média; (K) Correlação VEGF e Número de Procedimentos; (L) Correlação VEGF e Número de Medidas não Farmacológicas. São Paulo, 2020.

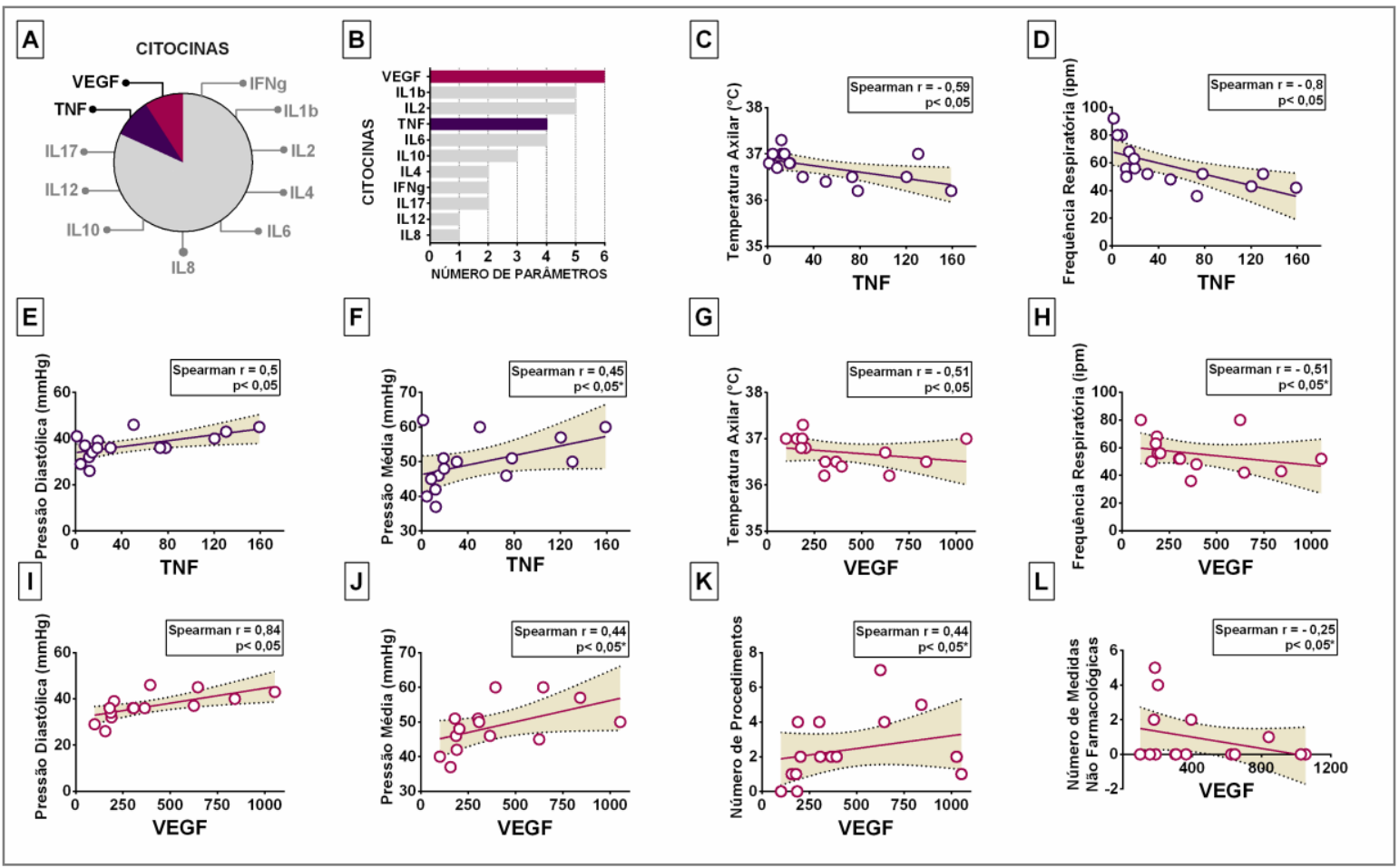




\section{DISCUSSÃO}

A partir da análise dos resultados deste estudo, foi possível caracterizar a população de RN admitidos na UTIN, identificar o número e o tipo de procedimentos potencialmente dolorosos, realizados nos primeiros três dias de hospitalização, identificar os dispositivos terapêuticos mantidos, assim como as estratégias farmacológicas e não farmacológicas empregadas. Também foram verificados os registros de escores de dor mensurados pela escala NIPS, registros de frequência cardíaca, pressão arterial, frequência respiratória, saturação periférica de oxigênio e temperatura axilar. Foram, ainda, identificados os níveis salivares de 11 mediadores inflamatórios. Finalmente, correlações entre as diferentes variáveis do estudo foram analisadas.

Em relação à caracterização dos $\mathrm{RN}$ incluídos neste estudo, constatou-se que a cesárea foi a principal via de parto $(53,33 \%)$. Esta porcentagem é superior àquela considerada ideal pela Organização Mundial da Saúde (OMS), que recomenda uma porcentagem entre 10-15\% de nascimentos por parto cesárea, visto que este procedimento pode causar complicações significativas e, às vezes, permanentes, tanto para mães quanto para os RN (Betran et al., 2015; Boerma et al., 2018). Salienta-se que, no ano de 2016, no Brasil, por exemplo, a taxa de cesárea foi de $56 \%$, dado que o inclui no grupo de países com as mais elevadas taxas de cesariana no mundo; ressalta-se que os partos cesárea, realizados nos serviços privados de saúde, representam cerca de $83 \%$ dos nascimentos e cerca de $41 \%$ no sistema público de saúde (Ministério da Saúde, 2018; Occhi et al., 2018).

A maioria dos RN incluídos era do sexo masculino, o que corrobora resultados de diversos estudos que descrevem maior prevalência de internação de $\mathrm{RN}$ do sexo masculino na UTIN (Lages et al., 2014; Oliveira et al., 2015). Observou-se a mesma proporção de RN prétermo $(48,88 \%)$ e de termo $(48,88 \%)$. O nascimento de prematuros representa um grande desafio para os serviços de saúde, por tratar-se de um determinante de morbimortalidade neonatal; além disso, a prematuridade representa a principal causa de mortalidade neonatal no Brasil e no mundo (França et al., 2017). Ressalta-se, contudo, que a mortalidade neonatal está relacionada a variáveis diversas, e a sobrevivência dos RN internados em UTIN não depende apenas do peso ao nascer e da idade gestacional, mas também de outros fatores perinatais e parâmetros fisiológicos, particularmente aqueles relacionados com a gravidade de suas patologias (Lima et al., 2015). 
Pontua-se, em relação ao Escore de Apgar, que a média do escore dos $\mathrm{RN}$ no $5^{\circ}$ minuto foi de 7,51, considerada adequada pela maioria dos autores (Platt, 2014; Schardosim, et al., 2018).

Em relação ao peso corporal, verificou-se variação da admissão ao terceiro dia de internação na UTIN, ocorrência característica nos primeiros dias de vida, denominada perda fisiológica de peso (Flaherman et al., 2015; Miller, 2015). Sugere-se que esta perda corresponda, principalmente, à redução de fluidos, mas também em consequência do uso de tecido adiposo como fonte de energia (Flaherman et al., 2015; Miller, 2015).

Destaca-se que o principal diagnóstico para a internação na UTIN foi o desconforto respiratório precoce $(60,0 \%)$. Estudos evidenciam as afecções respiratórias como as principais patologias preditoras para internação em UTIN (Lages et al., 2014; Lima et al., 2015; Parkash et al., 2015; Costa et al., 2017). De modo geral, dentre 5 e $29 \%$ dos neonatos são hospitalizados em UTIN devido a problemas respiratórios (Sabzehei et al., 2017). No estudo de Costa et al., (2017), as condições respiratórias representaram 46,1\% dos diagnósticos. Verificou-se, em outro estudo desenvolvido no Brasil, que 74,8\% dos RN foram admitidos na UTIN devido às afecções respiratórias (Lima et al., 2015). Em outra pesquisa realizada em uma maternidade pública no estado do Piauí, os problemas respiratórios $(57,2 \%)$ foram o principal motivo de admissão na UTIN (Lages et al., 2014).

No presente estudo, os RN permaneceram, em média, 55 horas na UTIN. Em alguns casos, os RN permaneceram por curtos períodos de tempo em terapia intensiva, para monitoramento. Trata-se de característica comum à população atendida na unidade de campo de estudo, visto que se trata de instituição de saúde de nível secundário que acompanha gestantes e RN de baixo e médio risco. Por outro lado, há RN que permanecem hospitalizados em UTIN por longos períodos, como é o caso dos RN pré-termo extremos, que eventualmente são atendidos no serviço. No estudo de Lee et al., (2016), por exemplo, o tempo médio de permanência em terapia intensiva foi de 79 dias quando o peso ao nascer foi inferior a $1.000 \mathrm{~g}$, 46 dias para RN com peso entre 1.000 a $1.500 \mathrm{~g}$ ao nascimento, média de 21 dias para peso de nascimento de 1.500 a $2.500 \mathrm{~g}$ e 8 dias de hospitalização, em média, para $\geq 2.500 \mathrm{~g}$. Contudo, não há indicadores para prever o tempo de permanência na UTIN devido à heterogeneidade da idade gestacional e da condição clínica; mas, de modo geral, quanto maior a idade gestacional menor é o tempo de permanência na UTIN (Seaton et al., 2019). Ressalta-se ainda, que o tempo de hospitalização na UTIN é um dos fatores cruciais no desenvolvimento do $\mathrm{RN}$ prematuro, particularmente porque isso ocorre durante um período crítico do neurodesenvolvimento (Kugelman e Colin, 2013; Spittle e Treyvaud, 2016). 
O ambiente da UTIN é, em geral, estressante para os RN, por isso torna-se importante a discussão acerca do período de hospitalização. O espaço é repleto de luzes intensas e constantes, sons e interrupção do ciclo de sono/vigília, devido às repetidas avaliações e aos procedimentos necessários, em maior ou menor frequência, a depender da gravidade do RN. Todos estes estímulos poderão impactar, futuramente, em sua qualidade de vida e no desenvolvimento neuropsicomotor (Martins et al., 2011).

Durante a permanência na UTIN, por exemplo, diferentes dispositivos diagnósticos e terapêuticos são utilizados. No presente estudo, verificou-se a permanência, em média, de 2,79 dispositivos na admissão, 2,74 no primeiro dia, 2,67 no segundo dia e 2,48 dispositivos no terceiro dia, ao longo do período da coleta de dados e que, em média, 10,75 dispositivos distintos são utilizados, sendo os principais a sonda orogástrica, acesso venoso periférico e CPAP nasal. Resultado semelhante foi observado no estudo de Sposito et al., (2017), em que ao longo da primeira semana de internação de neonatos em terapia intensiva, foram registrados 16 dispositivos distintos e média de 3,25 dispositivos por dia, ao longo de, em média, nove dias de hospitalização.

Além disso, constatou-se que durante o período de permanência na UTIN, os RN incluídos neste estudo foram submetidos ao total de 2.732 procedimentos potencialmente dolorosos e estressantes, entre a admissão e o terceiro dia de internação. De acordo com Perry et al., (2018), os RN podem experenciar mais de 300 procedimentos dolorosos durante toda a hospitalização. Verificou-se no presente estudo, que os RN foram submetidos, em média, a um total de 30,36 procedimentos dolorosos e estressantes no período estudado. Observou-se também, uma variação do número de procedimentos da admissão ao terceiro dia de internação, com média de 12,78 procedimentos na admissão, 8,1 no primeiro dia, 5,36 no segundo dia e, por fim, 3,84 no terceiro dia.

Em revisão sistemática sobre dor procedural em RN internados em UTIN, identificouse que os RN são submetidos entre 7,5 e 17,3 procedimentos invasivos, em média, para cada dia de internação (Cruz, Fernandes e Oliveira, 2016). Outros estudos identificaram que os RN prematuros hospitalizados em UTIN foram submetidos diariamente a cerca de 14 procedimentos dolorosos (Johnston et al., 2011; Simons et al., 2003). Este valor aproxima-se do número encontrado no presente trabalho, considerando-se a média diária de procedimentos potencialmente dolorosos e estressantes durante todo o período estudado. Por outro lado, Carbajal et al., (2008) demonstrou que os $\mathrm{RN}$ foram expostos a aproximadamente 20 procedimentos invasivos por dia, valor superior ao descrito no presente estudo. Já Hatfield 
(2014) constatou que os RN vivenciam uma média de 10 procedimentos dolorosos por dia na UTIN.

Ainda em estudos realizados no Brasil, em unidades de cuidados intensivos e intermediário neonatal, também se observa variação da média diária de procedimentos invasivos realizados por RN. Sposito et al., (2017), por exemplo, observou média de 6,6 procedimentos invasivos por dia em RN hospitalizados. No estudo de Bonutti et al., (2017), a média diária foi de 5,37 procedimentos em $\mathrm{RN}$ prematuros, média próxima à relatada por Capellini et al., (2012), de 5,9 procedimentos por RN. A despeito da grande variação do número de procedimentos descritos, tanto na literatura nacional quanto internacional, os RN são expostos repetidamente a procedimentos dolorosos e estressantes. Essa variação resulta, principalmente, dos diferentes delineamentos metodológicos (por exemplo, alguns estudos analisaram a primeira semana de vida, outros estudos, todo período de hospitalização), da complexidade clínica dos RN avaliados, e do contexto da unidade em que os dados foram coletados.

Dentro desse contexto, procedimentos potencialmente dolorosos e, por conseguinte, causadores de dano tecidual, são frequentemente realizados para prevenir, diagnosticar e tratar condições clínicas. Estes procedimentos variam de punção de calcâneo a cirurgias de grande porte (Farmer et al., 2015; Mitul e Sarin, 2017). No presente estudo, os procedimentos mais frequentemente realizados foram a punção de calcâneo para glicemia capilar (21\%), aspiração de VAS e/ou COT (14\%), fisioterapia respiratória (10\%), punção venosa para terapia IV (7\%), remoção de dispositivos (7\%) e instalação de CPAP (6\%).

Esses resultados são semelhantes aos observados em outros trabalhos, em que os procedimentos invasivos frequentemente realizados na UTIN são a punção de calcâneo, aspiração nasal/oral, punção venosa e inserção de cateter venoso periférico (Simons et al., 2003; Carbajal et al., 2008; Courtois et al., 2016; Cruz, Fernandes e Oliveira, 2016; Cong et al. 2017). Enfatiza-se que a punção no calcanhar é usada para obter amostras de sangue, principalmente para a avaliação dos níveis glicêmicos e triagem de exames laboratoriais. Geralmente, para obter quantidades adequadas de sangue para o teste, o calcanhar deve ser ordenhado, o que torna o procedimento mais doloroso do que punções venosas (Shah e Ohlsson, 2011). De modo geral, todos os procedimentos frequentemente realizados podem ocasionar estresse e dor leve à intensa, experiências que são inerentes aos cuidados diários aos quais os RNs são submetidos na UTIN (Stevens et al., 2011; Cong et al. 2017).

Esses eventos potencialmente nocivos ocorrem durante um período crítico de neurodesenvolvimento, quando o sistema nervoso é muito vulnerável devido à imaturidade e 
neuroplasticidade (Williams e Lascelles, 2020). Estudos têm demonstrado que, o elevado número de procedimentos dolorosos aos quais os RN são expostos e a implementação insuficiente de medidas de prevenção e alívio da dor, resultam em eventos negativos no neurodesenvolvimento, sendo associados a substanciais prejuízos como redução da substância branca no sistema nervoso central, alteração da estrutura do trato corticoespinhal e aumento da reatividade à dor e ao estresse, podendo ainda contribuir para condições metabólicas crônicas, como diabetes e obesidade (Brummelte et al., 2012; Vinall et al., 2012; Zwicker et al., 2013; Walker, 2017; Coviello et al., 2018; Schneider et al., 2018). Entretanto, futuros estudos são nescessários para a melhor compreensão da relação ente a experiência dolorosa repetida e não tratada e alterações neurocomportamentais em curto e longo prazo (Cong et al. 2017).

Além disso, em trabalho desenvolvido por Chau et al., (2019), com 57 RN prematuros (<32 semanas de IG) acompanhados longitudinalmente desde o nascimento até a idade escolar (8 anos de idade), o objetivo foi determinar, por neuroimagem, se a exposição ao estresse relacionado à dor procedural na UTIN afetava o desenvolvimento do sistema límbico e do tálamo. Os resultados indicaram correlação inversa entre a frequência de procedimentos invasivos e os volumes de amígdala e tálamo, o que sugere que as experiências dolorosas podem afetar tanto o desenvolvimento estrutural quanto funcional. Tais resultados são semelhantes aos observados em estudos realizados em modelos animais, nos quais se observa um comprometimento no desenvolvimento cognitivo e cerebral, causados por estímulos dolorosos (Dührsen et al., 2013; Henderson et al., 2015). Adicionalmente, trabalhos desenvolvidos com modelos animais, simulando os cuidados na UTIN e procedimentos dolorosos, evidenciaram a presença de alterações no desenvolvimento cerebral e comprometimento da memória a longo prazo (Anand et al., 1999; Nuseir et al., 2017; Ranger et al. 2019).

Assim, as experiências dolorosas e estressantes cumulativas no início da vida, incluindo procedimentos dolorosos repetidos, durante janelas críticas do neurodesenvolvimento, são um dos principais problemas ainda não resolvidos da terapia intensiva. Durante o desenvolvimento, os RN apresentam alto grau de neuroplasticidade e são vulneráveis aos efeitos moduladores de estímulos nocivos, principalmente se forem de natureza repetitiva (Schwaller e Fitzgerald, 2014; Beggs, 2015). Em metanálise realizada por Mwaniki et al., (2012), resultados indicaram que 39,4\% dos sobreviventes da UTIN tinham pelo menos um déficit no desenvolvimento neurológico. Tais danos podem ter efeitos significativos e a longo prazo, que persistem na infância até a idade adulta (Grunau, Holsti e 
Peters, 2006; Walker et al., 2018). Logo, são necessários mais esforços para reduzir o número de procedimentos dolorosos, bem como melhorar o tratamento da dor, uma vez que, diferentemente dos fatores clínicos do neonato, os fatores organizacionais podem ser modificados para promover o manejo adequado da dor (Coviello et al., 2018).

Frente ao grande número de procedimentos potencialmente dolorosos, diferentes estratégias não farmacológicas e farmacológicas foram empregadas. Ao todo, 540 estratégias não farmacológicas foram registradas. sendo que cada RN recebeu seis medidas não farmacológicas, em média, durante o período de coleta dos dados. Em 21,1\% dos prontuários, nenhuma medida não farmacológica foi documentada entre a admissão ao terceiro dia de internação. Constata-se, ainda, variação do emprego de medidas não farmacológicas ao longo dos dias de coleta dos dados, com a adoção média de 1,98 a 0,97 estratégias não farmacológicas no dia da admissão e no terceiro dia, respectivamente.

Nesse sentido, ressalta-se que as estratégias não farmacológicas para alívio da dor são "sub-apreciadas, sub-utilizadas e sub-estudadas" (Ismail e Gandhi, 2011). Entende-se que as estratégias não farmacológicas reduzem consistentemente as respostas comportamentais aos procedimentos dolorosos agudos de intensidade leve a moderada. Tais intervenções são importantes no controle da dor e do estresse neonatal no ambiente hospitalar e podem ser usadas de modo isolado ou combinado (Perry et al., 2018). Logo, as intervenções não farmacológicas para reduzir a dor devem ser buscadas sempre que possível, devido à sua eficácia, baixo custo e segurança (Hsieh et al., 2018). Sempre que possível, estas intervenções devem ser empregadas em RN internados em terapia intensiva, a depender de sua condição clínica e dos procedimentos realizados.

Com isso, as terapias não farmacológicas, frequentemente estudadas para alívio da dor durante procedimentos invasivos em RN, incluem solução adocicada, sucção não nutritiva, leite materno, aleitamento materno, aninhamento, contenção facilitada, canguru e massoterapia (Shah et al., 2012; Stevens et al, 2016; Benoit et al., 2017; Johnston et al., 2017; Bucsea e Pillai-Riddel, 2019). Além desses métodos, alguns estudos demonstraram que a música é eficaz como medida não farmacológica no alívio da dor (Bergomi et al., 2014; Moran et al., 2015).

Portanto, as estratégias não farmacológicas mais frequentemente empregadas neste estudo foram redução de luminosidade (28\%), aconchego no leito/aninhamento (26\%), manipulação mínima (20\%), sucção não nutritiva (6\%) e solução adocicada (5\%). Resultados semelhantes aos encontrados em Maciel et al., (2019), em que as medidas não farmacológicas mais frequentemente utilizadas incluíram o aconchego no leito/aninhamento (26\%), controle 
de ambiente por meio da redução de luminosidade (20\%) e ruídos (19\%), manipulação mínima (12\%) e contenção facilitada (11\%).

As evidências sugerem que a diminuição da estimulação multissensorial, que inclui a redução de luz e ruído, pode diminuir a resposta à dor associada a procedimentos dolorosos e estressantes (Baharlooei, Marofi e Abdeyazdan, 2017; Hatfield et al., 2019). Pontua-se que a luz intensa é considerada um fator estressante, e pode afetar os estados de sono e vigília nos $\mathrm{RN}$, além de interferir em todo ritmo circadiano (Jordão et al., 2016). Entende-se que a luminosidade periódica, de baixa intensidade (180 a 200 lux), estimula o desenvolvimento do relógio biológico, tornando-se um componente cada vez mais importante dos cuidados neonatais. Ressalta-se, ainda, que não somente a exposição excessiva à luz pode interferir negativamente no desenvolvimento, mas a penumbra contínua também não é indicada (Jordão et al., 2016).

Desse modo, em estudo realizado para avaliar os efeitos do aninhamento/aconchego no leito durante a punção no calcâneo, observou-se que as alterações da frequência cardíaca e saturação de oxigênio, no grupo do aninhamento/aconchego no leito, foram significativamente menores do que as alterações observadas no grupo controle, imediatamente e após dois, quatro e seis minutos da punção no calcâneo (Ho et al., 2016). Além disso, os valores de FC e saturação de oxigênio, dos RN do grupo do aninhamento/aconchego, voltaram aos níveis basais em dois minutos, enquanto o grupo controle não atingiu esse estado, mesmo após seis minutos da realização do estímulo doloroso. Outros estudos também sugerem que o emprego do aninhamento/aconchego, sozinho ou combinado com outra estratégia não farmacológica, como a sucção e as soluções adocicadas, é eficaz no alívio da dor em RN prematuros e a termo (Erkut e Yildiz, 2017; Efendi, Rustina e Gayatri, 2018; Perroteau et al., 2018; Bucsea e Pillai-Riddell, 2019). Por fim, os resultados de diferentes revisões (Pillai-Riddel et al., 2015; Hartley, Miller e Gephart, 2015; Mangat et al., 2018; Gomes Neto et al., 2020) reforçam a eficácia das estratégias não farmacológicas, de modo geral, na redução da dor neonatal.

Apesar das evidências sobre a eficácia de medidas não farmacológicas no alívio da dor em RN, outra questão é como essas estratégias são utilizadas na prática clínica (Pölkki, Korhonen e Laukkala, 2018). Observa-se que inúmeros fatores podem limitar a adoção de mediadas não farmacológicas no tratamento da dor em unidades neonatais, como por exemplo, o desconhecimento, por parte dos pais e dos profissionais, acerca da eficácia e dos benefícios destas estratégias; as crenças, por parte dos profissionais, de que os neonatos associarão o uso de amamentação ou ao contato pele a pele à estimulação dolorosa; a falta de 
orientação dos pais para a utilização desses recursos, além da necessidade de ajustar a técnica do procedimento ao uso das estratégias de alívio da dor (por exemplo, a posição a ser adotada pelo profissional para imunizar e realizar punções em um RN durante a amamentação) (Lago et al., 2017). Logo, são necessárias intervenções educacionais para melhorar as práticas de avaliação e manejo da dor nas UTIN (Pölkki, Korhonen e Laukkala, 2018), a serem oferecidas aos profissionais e familiares.

No que se refere às estratégias farmacológicas, foram registradas um total de 216 intervenções, com média de 2,3 medidas farmacológicas empregadas por RN, ao longo do período de coleta de dados. Constatou-se, ainda, variação da frequência de estratégias farmacológicas administradas ao longo dos dias, com a adoção média de 0,81 intervenções na admissão, 0,66 no primeiro dia, 0,54 no segundo dia e 0,36 no terceiro dia. Além disso, observou-se que, em cerca de $80 \%$ da população estudada, apesar do grande número de procedimentos potencialmente dolorosos e estressantes, nenhum tipo de medida farmacológica foi registrada. Em trabalho realizado por Hatfield (2014), por exemplo, os resultados indicaram que 79\% dos procedimentos dolorosos são realizados em RN prematuros sem analgesia. Ainda em relação às estratégias farmacológicas, estudo de Maciel et al., (2019) também verificou que houve o uso limitado de fármacos para o controle da dor nos neonatos, no cenário brasileiro.

Assim, a administração de analgésicos na UTIN deve ser cuidadosa. Historicamente, os analgésicos opióides têm sido a primeira escolha para o manejo da dor intensa e pósoperatória em UTIN. Embora amplamente difundidos e comumente usados, os agentes opióides podem ocasionar efeitos adversos, incluindo efeitos no desenvolvimento neurológico (Ferguson et al., 2012; de Graaf et al., 2011). A função renal do RN é imatura, resultando em diminuição da depuração devido à taxa de filtração glomerular, que em combinação com prematuridade e doenças subsequentes, podem levar à depressão respiratória, limitando desta forma, a utilização destes medicamentos na prática clínica (Bhalla, Shepherd e Tobias, 2014; Christoffel et al., 2017). Sabe-se que as práticas analgésicas e sedativas variam consideravelmente entre hospitais, mesmo para $\mathrm{RN}$ com características semelhantes (McPherson e Grunau, 2014); contudo, a administração de analgesia preventiva previne dor aguda (McPherson et al., 2020).

Não obstante, diferentes tipos de terapias analgésicas farmacológicas podem ser utilizadas na UTIN. No presente trabalho, destaca-se que as principais medidas farmacológicas empregadas foram o fentanil contínuo (49\%), midazolam intermitente (19\%), fentanil intermitente (14\%) e morfina intermitente (9\%). Ressalta-se que a infusão 
endovenosa contínua de fentanil é a forma de administração mais utilizada devido à estabilidade dos níveis séricos terapêuticos da droga (Bonutti et al., 2017). No estudo de Sposito et al., (2017), por exemplo, as intervenções farmacológicas mais frequentes foram a combinação de midazolam e fentanil $(37,8 \%)$ e administração isolada de midazolam (33,9\%).

Nesse sentido, estudos sobre o fentanil, que é frequentemente usado como analgésico antes dos procedimentos mais invasivos em $\mathrm{RN}$, produziram resultados variados (Hall \& Anand, 2014). Em um estudo controlado e randomizado, envolvendo $150 \mathrm{RN}$ prematuros (idade gestacional 27-32 semanas), foi utilizada a escala CRIES para a avaliação da dor resultante da punção de calcâneo (Gitto et al., 2012). Este estudo comparou a administração de fentanil, a contenção facilitada e saturação sensorial (competição entre estímulos sensoriais não dolorosos como, por exemplo: tato, olfato, audição) e foram observados escores mais baixos de dor e níveis mais baixos de citocinas no grupo fentanil (Gitto et al., 2012). No entanto, em outro estudo multicêntrico, duplo-cego, controlado e randomizado, investigou-se a eficácia analgésica de duas modalidades terapêuticas de administração de fentanil em uma população de $131 \mathrm{RN}$, com idade gestacional < 32 semanas e sob ventilação mecânica (Ancora et al., 2013). Observou-se que, embora o fentanil tenha reduzido a dor aguda com base na escala PIPP e em comparação com um grupo placebo, não houve diferenças entre o grupo fentanil e o placebo na dor prolongada, avaliada utilizando-se a escala EDIN (Ancora et al., 2013). Neste mesmo estudo, quando o fentanil foi comparado à morfina, o grupo fentanil teve menor efeito sedativo, resultou em menor ocorrência de hipotensão e menor efeito sobre a motilidade gastrointestinal (Ancora et al., 2013).

Dessa forma, as preocupações mais frequentes relacionadas ao uso da morfina são o seu potencial para hipotensão, a necessidade de maior ventilação mecânica e a menor tolerância à alimentação. Em uma revisão de 13 ensaios clínicos randomizados, os RN prematuros que receberam morfina tiveram menores escores PIPP, mas exigiram mais tempo para tolerar a alimentação (Bellu, de Waal \& Zanini, 2010). De modo geral, dados sobre a segurança e os efeitos colaterais, resultantes do uso da morfina em RN, bem como os resultados a longo prazo desses agentes farmacológicos, são controversos (Carbajal et al., 2005; Devlin e Roberts, 2009 Devlin e Roberts, 2011; McPherson e Grunau, 2014; Shafiekhani, Mirjalili e Vazin, 2018).

Já os fármacos não opióides são comumente usados em neonatos para induzir sedação e relaxamento muscular (Christoffel et al., 2017). O midazolam, por exemplo, embora não apresente efeitos analgésicos, é frequentemente administrado em conjunto com medicamentos como a morfina e o fentanil, para potencializar a sedação. No entanto, devido a potenciais 
efeitos adversos, é necessária a administração cuidadosa em RN, embora não existam estudos que demonstrem a contra indicação de utilização intermitente de midazolam (Hall e Shbarou, 2009; Kraychete, Siqueira, Garcia, 2014; Christoffel et al., 2017). Ressalta-se, ainda, que as intervenções farmacológicas e não farmacológicas também podem ser usadas em conjunto para aumentar a eficácia da analgesia (Perry et al., 2018).

De modo geral, a ausência de protocolos institucionais, para o alívio da dor procedural em neonatos internados na UTIN, utilizando-se estratégias farmacológicas e não farmacológicas, contribui para a ampla variedade de medidas analgésicas empregadas, bem como para o número insuficiente de ocasiões em que os $\mathrm{RN}$ receberam algum tipo de analgesia. A literatura apresenta corpo significativo de evidências acerca dos eventos negativos, resultantes da dor repetida e não tratada em neonatos, bem como dos benefícios e segurança de diversas estratégias farmacológicas e não farmacológicas para o alívio da dor. $\mathrm{O}$ que reforça a necessidade do desenvolvimento e implementação de protocolos clínicos nos diversos serviços de cuidado neonatal.

Em relação à avaliação da dor, verificou-se uma redução dos escores NIPS registrados da admissão até o terceiro dia, tanto na média, quanto ao agrupar-se os RN em pré-termo, termo e pós-termo. Os registros de escore de dor são realizados, na maior parte, em conjunto com a avaliação dos sinais vitais e não por ocasião da realização de procedimentos dolorosos. Dessa forma, é possível que haja inconsistência entre os registros e a experiência dolorosa dos RN incluídos neste estudo. Resultados semelhantes foram observados no trabalho de Sposito et al., (2017), estudo retrospectivo e transversal, realizado na UTIN na mesma instituição, no qual constatou-se que a aplicação da escala NIPS não reflete a condição vivenciada pelos RN, considerando a quantidade de procedimentos realizados.

Entende-se, portanto, que a avaliação da dor neonatal é desafiadora devido ao desenvolvimento físico, cognitivo e comportamental dos RN (Pölkki, Korhonen e Laukkala, 2018). Por isso, a avaliação da dor é baseada em instrumentos específicos para a avaliação da dor e depende da capacidade e do conhecimento dos profissionais de saúde de reconhecer os sinais de dor, incluindo alterações comportamentais, físicas e expressões faciais (Pölkki, Korhonen e Laukkala, 2018). Apesar da existência de uma variedade de instrumentos validados, eles não são rotineiramente utilizados na prática clínica; além disso, nenhum instrumento é considerado ideal para a avaliação da dor no RN (Kyololo et al., 2014; Maxwell, Fraga e Malavolta, 2019; Eriksson e Campbell-Yeo, 2019). Em um estudo de corte prospectivo realizado em 243 UTIN de 18 países europeus, registrou-se a frequência da avaliação da dor prolongada em 6.648 RN, por até 28 dias após a admissão na UTIN (Anand 
et al., 2017). Observou-se que a avaliação da dor ocorreu em menos de um terço das internações em UTIN e diariamente em apenas 10\% dos neonatos (Anand et al., 2017).

Estudos demonstram, ainda, que existem diferenças significativas entre o nível de treinamento e a experiência do profissional no reconhecimento da dor (Stevens et al., 2011). Além disso, pontua-se que quando os $\mathrm{RN}$ experienciam dor prolongada, geralmente parecem estar em um estado passivo, com movimentos corporais limitados, expressões faciais de difícil leitura e reatividade fisiológica reduzida (Hall \& Anand, 2014). Todos esses aspectos interferem não só na identificação e na avaliação, mas também na tomada de decisão e no manejo adequado da dor (Veronez M, Correa, 2010; Santos et al., 2012; Victoria e Murphy, 2016).

Diante de tal panorama, observa-se que existe uma lacuna importante na avaliação e gerenciamento da dor neonatal (Maxwell, Malavolta e Fraga et al., 2013; Perry et al., 2018). Nota-se uma limitação das escalas de dor em função de sua subjetividade, interpretação e sua questionável confiabilidade entre avaliadores (Field, 2017), sendo que alguns estudos demonstraram ainda que diferentes tipos de respostas à dor podem ser divergentes (LucasThompson, Townsend e Gunna, 2008). Estudo realizado por Bartocci et al., (2006), por exemplo, observou que a resposta cortical, avaliada por espectroscopia no infravermelho próximo (near infrared spectroscopy - NIRS), a punção venosa apresentou correlação negativa com a idade gestacional e correlação positiva com a idade pós-natal, sendo as respostas corticais mais pronunciadas nos RN do sexo masculino, em comparação aos RN do sexo feminino.

Portanto, a prática atual enfatiza a importância da avaliação da dor neonatal antes, durante e após procedimentos invasivos, e essas escalas são convenientes para este monitoramento (American Academy of Pediatrics, 2016). Observa-se, contudo, que existe uma lacuna entre as práticas recomendadas e a avaliação da dor neonatal à beira leito (Keels e Sethna, 2016).

De qualquer maneira, os dados apresentados no presente estudo, assim como resultados descritos em outros trabalhos desenvolvidos no cenário nacional e internacional, confirmam que a dor neonatal não é suficientemente avaliada ou tratada (Carbajal et al., 2008; Johnston et al., 2011; Stevens et al., 2011; Maciel et al., 2019). Observa-se que na prática clínica a avaliação, assim como o manejo da dor neonatal, permanece inadequada e inconsistente. Contudo, deve-se enfatizar que no presente estudo, apesar da disparidade entre o número de procedimentos e estratégias farmacológicas e não farmacológicas, constatou-se correlação positiva entre o número de procedimentos e o emprego de medidas farmacológicas. 
Isso porque a dor ativa mecanismos compensatórios do sistema nervoso autônomo, produzindo respostas que incluem alterações das FC, FR, PA, SpO2, vasoconstrição periférica, sudorese, dilatação de pupila e aumento da liberação de catecolaminas e hormônios adrenocorticosteroides (Holsti et al., 2011; Walker, 2013). Os parâmetros fisiológicos incluídos na avaliação da dor são medidas relativamente não invasivas, obtidos dos monitores da UTIN, incluindo frequência cardíaca, frequência respiratória, saturação de oxigênio e pressão arterial (Faye et al., 2010; Lemos et al., 2010; Holsti et al., 2011).

No presente estudo, foram avaliados os dados registrados nos prontuários clínicos em relação à temperatura axilar, frequência cardíaca e respiratória, saturação periférica de oxigênio e pressão arterial, em intervalos de quatro horas da admissão ao terceiro dia de internação na UTIN, conforme rotina institucional. Em relação à temperatura axilar e à frequência cardíaca, constatou-se oscilação dentro da faixa de normalidade desde a admissão ao terceiro dia de permanência na UTIN. Sabe-se que a frequência cardíaca, utilizada de modo isolado, é inespecífica para a avaliação da dor, visto que seus valores podem variar em função de inúmeras condições, como patologias e medicamentos, por exemplo. Destaca-se ainda que a FC está, em geral, aumentada na ocorrência de dor aguda, mas apresenta menor variação em resposta à dor prolongada ou crônica (de Jesus et al., 2011; De Jonckheere et al., 2011).

Já em relação à variação da frequência respiratória e da saturação periférica de oxigênio, constatou-se que esses parâmetros permaneceram na faixa superior do intervalo de normalidade, nos registros clínicos dos RN incluídos no estudo. O principal diagnóstico relacionado à internação em UTIN foram as afecções respiratórias, e por isso, os RN estudados permanecem com algum suporte de oxigênio, o que pode interferir não somente na frequência respiratória e saturação de oxigênio, mas também nos demais parâmetros vitais. Ressalta-se que, no presente trabalho, os sinais vitais não foram registrados necessariamente após um procedimento doloroso, mas ao longo do dia, de modo a refletir a influência dos procedimentos dolorosos na hemodinâmica. Aponta-se que, em um dos primeiros estudos empíricos sobre as respostas fisiológicas dos RN prematuros, a punção no calcâneo acarretava declínios significativos na saturação de oxigênio (Morrow et al., 1990) e, que na presença da dor ocorrem taquipnéia e taquicardia (Nicolau et al., 2008).

Por essa razão considera-se, dentre as ferramentas para a avaliação da dor, o autorelato como a forma ideal, exigindo que um indivíduo processe informações externas e comunique verbalmente sua experiência pessoal. Todavia, existem circunstâncias nas quais isso não é possível ou confiável, como ocorre em indivíduos pré-verbais, não verbais ou 
portadores de déficit cognitivo ou de comunicação. Logo, recomenda-se a combinação de indicadores em instrumentos validados e confiáveis para a avaliação da dor em RN (Hatfield and Ely, 2015).

Além de ser avaliada por aspectos comportamentais e fisiológicos, respostas corticais, metabólicas e hormonais podem ser utilizadas para a avaliação da dor neonatal (Ren e Dubner, 2010; Grunau, 2013; Grace et al., 2014; Hartley e Slater, 2014; Dantzer, 2018). Sabese que a dor é mediada por neurônios sensoriais nociceptores, os quais detectam estímulos nocivos e que são sensibilizados por mediadores inflamatórios, produzidos pelo sistema imunológico (Baral, Udit e Chiu, 2019; Matsuda et al., 2019).

Essas interações entre o sistema imunológico e o sistema somatossensorial são bidirecionais (Calvo, Dawes e Bennett, 2012). As células imunes liberam citocinas, lipídios e fatores de crescimento que atuam nos nociceptores periféricos e nos neurônios do sistema nervoso central. Por sua vez, os nociceptores liberam ativamente neuropeptídeos de seus terminais nervosos periféricos, que modulam a atividade das células imunes inatas e adaptativas (Chiu, von Hehn e Woolf, 2012; Pinho-Ribeiro, Verri e Chiu, 2017; Baral et al., 2016; Baral, Udit e Chiu, 2019). Bem como as citocinas são essenciais na modulação da dor e estão envolvidas em múltiplas funções biológicas, como diferenciação celular e metabolismo, pleiotropia, que destaca o papel chave que essas moléculas desempenham nas interações neuroimune (Verri et al., 2006; Chiu, von Hehn e Woolf, 2012; Cook et. al, 2018; Dantzer, 2018; Matsuda et al., 2019; Gonçalves dos Santos et al., 2020).

Logo, a descrição do comportamento das citocinas na vida pós-natal é fundamental e permite avaliar o potencial estressor dos procedimentos realizados nas primeiras horas de vida (Marcatto et al., 2017). Ressalta-se que os mediadores inflamatórios podem ser detectados no soro ou saliva, e que o desenvolvimento de testes de imunoensaio multiplex permitiu a detecção rápida de múltiplas citocinas em uma única amostra (Vignali, 2000). Aponta-se ainda, que como observado em outros estudos, os biomarcadores salivares demonstram boa correlação com os níveis plasmático e urinário (Okamura et al., 2014). Frente a estes aspectos, no presente estudo foram avaliadas 11 citocinas (IFNg, IL1b, IL2, IL4, IL6, IL8, IL10, IL12, IL17, TNF e VEGF) nas amostras de saliva, no primeiro e no segundo dia de vida de RN hospitalizados na UTIN, de modo a avaliar o impacto da exposição a procedimentos potencialmente dolorosos nos níveis desses mediadores inflamatórios.

Entende-se, assim, que muitos dos procedimentos dolorosos podem causar respostas inflamatórias, edema e dano tecidual local (Lee et al., 2016). Ressalta-se, ainda, que a dor é uma das principais características de muitas doenças e, considerando-se que o sistema 
imunológico e somatossensorial influenciam-se mutuamente, torna-se difícil determinar se o bloqueio da nocicepção contribui para a redução da produção de citocinas pró-inflamatórias, ou vice-versa (Baral, Udit e Chiu, 2019).

Observa-se, então, que investigações acerca dos níveis séricos de citocinas em RN prematuros têm sido conduzidas com o objetivo de fornecer diagnósticos precoces, aumentar a sobrevida, minimizar morbidade e mortalidade, além de possibilitar a adoção de medidas preventivas e mudanças nas práticas assistenciais (Bose, Damman e Laughon, 2008; Lam et al., 2008; Silveira, Fortes Filho e Procianoy, 2011). Contudo, a associação desses mediadores inflamatórios aos sinais vitais e comportamentais não foi realizada até o momento.

Portanto, ressalta-se que há pouca informação sobre a ontogênese do sistema imune pela análise dos componentes imunológicos da saliva em RN. A maioria dos estudos que avaliaram citocinas em $\mathrm{RN}$, em diferentes quadros clínicos, utilizaram outros tipos de amostras, como sangue, líquor e líquido amniótico (Bender et al., 2008; Lyon et al., 2010; Wei et al., 2010; Habiyaremye et al., 2017; Leal et al., 2019; Nist e Pickler, 2019). Não foram encontrados estudos, até o momento, que tenham avaliado continuamente os níveis de citocinas na saliva de RN internados na UTIN, ao longo dos primeiros dias de vida.

Neste trabalho, além da variação dos níveis das citocinas, também se evidenciaram correlações entre os mediadores inflamatórios e diferentes variáveis associadas à dor. Constatou-se, por exemplo, correlação positiva entre o número de procedimentos potencialmente dolorosos e a IL1b, IL2, IL6 e VEGF, o que significa que quanto maior número de procedimentos dolorosos, mais elevados são os valores destas citocinas. Além disso, também foram identificadas correlações negativas entre a frequência respiratória e/ou saturação periférica de oxigênio e os seguintes mediadores inflamatórios: IFNg, IL1b, IL2, IL4, IL6, IL10, IL12, IL17, TNF e VEGF. Tais correlações podem refletir aspectos relacionados às afecções respiratórias, principal diagnóstico dos $\mathrm{RN}$ hospitalizados em UTIN. Verificou-se também, correlações positivas entre a pressão arterial e as seguintes citocinas: IL1b, IL2, IL17, TNF e VEGF. Estas podem refletir o quadro clínico e a condição hemodinâmica do RN e sua correlação com a experiência dolorosa em RN merece ser melhor investigada.

Em relação às medidas não farmacológicas, observaram-se correlações negativas com as seguintes citocinas: IFNg, IL6, IL8 e VEGF. Finalmente, constatou-se correlação positiva entre a IL10 e as estratégias farmacológicas. Ou seja, identificaram-se correlações entre diferentes mediadores inflamatórios, parâmetros fisiológicos, número de procedimentos potencialmente dolorosos, estratégias farmacológicas e não farmacológicas. Estes achados 
fundamentam a dosagem destes mediadores inflamatórios não só para avaliação do quadro clínico, diagnóstico e prognóstico, mas também para integrar o manejo da dor em diferentes populações e condições, de modo a contribuir no diagnóstico, na evolução clínica e no tratamento. Vale ressaltar que estas informações foram obtidas por meio das dosagens e análises das amostras de saliva, procedimento simples, não invasivo e que não interfere no nível dos biomarcadores avaliados.

Em avaliação individualizada, verifica-se que os níveis de VEGF correlacionam-se positivamente com a pressão arterial e o número de procedimentos, e negativamente com a frequência respiratória e número de medidas não farmacológicas. $\mathrm{O}$ envolvimento do VEGF na fisiopatologia da dor ainda não está totalmente esclarecido, mas os níveis de VEGF são críticos para a modulação da dor em condições normais e na neuropatia (Hulse et al., 2014). Observa-se que níveis elevados de VEGF estão associados à progressão da osteoartrite, maiores escores de dor (Takano et al., 2018) e pior prognóstico de dor associada à osteoartrite (Hamilton et al., 2016). Além disso, o VEGF também está associado à síndrome do desconforto respiratório e displasia broncopulmonar, patologias que contribuem significativamente para a morbimortalidade neonatal (Meller e Bhandari, 2012).

Ainda, verificou-se que a IL2 e IL1b estão correlacionados com a frequência respiratória, pressão arterial e número de procedimentos. A IL-2 desempenha papel importante nas doenças inflamatórias autoimunes, pois está envolvida na regulação de células $\mathrm{T}$, proliferação e mecanismos de defesa do hospedeiro. Por isso, tem sido estudada em aplicações clínicas, tais como terapia oncológica, imunodeficiência e rejeição de transplantes (Sack et al., 2006; Zhou et al., 2017). Outros estudos observaram que os níveis de IL-2, apesar de elevados na apendicite, não são preditores desta patologia (Sack et al., 2006; Serour et al., 2010).

Além do mais, a IL-1b está associada à fadiga, distúrbios do sono e, tem importante função no desenvolvimento e na manutenção da dor pós-operatória (Wallace, 2006; Wolf et al., 2008). Estudos realizados em roedores demonstraram a ação hiperalgésica da IL-1b em modelos de dor inflamatória (Ebbinghaus et al., 2012). Níveis elevados de IL-1b também foram encontrados em modelos de roedores para dor neuropática (del Rey et al., 2016). Pontua-se, ainda, que Breitbart et al., (2014) também encontrou associação entre a IL-1b, assim como das IL-4 e IL-12 e a intensidade da dor. Além disso, a IL-1b é considerada um importante mediador da resposta à dor, atuando na dor inflamatória, aguda e crônica, assim como a IL6 (Baral, Udit e Chiu, 2019; Krock et al., 2019). 
Em relação à IL6, observa-se correlação negativa com a frequência respiratória, temperatura axilar e número de medidas não farmacológicas, assim como correlação positiva com o número de procedimentos dolorosos. Recentemente, vários modelos de dor crônica, que são caracterizadas por limiar baixo e resposta exagerada a estímulos dolorosos, e incluem a dor neuropática, enfatizaram o papel central da IL-6 na dor, com níveis elevados da expressão de IL6 e de seu receptor na medula espinal e nos gânglios da raiz dorsal (Kuner, 2010; Luo, Kuner e Kuner, 2014; Zhou et al., 2016). Demonstrou-se que, após uma lesão, concentrações plasmáticas de IL-6 são detectáveis em 60 minutos, com pico entre 4 e 6 horas, podendo persistir por 10 dias (Hong e Lim, 2008). Este é considerado o marcador mais relevante do grau de lesão tecidual durante um procedimento cirúrgico, em que o aumento excessivo e prolongado está associado a uma maior morbidade pós-operatória (Hong e Lim, 2008). Desse modo, pode-se inferir que a correlação positiva observada entre a IL-6 e o número de procedimentos é resultado de danos teciduais relacionados a procedimentos invasivos, como glicemia capilar e punção venosa para terapia IV, principais procedimentos estressantes, potencialmente dolorosos e mais frequentemente realizados no presente estudo.

Constata-se, ainda, o aumento da expressão da IL-6 em modelos animais para o estudo de artrite, assim como seu papel-chave nos mecanismos associados à dor e à inflamação (Krock, Jurczak e Svensson, 2018; Gonçalves dos Santos et al., 2020). Observa-se, também, a avaliação dos níveis de citocinas distintas no diagnóstico de diferentes patologias. Neste contexto, níveis elevados de IL-6 podem ser úteis no diagnóstico e/ou prognóstico de sepse neonatal e apendicite, por exemplo (Sack et al., 2006; Serour et al., 2010; Qiu et al., 2018).

Assim como a IL-6, o TNF correlaciona-se com a frequência respiratória. Além disso, também se aponta correlação positiva com a pressão arterial e correlação negativa com a temperatura axilar. O TNF desempenha papel fundamental em alguns modelos de dor, atuando em diferentes vias de sinalização através de dois receptores de superfície celular, TNFR1 e TNFR2 (Zhang e An, 2007; Cook et al., 2018). Em pacientes com artrite reumatóide, por exemplo, observa-se aumento dos níveis de TNF no soro (Chalan et al., 2016). O bloqueio do TNF em pacientes com artrite reumatóide reduz significativamente a dor, proporcionando não apenas alívio sintomático, mas também alterações no sinal nociceptivo no tálamo e no córtex somatossensorial, envolvidos na percepção da dor (Hess et al., 2011).

Portanto, observa-se na literatura que há evidências abundantes de que a IL-1b, IL-6 e o TNF estão envolvidos no processo da dor crônica e que podem modular diretamente a atividade neuronal em várias classes de neurônios no sistema nervoso central e periférico 
(Ozaktay et al., 2006; Zhang e An, 2007). Estas citocinas são importantes mediadores no recrutamento e ativação de células e, seu papel na indução da dor foi extensivamente estudado (Schaible, 2014; McMahon et al., 2015; Chavan, et al., 2017; Pinho-Ribeiro et al., 2017). Constata-se, então, que em condições de dor crônica há aumento das citocinas próinflamatórias circulantes e, que pacientes com dor lombar, por exemplo, apresentam produção elevada de IL-1b, IL-6 e TNF (Zu et al., 2016; Teodorczyk-Injeyan, Triano e Injeyan, 2019). Deste modo, uma atenção especial deve ser despendida para este grupo de citocinas no manejo da dor, avaliação que deve ser realizada em conjunto com outras variáveis fisiológicas e comportamentais, considerando-se ainda o diagnóstico clínico e o tipo de dor.

A IL-10, por exemplo, é produzida principalmente por monócitos e, em menor grau, por linfócitos (Pandey, Chauhan e Awasthi 2017), modula a regulação imune e a inflamação (Pandey, Chauhan e Awasthi, 2017). Estudos têm mostrado que a IL-10, assim como a IL-6, é um importante marcador inflamatório de sepse neonatal (Bender et al., 2008), porque níveis elevados de IL-10 foram detectados no soro de prematuros com sepse (Romagnoli et al., 2001; Cancelier et al., 2009). Receptores de IL-10 foram também identificados em várias áreas neuronais relacionadas à respiração, sugerindo que a IL-10 pode estar envolvida na regulação do controle da respiração (Giannakopoulou et al., 2019).

Observa-se, também, que a redução nos níveis de IL-10 pode ser um fator de risco adicional para a fibromialgia (Albertoni Giraldes et al., 2016). Sugere-se, ainda, que a IL-10 desempenha papel crucial no estabelecimento e manutenção da dor no nível do córtex cerebral, visto que o bloqueio e/ou administração de IL-10 reduz a dor neuropática em modelos animais (Shao et al., 2015). No presente trabalho, registrou-se correlação negativa da IL-10 com a frequência respiratória, temperatura axilar e saturação de oxigênio, variação hemodinâmica que está associada com as afecções respiratórias, diagnóstico mais frequente nos RN estudados. Também se constatou correlação positiva da IL-10 com o número de medidas farmacológicas. Pode-se inferir, frente ao exposto, que a avaliação do nível da IL-10 pode refletir a condição hemodinâmica, auxiliar no diagnóstico de afecções inflamatórias e contribuir no entendimento da dinâmica e do manejo da dor.

Evidenciou-se, também, a correlação negativa da IL4 com a frequência respiratória e saturação periférica de oxigênio. A IL-4 é um importante regulador da imunidade que também possui propriedades antinociceptivas, com diversos papéis em processos, como proliferação de células $T$, estimulação de células $B$ ativada, ativação de macrófagos, inflamação crônica e reparo de feridas (Gadani et al., 2012; Baral, Udit e Chiu, 2019). A IL-4 tem potencial terapêutico em muitas situações clínicas, como, por exemplo, em psoríase, osteoartrite, 
linfoma e asma (Kurtz et al., 2007; Ren et al., 2009). Estudos clínicos também indicam que baixos níveis sanguíneos de IL-4 e IL-10 foram encontrados em pacientes com dor crônica generalizada (Uceyler et al., 2006).

Notou-se, ainda, correlação negativa entre IFNg e a saturação periférica de oxigênio e o número de medidas não farmacológicas. Observou-se também correlação negativa da IL-12 com a saturação periférica de oxigênio. O IFNg é um importante modulador da resposta imune central e periférica, além de desempenhar um papel importante na patogênese da dor neuropática (Moen et al., 2017). Nesse sentido, há o estudo realizado por Sesso, et al., (2014), cujo objetivo foi caracterizar os níveis de IL-6, IL-10, IL-12 e interferon gama (IFN- $\gamma$ ) em amostras de saliva de $\mathrm{RN}$ a termo $(\mathrm{n}=25)$ e pré-termo $(\mathrm{n}=25)$, ao nascimento e após 3 meses de vida. Neste trabalho constatou-se que os níveis dessas citocinas ao nascimento foram significativamente maiores em RN pré-termo, comparado aos de termo e que diminuíram do nascimento ao terceiro mês de vida, o que parece ser influenciado pela idade gestacional, e por outros fatores após o nascimento, como infecção e situação de estresse.

Já a IL-17, apresenta correlação com a frequência respiratória e pressão arterial e, a IL8 com o número de medidas não farmacológicas. Constatou-se, em um modelo de dor para artrite induzida por antígeno, que os níveis de IL-17 aumentaram após a indução de artrite e correlacionaram-se com hiperalgesia (Pinto et al., 2010; McNamee et al., 2011). Verificou-se em outros trabalhos, a elevação do nível de IL-17, assim como do TNF, IL-1b e IL-6 em modelos animais de dor neuropática e, no líquido cefalorraquidiano e no sangue de pacientes com dor neuropática (Allison et al., 2016; Wang et al., 2016). Além disso, constatou-se que a IL-17 estava correlacionada com outras citocinas pró-inflamatórias, incluindo TNF, IFNg, IL2, IL-4 e IL-10 (Pernambuco et al., 2013).

Dentro desse contexto, indica-se que a IL-8 está elevada no LCR de indivíduos com dor lombar crônica (Krock et al., 2018), e também tem sido implicada em condições de dor orofacial (Barry et al., 2018; Krock et al., 2019). Outros estudos sugeriram que a IL-17 e a IL8 desempenham papéis importantes na indução de dor inflamatória em modelos de artrite (Mens et al., 2018; Wigerblad et al., 2016). Além disso, vários estudos mostraram níveis elevados de IL-6, IL-8, IL-1b, TNF e IL-17 na fibromialgia (Bote et al., 2012; Malhotra et al., 2012; Imamura et al., 2012; Pernambuco et al., 2013; Mendieta et al., 2016). Por fim, em revisão realizada por DeVon et al., (2014), constatou-se a elevação dos níveis de TNF, IL-2, IL-6, IL-8 e IL-10 em condições dolorosas, em comparação com controles saudáveis. Percebe-se que diferente dos resultados presentes na literatura, no presente trabalho não se identificou correlação do número de procedimentos dolorosos e, consequentemente, da dor 
neonatal, nas dosagens de IL-17 e IL-8, apesar da variação destes mediadores ao longo do período avaliado.

Sabe-se, de qualquer maneira, que os mediadores inflamatórios presentes em condições de estresse crônico estão associados a alterações na cognição e no comportamento (Capuron e Miller, 2011). Pontua-se, ainda, que níveis elevados sustentados de citocinas próinflamatórias estão associados a um pior desenvolvimento neurológico (Leviton et al., 2016).

De modo geral, constatou-se a variação de diferentes mediadores inflamatórios nas amostras de saliva, ao longo dos primeiros dias de vida de RN internados na UTIN. Além disso, verificou-se que algumas citocinas estiveram correlacionadas ao número de procedimentos potencialmente dolorosos e diferentes parâmetros fisiológicos. Aponta-se ainda que, na população neonatal, além de fornecer dados relacionados à dor, a dosagem dessas citocinas também poderá auxiliar na avaliação hemodinâmica, no diagnóstico, tratamento e prognóstico das afecções respiratórias, dor aguda, prolongada e crônica. Estas citocinas, particularmente a IL-1b, IL-2, IL-6 e VEGF, apresentam potencial diagnóstico e terapêutico no manejo da dor, fatos que contribuem para impulsionar novos estudos relacionados ao papel destes mediadores inflamatórios na avaliação da dor em RN e outras faixas etárias, expostos a procedimentos estressantes e potencialmente dolorosos.

No entanto, embora exista uma promessa teórica de explorar os biomarcadores como uma medida objetiva da dor, é improvável que exista um mediador específico e único que sinalize a dor (Cowen et al., 2015). Percebe-se que diferentes métodos são empregados para avaliar os níveis dos mediadores inflamatórios e, que esta coleta é realizada em momentos variados e a partir de diferentes fluídos, fatores que podem explicar resultados distintos descritos na literatura e que dificultam comparações entre diferentes estudos. Ressalta-se, de qualquer forma, que a secreção de citocinas varia amplamente e suas concentrações são influenciadas por vários fatores ambientais, medicamentosos, dor aguda versus crônica, variação e gravidade dos sintomas da patologia. (Albertoni Giraldes et al., 2016).

Em revisão realizada por DeVon et al., (2014), verificou-se que as citocinas são alteradas na presença de dor autorreferida em indivíduos adultos, mas que não há evidências suficientes para apoiar o uso de citocinas como biomarcadores de dor. Por outro lado, apontase que as citocinas desempenham papel-chave na indução e manutenção da dor (Gonçalves Dos Santos et al., 2020). Os resultados do presente estudo fornecem evidências, como por exemplo, a correlação positiva da IL-1b, IL-2, IL-6 e VEGF com o número de procedimentos estressantes e potencialmente dolorosos, que permitem afirmar que o nível destas citocinas é potencialmente alterado pela presença de estímulos dolorosos. Logo, defende-se que a 
incorporação de mediadores inflamatórios, como medidas complementares, poderá fornecer informações valiosas em pesquisas para avaliação e manejo adequado da dor neonatal.

Entende-se, portanto, que a abordagem dos perfis dos mediadores inflamatórios pode ser mais útil na avaliação e consequente manejo da dor, independente da faixa etária, por meio de avaliação multidimensional. Por fim, compreende-se que embora clinicamente necessário e teoricamente promissor, atualmente não há evidências suficientes para apoiar o uso generalizado de quaisquer marcadores fisiológicos como medidas "objetivas" de dor e nocicepção (Cowen et al., 2015).

Em relação às limitações do estudo, aponta-se que o registro dos sinais vitais, assim como a avaliação da dor por intermédio da escala NIPS, foi realizado nos horários préestabelecidos e registrado em prontuário clínico, conforme a rotina da unidade. Isto se constitui como uma limitação para a exploração destes dados diretamente relacionados aos inúmeros procedimentos dolorosos registrados, permitindo apenas uma exploração dos impactos hemodinâmicos nos RN, de modo geral. Ressalta-se que as amostras de saliva foram coletadas em horários específicos, de modo a refletir os níveis destes mediadores ao longo do dia e não em conjunto com os procedimentos estressantes e potencialmente dolorosos, para padronizar o horário das coletas e possibilitar a avalição de possíveis correlações também com outros parâmentros. Além disso, em função de restrições financeiras e de insumos, somente um número limitado de RN teve suas amostras de saliva dosadas. A dosagem de maior número de amostras poderia contribuir para os resultados deste estudo e avançar o conhecimento quanto à variação das citocinas ao longo do período de coleta de dados, assim como na exploração de outras correlações destes mediadores com os parâmetros fisiológicos e comportamentais.

Ainda assim, constatou-se que a dosagem dos mediadores salivares na população composta por RN pré-termo, termo e pós-termo são indicadores mensuráveis objetivos de processos biológicos que permitem contribuir para a avaliação e manejo da dor neonatal, pois além de permitir avaliar respostas biológicas às intervenções, auxilia no diagnóstico e monitoramento de diferentes patologias.

Atualmente, existem poucos parâmetros para orientar os pesquisadores na escolha de mediadores inflamatórios apropriados para a avaliação da dor. Os mediadores inflamatórios presentes na saliva, avaliados neste trabalho, em especial a IL-1b, IL-2, IL-6 e VEGF, representam importantes medidas endócrinas com potencial para contribuir significativamente com pesquisas futuras sobre a dor neonatal. Portanto, pontua-se que mais pesquisas relacionados à avaliação da dor, incorporando cuidadosamente os mediadores inflamatórios 
na avaliação conjunta com instrumentos validados, poderão contribuir para a compreensão mais abrangente e diferenciada da dor, aprimorando a assistência ao neonato realizada pela enfermagem, de modo a desenvolver intervenções e promover manejo adequado da dor, reduzindo impactos imediatos e tardios, decorrentes da exposição do RN a procedimentos potencialmente dolorosos, fundamentando proposições futuras para a gestão da dor neonatal. 


\section{CONCLUSÕES}

A partir dos resultados desta pesquisa, evidencia-se que da admissão ao terceiro dia de internação na UTIN, os RN são expostos a número elevado de procedimentos potencialmente dolorosos e estressantes, sendo insuficiente o uso de medidas farmacológicas e não farmacológicas, empregadas para o manejo da dor. Apontam-se alterações dos parâmetros fisiológicos (FC, FR, saturação periférica de oxigênio e pressão arterial) e comportamentais registrados de modo sistemático ao longo da hospitalização, que não refletem necessariamente o número de intervenções às quais os RN são submetidos. Ressalta-se, ainda, que esses parâmetros oscilam devido a diferentes situações e, que avaliação comportamental depende da interpretação do profissional da saúde que está à beira leito, que por sua vez é influenciado por diversos aspectos que incluem a condição clínica do RN, conhecimentos e habilidades profissionais relacionados à avaliação, condições organizacionais, entre outros. Logo, a capacitação e sensibilização de toda equipe é de suma importância para evitar a subavaliação e subtratamento da dor neonatal.

Considera-se que o manejo inadequado da dor, seja na avaliação, emprego de estratégias farmacológicas e não farmacológicas, assim como na reavaliação, pode acarretar consequências deletérias a curto, médio e longo prazo. Dessa forma, avançar o conhecimento com vistas a melhor compreender o fenômeno doloroso nesta população pode contribuir para o manejo da dor no RN.

Destaca-se, ainda, que há consenso geral da importância do manejo adequado da dor neonatal e, que este deve fazer parte dos cuidados na UTIN. Portanto, evidencia-se que a avaliação adequada da dor é vital e, que as interações neuroimunes podem desempenhar um papel crucial na avaliação da dor, que pode ser realizada por meio de uma abordagem multidimensional, incluindo medidas das respostas fisiológicas, endócrinas e comportamentais.

Neste estudo se verificaram padrões e correlações entre as variáveis fisiológicas, comportamentais e endócrinas. Destaca-se o ineditismo da dosagem dos mediadores inflamatórios nas amostras de saliva de $\mathrm{RN}$, potenciais biomarcadores para a avaliação da dor, que podem vir a fornecer fundamentação científica para avaliação e manejo da dor neonatal. Uma vez que a detecção dessas citocinas são passíveis de serem realizadas na saliva e, os dados obtidos sugerem uma forma não invasiva e quantitativa para a análise de procedimentos estressantes e potencialmente dolorosos, durante a internação na UTIN. Acredita-se que a avaliação destas citocinas, em especial IL1b, IL2, IL6 e VEGF, juntamente com os 
parâmetros fisiológicos e comportamentais, poderá ser empregada na população neonatal de diferentes formas. Por exemplo, na avaliação da dor, no acompanhamento a curto, médio e longo prazo, de modo a avaliar consequências deletérias da exposição a procedimentos invasivos, dolorosos e repetitivos.

Evidencia-se, por tal razão, que o presente estudo contribui para a compreensão da dor neonatal, por meio da avaliação de diferentes mediadores inflamatórios, detectados nas amostras de saliva, já que, à medida que se compreende o perfil dos mediadores inflamatórios de RN internados em UTIN, expostos a procedimentos potencialmente dolorosos, amplia-se a fundamentação para a avaliação e consequente manejo adequado da dor neonatal.

Finalmente, conclui-se que os mediadores inflamatórios possuem potencial para integrar a avaliação multidimensional da dor neonatal. Desta forma, futuras pesquisas para investigar a associação entre dor e biomarcadores salivares poderão contribuir para a melhor compreensão das características das condições dolorosas, de modo a apoiar tomadas de decisões no manejo da dor neonatal. 


\section{REFERÊNCIAS}

Akuma AO, Jordan S. Pain management in neonates: a survey of nurses and doctors. J Adv Nurs. 2012 Jun;68(6):1288-301.

Albertoni Giraldes AL, Salomão R, Leal PD, Brunialti MK, Sakata RK. Effect of intravenous lidocaine combined with amitriptyline on pain intensity, clinical manifestations and the concentrations of IL-1, IL-6 and IL-8 in patients with fibromyalgia: A randomized doubleblind study. Int J Rheum Dis. 2016 Oct;19(10):946-953.

Allison DJ, Thomas A, Beaudry K, Ditor DS. Targeting inflammation as a treatment modality for neuropathic pain in spinal cord injury: a randomized clinical trial. J Neuroinflammation. 2016 Jun 17;13(1):152.

Anand KJ, Sippell WG, Aynsley-Green A. Randomised trial of fentanyl anaesthesia in preterm babies undergoing surgery: effects on the stress response. Lancet. 1987 Jan 31;1(8527):243-8.

Anand KJ, Coskun V, Thrivikraman KV, Nemeroff CB, Plotsky PM. Long-term behavioral effects of repetitive pain in neonatal rat pups. Physiol Behav. 1999 Jun;66(4):627-37

Anand KJS, Eriksson M, Boyle EM, Avila-Alvarez A, Andersen RD, Sarafidis K, Polkki T, Matos C, Lago P, Papadouri T, Attard-Montalto S, Ilmoja ML, Simons S, Tameliene R, van Overmeire B, Berger A, Dobrzanska A, Schroth M, Bergqvist L, Courtois E, Rousseau J, Carbajal R; EUROPAIN survey working group of the NeoOpioid Consortium. Assessment of continuous pain in newborns admitted to NICUs in 18 European countries. Acta Paediatr. 2017 Aug;106(8):1248-1259.

Anand KJ. Pain assessment in preterm neonates. Pediatrics. 2007 Mar;119(3):605-7.

Anand KJ. Clinical importance of pain and stress in preterm neonates. Biol Neonate. 1998;73(1):1-9. 
Ancora G, Lago P, Garetti E, Pirelli A, Merazzi D, Mastrocola M, Pierantoni L, Faldella G. Efficacy and safety of continuous infusion of fentanyl for pain control in preterm newborns on mechanical ventilation. J Pediatr. 2013 Sep;163(3):645-51.e1.

Baharlooei F, Marofi M, Abdeyazdan Z. Effect of Environmental and Behavioral Interventions on Pain Intensity in Preterm Infants for Heel Prick Blood Sampling in the Neonatal Intensive Care Unit. Iran J Nurs Midwifery Res. 2017 Sep-Oct;22(5):388-391.

Baral P, Mills K, Pinho-Ribeiro FA, Chiu IM. Pain and Itch: Beneficial or Harmful to Antimicrobial Defense? Cell Host Microbe. 2016 Jun 8;19(6):755-9.

Baral P, Udit S, Chiu IM. Pain and immunity: implications for host defence. Nat Rev Immunol. 2019 Jul;19(7):433-447.

Barry A, O'Halloran KD, McKenna JP, McCreary C, Downer EJ. Plasma IL-8 signature correlates with pain and depressive symptomatology in patients with burning mouth syndrome: Results from a pilot study. J Oral Pathol Med. 2018 Feb;47(2):158-165.

Bartocci M, Bergqvist LL, Lagercrantz H, Anand KJ. Pain activates cortical areas in the preterm newborn brain. Pain. 2006 May;122(1-2):109-17.

Bartocci M, Bergqvist LL, Lagercrantz H, Anand KJ. Pain activates cortical areas in the preterm newborn brain. Pain. 2006 May;122(1-2):109-17.

Beggs S. Long-Term Consequences of Neonatal Injury. Can J Psychiatry. 2015 Apr;60(4):176-80.

Bellù R, de Waal KA, Zanini R. Opioids for neonates receiving mechanical ventilation. Cochrane Database Syst Rev. 2008 Jan 23;(1):CD004212.

Bellù R, de Waal K, Zanini R. Opioids for neonates receiving mechanical ventilation: a systematic review and meta-analysis. Arch Dis Child Fetal Neonatal Ed. 2010 Jul;95(4):F24151. 
Bender L, Thaarup J, Varming K, Krarup H, Ellermann-Eriksen S, Ebbesen F. Early and late markers for the detection of early-onset neonatal sepsis. Dan Med Bull. 2008 Nov;55(4):21923.

Benoit B, Martin-Misener R, Latimer M, Campbell-Yeo M. Breast-Feeding Analgesia in Infants: An Update on the Current State of Evidence. J Perinat Neonatal Nurs. 2017 Apr/Jun;31(2):145-159.

Benoit B, Martin-Misener R, Newman A, Latimer M, Campbell-Yeo M. Neurophysiological assessment of acute pain in infants: a scoping review of research methods. Acta Paediatr. $2017 \mathrm{Jul} ; 106(7): 1053-1066$.

Bergomi P, Chieppi M, Maini A, Mugnos T, Spotti D, Tzialla C, Scudeller L. Nonpharmacological techniques to reduce pain in preterm infants who receive heel-lance procedure: a randomized controlled trial. Res Theory Nurs Pract. 2014;28(4):335-48.

Betran AP, Torloni MR, Zhang J, Ye J, Mikolajczyk R, Deneux-Tharaux C, Oladapo OT, Souza JP, Tunçalp Ö, Vogel JP, Gülmezoglu AM. What is the optimal rate of caesarean section at population level? A systematic review of ecologic studies. Reprod Health. 2015 Jun 21;12:57.

Bhalla T, Shepherd E, Tobias JD. Neonatal pain management. Saudi J Anaesth. 2014 Nov;8(Suppl 1):S89-97.

Blauer T, Gerstmann D. A simultaneous comparison of three neonatal pain scales during common NICU procedures. Clin J Pain. 1998 Mar;14(1):39-47.

Blencowe H, Cousens S, Oestergaard MZ, Chou D, Moller AB, Narwal R, Adler A, Vera Garcia C, Rohde S, Say L, Lawn JE. National, regional, and worldwide estimates of preterm birth rates in the year 2010 with time trends since 1990 for selected countries: a systematic analysis and implications. Lancet. 2012 Jun 9;379(9832):2162-72. 
Boerma T, Ronsmans C, Melesse DY, Barros AJD, Barros FC, Juan L, Moller AB, Say L, Hosseinpoor AR, Yi M, de Lyra Rabello Neto D, Temmerman M. Global epidemiology of use of and disparities in caesarean sections. Lancet. 2018 Oct 13;392(10155):1341-1348.

Bonutti DP, Daré MF, Castral TC, Leite AM, Vici-Maia JA, Scochi CGS. Dimensioning of painful procedures and interventions for acute pain relief in premature infants. Rev. LatinoAm. Enfermagem. 2017;25:e2917.

Bose CL, Dammann CE, Laughon MM. Bronchopulmonary dysplasia and inflammatory biomarkers in the premature neonate. Arch Dis Child Fetal Neonatal Ed. 2008 Nov;93(6):F455-61.

Bosenberg A, Flick RP. Regional anesthesia in neonates and infants. Clin Perinatol. 2013 Sep;40(3):525-38.

Bote ME, García JJ, Hinchado MD, Ortega E. Inflammatory/stress feedback dysregulation in women with fibromyalgia. Neuroimmunomodulation. 2012;19(6):343-51.

Bouza H. The impact of pain in the immature brain. J Matern Fetal Neonatal Med. 2009 Sep;22(9):722-32.

Brasil, Ministerio da Saude. DATASUS/SINASC—Sistema de Informações sobre Nascidos Vivos 2018. http://tabnet.datasus.gov.br/cgi/deftohtm.

Breitbart W, Rosenfeld B, Tobias K, Pessin H, Ku GY, Yuan J, Wolchok J. Depression, cytokines, and pancreatic cancer. Psychooncology. 2014 Mar;23(3):339-45.

Britto CD, Rao Pn S, Nesargi S, Nair S, Rao S, Thilagavathy T, Ramesh A, Bhat S. PAIN-perception and assessment of painful procedures in the NICU. J Trop Pediatr. 2014 Dec;60(6):422-7. 
Brummelte S, Chau CM, Cepeda IL, Degenhardt A, Weinberg J, Synnes AR, Grunau RE. Cortisol levels in former preterm children at school age are predicted by neonatal procedural pain-related stress. Psychoneuroendocrinology. 2015 Jan;51:151-63.

Brummelte S, Grunau RE, Chau V, Poskitt KJ, Brant R, Vinall J, Gover A, Synnes AR, Miller SP. Procedural pain and brain development in premature newborns. Ann Neurol. 2012 Mar;71(3):385-96.

Bucsea O, Pillai Riddell R. Non-pharmacological pain management in the neonatal intensive care unit: Managing neonatal pain without drugs. Semin Fetal Neonatal Med. 2019 Aug;24(4):101017.

Bueno M, Kimura AF, Pimenta CAM. Avaliação da dor em recém-nascidos submetidos à cirurgia cardiáca. Acta Paul Enferm. 2007;20(4):428-33.

Busch-Dienstfertig M, González-Rodríguez S. IL-4, JAK-STAT signaling, and pain. JAKSTAT. 2013 Oct 1;2(4):e27638.

Buskila D, Neumann L, Zmora E, Feldman M, Bolotin A, Press J. Pain sensitivity in prematurely born adolescents. Arch Pediatr Adolesc Med. 2003 Nov;157(11):1079-82.

Calvo M, Dawes JM, Bennett DL. The role of the immune system in the generation of neuropathic pain. Lancet Neurol. 2012 Jul;11(7):629-42.

Cancelier AC, Petronilho F, Reinke A, Constantino L, Machado R, Ritter C, Dal-Pizzol F. Inflammatory and oxidative parameters in cord blood as diagnostic of early-onset neonatal sepsis: a case-control study. Pediatr Crit Care Med. 2009 Jul;10(4):467-71.

Capellini VK, Daré MF, Castral TC, Christoffel MMC, Leite AM, Scochi CGS. Conhecimento e atitudes de profissionais de saúde sobre avaliação e manejo da dor neonatal. Rev. Eletr. Enf. [Internet]. 30 de junho de 2014 [citado 14º de junho de 2020];16(2):361-9. Disponível em: https://revistas.ufg.br/fen/article/view/23611 
Capellini, V,K. Exposição, avaliação e manejo da dor aguda do recém-nascido em unidades neonatais de um hospital estadual. 2012. 134 f. Dissertação (Mestrado) - Escola de Enfermagem de Ribeirão Preto, Universidade de São Pailo, Ribeirão Preto, 2012.

Capuron L, Miller AH. Immune system to brain signaling: neuropsychopharmacological implications. Pharmacol Ther. 2011 May;130(2):226-38.

Carbajal R, Lenclen R, Jugie M, Paupe A, Barton BA, Anand KJ. Morphine does not provide adequate analgesia for acute procedural pain among preterm neonates. Pediatrics. 2005 Jun;115(6):1494-500.

Carbajal R, Rousset A, Danan C, Coquery S, Nolent P, Ducrocq S, Saizou C, Lapillonne A, Granier M, Durand P, Lenclen R, Coursol A, Hubert P, de Saint Blanquat L, Boëlle PY, Annequin D, Cimerman P, Anand KJ, Bréart G. Epidemiology and treatment of painful procedures in neonates in intensive care units. JAMA. $2008 \mathrm{Jul}$ 2;300(1):60-70.

Castro M, Elias PC, Quidute AR, Halah FP, Moreira AC. Out-patient screening for Cushing's syndrome: the sensitivity of the combination of circadian rhythm and overnight dexamethasone suppression salivary cortisol tests. J Clin Endocrinol Metab. 1999 Mar;84(3):878-82.

Castro Margaret, Moreira Ayrton C.. Análise crítica do cortisol salivar na avaliação do eixo hipotálamo-hipófise-adrenal. Arq Bras Endocrinol Metab [Internet]. 2003 Aug [cited 2020 June 15]; 47( 4 ): 358-367.

Chalan P, Bijzet J, van den Berg A, Kluiver J, Kroesen BJ, Boots AM, Brouwer E. Analysis of serum immune markers in seropositive and seronegative rheumatoid arthritis and in highrisk seropositive arthralgia patients. Sci Rep. 2016 May 18;6:26021.

Chau CMY, Ranger M, Bichin M, Park MTM, Amaral RSC, Chakravarty M, Poskitt K, Synnes AR, Miller SP, Grunau RE. Hippocampus, Amygdala, and Thalamus Volumes in Very Preterm Children at 8 Years: Neonatal Pain and Genetic Variation. Front Behav Neurosci. 2019 Mar 19;13:51. 
Chavan SS, Pavlov VA, Tracey KJ. Mechanisms and Therapeutic Relevance of Neuroimmune Communication. Immunity. 2017 Jun 20;46(6):927-942.

Chen M, Shi X, Chen Y, Cao Z, Cheng R, Xu Y, Liu L, Li X. A prospective study of pain experience in a neonatal intensive care unit of China. Clin J Pain. 2012 Oct;28(8):700-4.

Chiu IM, von Hehn CA, Woolf CJ. Neurogenic inflammation and the peripheral nervous system in host defense and immunopathology. Nat Neurosci. 2012 Jul 26;15(8):1063-7.

Christoffel MM, Castral TC, Daré MF, Montanholi LL, Gomes ALM, Scochi CGS. Atitudes dos profissionais de saúde na avaliação e tratamento da dor neonatal. Esc. Anna Nery [Internet]. 2017 [cited 2020 July 25] ; 21( 1 ): e20170018.

Cignacco E, Hamers JP, Stoffel L, van Lingen RA, Gessler P, McDougall J, Nelle M. The efficacy of non-pharmacological interventions in the management of procedural pain in preterm and term neonates. A systematic literature review. Eur J Pain. 2007 Feb;11(2):13952.

Cignacco E, Hamers J, van Lingen RA, Stoffel L, Büchi S, Müller R, Schütz N, Zimmermann L, Nelle M. Neonatal procedural pain exposure and pain management in ventilated preterm infants during the first 14 days of life. Swiss Med Wkly. 2009 Apr 18;139(15-16):226-32.

COMMITTEE ON FETUS AND NEWBORN and SECTION ON ANESTHESIOLOGY AND PAIN MEDICINE. Prevention and Management of Procedural Pain in the Neonate: An Update. Pediatrics. 2016 Feb;137(2):e20154271.

Cong X, Wu J, Vittner D, Xu W, Hussain N, Galvin S, Fitzsimons M, McGrath JM, Henderson WA. The impact of cumulative pain/stress on neurobehavioral development of preterm infants in the NICU. Early Hum Dev. 2017 May;108:9-16.

Cook AD, Christensen AD, Tewari D, McMahon SB, Hamilton JA. Immune Cytokines and Their Receptors in Inflammatory Pain. Trends Immunol. 2018 Mar;39(3):240-255. 
Costa LD, Andersen VF, Perondi AR, França VF, Cavalheiri JC, Bortoloti DS. Predicting factors for admission of newborns in neonatal intensive care units. Rev baiana enferm. 2017;31(4):e20458.

Courtois E, Droutman S, Magny JF, Merchaoui Z, Durrmeyer X, Roussel C, Biran V, Eleni S, Vottier G, Renolleau S, Desfrere L, Castela F, Boimond N, Mellah D, Bolot P, Coursol A, Brault D, Chappuy H, Cimerman P, Anand KJ, Carbajal R. Epidemiology and neonatal pain management of heelsticks in intensive care units: EPIPPAIN 2, a prospective observational study. Int J Nurs Stud. 2016 Jul;59:79-88.

Coviello C, Popple Martinez M, Drovandi L, Corsini I, Leonardi V, Lunardi C, Antonelli C, Pratesi S, Dani C. Painful procedures can affect post-natal growth and neurodevelopment in preterm infants. Acta Paediatr. 2018 May;107(5):784-790.

Cowen R, Stasiowska MK, Laycock H, Bantel C. Assessing pain objectively: the use of physiological markers. Anaesthesia. 2015 Jul;70(7):828-47.

Cruz MD, Fernandes AM, Oliveira CR. Epidemiology of painful procedures performed in neonates: A systematic review of observational studies. Eur J Pain. 2016 Apr;20(4):489-98.

Cunha FQ, Lorenzetti BB, Poole S, Ferreira SH. Interleukin-8 as a mediator of sympathetic pain. Br J Pharmacol. 1991 Nov;104(3):765-7.

Cunha TM, Verri WA Jr, Silva JS, Poole S, Cunha FQ, Ferreira SH. A cascade of cytokines mediates mechanical inflammatory hypernociception in mice. Proc Natl Acad Sci U S A. 2005 Feb 1;102(5):1755-60.

Curfs JH, Meis JF, Hoogkamp-Korstanje JA. A primer on cytokines: sources, receptors, effects, and inducers. Clin Microbiol Rev. 1997 Oct;10(4):742-80.

Dahl M, Kamper J. Physical outcome and school performance of very-low-birthweight infants treated with minimal handling and early nasal CPAP. Acta Paediatr. 2006 Sep;95(9):1099103. 
Dantzer R. Cytokine-induced sickness behaviour: a neuroimmune response to activation of innate immunity. Eur J Pharmacol. 2004 Oct 1;500(1-3):399-411.

Dantzer R. Neuroimmune Interactions: From the Brain to the Immune System and Vice Versa. Physiol Rev. 2018 Jan 1;98(1):477-504.

de Graaf J, van Lingen RA, Simons SH, Anand KJ, Duivenvoorden HJ, Weisglas-Kuperus N, Roofthooft DW, Groot Jebbink LJ, Veenstra RR, Tibboel D, van Dijk M. Long-term effects of routine morphine infusion in mechanically ventilated neonates on children's functioning: five-year follow-up of a randomized controlled trial. Pain. 2011 Jun;152(6):1391-7

de Jesus JA, Tristao RM, Storm H, da Rocha AF, Campos D Jr. Heart rate, oxygen saturation, and skin conductance: a comparison study of acute pain in Brazilian newborns. Conf Proc IEEE Eng Med Biol Soc. 2011;2011:1875-9.

De Jonckheere J, Rakza T, Logier R, Jeanne M, Jounwaz R, Storme L. Heart rate variability analysis for newborn infants prolonged pain assessment. Conf Proc IEEE Eng Med Biol Soc. 2011;2011:7747-50.

de Oliveira CM, Sakata RK, Issy AM, Gerola LR, Salomão R. Cytokines and pain. Rev Bras Anestesiol. 2011 Mar-Apr;61(2):255-9, 260-5, 137-42

De Palo EF, Antonelli G, Benetazzo A, Prearo M, Gatti R. Human saliva cortisone and cortisol simultaneous analysis using reverse phase HPLC technique. Clin Chim Acta. 2009 Jul;405(1-2):60-5.

de Souza S, Duim E, Nampo FK. Determinants of neonatal mortality in the largest international border of Brazil: a case-control study. BMC Public Health. 2019 Oct $16 ; 19(1): 1304$.

Debillon T, Zupan V, Ravault N, Magny JF, Dehan M. Development and initial validation of the EDIN scale, a new tool for assessing prolonged pain in preterm infants. Arch Dis Child Fetal Neonatal Ed. 2001 Jul;85(1):F36-41. 
del Rey A, Yau HJ, Randolf A, Centeno MV, Wildmann J, Martina M, Besedovsky HO, Apkarian AV. Chronic neuropathic pain-like behavior correlates with IL-1 $\beta$ expression and disrupts cytokine interactions in the hippocampus. Pain. 2011 Dec;152(12):2827-35.

Devlin JW, Roberts RJ. Pharmacology of commonly used analgesics and sedatives in the ICU: benzodiazepines, propofol, and opioids. Anesthesiol Clin. 2011 Dec;29(4):567-85.

Devlin JW, Roberts RJ. Pharmacology of commonly used analgesics and sedatives in the ICU: benzodiazepines, propofol, and opioids. Crit Care Clin. 2009 Jul;25(3):431-49, vii.

DeVon HA, Piano MR, Rosenfeld AG, Hoppensteadt DA. The association of pain with protein inflammatory biomarkers: a review of the literature. Nurs Res. 2014 Jan-Feb;63(1):5162.

Dührsen L, Simons SH, Dzietko M, Genz K, Bendix I, Boos V, Sifringer M, Tibboel D, Felderhoff-Mueser U. Effects of repetitive exposure to pain and morphine treatment on the neonatal rat brain. Neonatology. 2013;103(1):35-43.

Ebbinghaus M, Uhlig B, Richter F, von Banchet GS, Gajda M, Bräuer R, Schaible HG. The role of interleukin- $1 \beta$ in arthritic pain: main involvement in thermal, but not mechanical, hyperalgesia in rat antigen-induced arthritis. Arthritis Rheum. 2012 Dec;64(12):3897-907.

Efendi D, Rustina Y, Gayatri D. Pacifier and swaddling effective in impeding premature infant's pain score and heart rate. Enferm Clin. 2018 Feb;28 Suppl 1:46-50. English, Spanish.

Eriksson M, Campbell-Yeo M. Assessment of pain in newborn infants. Semin Fetal Neonatal Med. 2019 Aug;24(4):101003.

Erkut Z, Yildiz S. The Effect of Swaddling on Pain, Vital Signs, and Crying Duration during Heel Lance in Newborns. Pain Manag Nurs. 2017 Oct;18(5):328-336.

Farmer D, Sitkin N, Lofberg K, Donkor P, Ozgediz D. Surgical interventions for congenital anomalies. In Debas HT, Donkor P, Gawande A, Jamison DT, KrukME,Mock CN, editors. 
Essential Surgery:Disease Control Priorities. The International Bank for Reconstruction and Development. Washington, DC: TheWorld Bank 2015. p. 129-49.

Faye PM, De Jonckheere J, Logier R, Kuissi E, Jeanne M, Rakza T, Storme L. Newborn infant pain assessment using heart rate variability analysis. Clin J Pain. 2010 NovDec;26(9):777-82.

Ferguson SA, Ward WL, Paule MG, Hall RW, Anand KJ. A pilot study of preemptive morphine analgesia in preterm neonates: effects on head circumference, social behavior, and response latencies in early childhood. Neurotoxicol Teratol. 2012 Jan-Feb;34(1):47-55.

Field T. Preterm newborn pain research review. Infant Behav Dev. 2017 Nov;49:141-150. doi: 10.1016/j.infbeh.2017.09.002. Epub 2017 Sep 9.

Fitzgerald M, Beggs S. The neurobiology of pain: developmental aspects. Neuroscientist. 2001 Jun;7(3):246-57.

Fitzgerald M, Walker SM. Infant pain management: a developmental neurobiological approach. Nat Clin Pract Neurol. 2009 Jan;5(1):35-50.

Flaherman VJ, Schaefer EW, Kuzniewicz MW, Li SX, Walsh EM, Paul IM. Early weight loss nomograms for exclusively breastfed newborns. Pediatrics. 2015 Jan;135(1):e16-23.

Fogaça MC, Carvalho WB, Peres CA, Lora MI, Hayashi LF, Verreschi ITN. Cortisol salivar como indicador da função adrenocorticol em lactentes sadios com massagem terapêutica. Sao Paulo Med J. 2005; 123:215-18.

Foster J, Spence K, Henderson-Smart D, Harrison D, Gray PH, Bidewell J. Procedural pain in neonates in Australian hospitals: a survey update of practices. J Paediatr Child Health. 2013 Jan;49(1):E35-9.

França EB, Lansky S, Rego MAS, Malta DC, França JS, Teixeira R, Porto D, Almeida MF, Souza MFM, Szwarcwald CL, Mooney M, Naghavi M, Vasconcelos AMN. Leading causes 
of child mortality in Brazil, in 1990 and 2015: estimates from the Global Burden of Disease study. Rev Bras Epidemiol. 2017 May;20Suppl 01(Suppl 01):46-60.

Franck LS, Boyce WT, Gregory GA, Jemerin J, Levine J, Miaskowski C. Plasma norepinephrine levels, vagal tone index, and flexor reflex threshold in premature neonates receiving intravenous morphine during the postoperative period: a pilot study. Clin J Pain. 2000 Jun;16(2):95-104.

Franck LS. Some pain, some gain: reflections on the past two decades of neonatal pain research and treatment. Neonatal Netw. 2002 Aug;21(5):37-41.

Freitas, Patricia e Kimura, Amelia. Biomarcadores de estresse em recém-nascidos pré-termos expostos ao banho: estudo piloto. Online Brazilian Journal of Nursing. 2019;17. 12. $10.17665 / 1676-4285.20185920$.

Gadani SP, Cronk JC, Norris GT, Kipnis J. IL-4 in the brain: a cytokine to remember. J Immunol. 2012 Nov 1;189(9):4213-9.

Ganguly A, Bhadesia PJ, Phatak AG, Nimbalkar AS, Nimbalkar SM. Pain profile of premature infants during routine procedures in neonatal intensive care: An observational study. J Family Med Prim Care. 2020 Mar 26;9(3):1517-1521.

Giannakopoulou CE, Sotiriou A, Dettoraki M, Yang M, Perlikos F, Toumpanakis D, Prezerakos G, Koutsourelakis I, Kastis GA, Vassilakopoulou V, Mizi E, Papalois A, Greer JJ, Vassilakopoulos T. Regulation of breathing pattern by IL-10. Am J Physiol Regul Integr Comp Physiol. 2019 Jul 1;317(1):R190-R202.

Gibbins S, Stevens B, Asztalos E. Assessment and management of acute pain in high-risk neonates. Expert Opin Pharmacother. 2003 Apr;4(4):475-83.

Gibbins S, Stevens B, McGrath PJ, Yamada J, Beyene J, Breau L, Camfield C, Finley A, Franck L, Johnston C, Howlett A, McKeever P, O'Brien K, Ohlsson A. Comparison of pain responses in infants of different gestational ages. Neonatology. 2008;93(1):10-8. 
Giordano V, Edobor J, Deindl P, Wildner B, Goeral K, Steinbauer P, Werther T, Berger A, Olischar M. Pain and Sedation Scales for Neonatal and Pediatric Patients in a Preverbal Stage of Development: A Systematic Review. JAMA Pediatr. 2019 Oct 14.

Gitto E, Pellegrino S, Manfrida M, Aversa S, Trimarchi G, Barberi I, Reiter RJ. Stress response and procedural pain in the preterm newborn: the role of pharmacological and nonpharmacological treatments. Eur J Pediatr. 2012 Jun;171(6):927-33.

Goksan S, Hartley C, Emery F, Cockrill N, Poorun R, Moultrie F, Rogers R, Campbell J, Sanders M, Adams E, Clare S, Jenkinson M, Tracey I, Slater R. Correction: fMRI reveals neural activity overlap between adult and infant pain. Elife. 2015 May 28;4:e08663.

Gomes Neto M, da Silva Lopes IA, Araujo ACCLM, Oliveira LS, Saquetto MB. The effect of facilitated tucking position during painful procedure in pain management of preterm infants in neonatal intensive care unit: a systematic review and meta-analysis. Eur J Pediatr. 2020 May;179(5):699-709.

Gonçalves Dos Santos G, Delay L, Yaksh TL, Corr M. Neuraxial Cytokines in Pain States. Front Immunol. 2020 Jan 28;10:3061.

Grace PM, Hutchinson MR, Maier SF, Watkins LR. Pathological pain and the neuroimmune interface. Nat Rev Immunol. 2014 Apr;14(4):217-31.

Grunau RE, Haley DW, Whitfield MF, Weinberg J, Yu W, Thiessen P. Altered basal cortisol levels at 3, 6, 8 and 18 months in infants born at extremely low gestational age. J Pediatr. $2007 \mathrm{Feb} ; 150(2): 151-6$.

Grunau RE, Holsti L, Haley DW, Oberlander T, Weinberg J, Solimano A, Whitfield MF, Fitzgerald $\mathrm{C}, \mathrm{Yu}$ W. Neonatal procedural pain exposure predicts lower cortisol and behavioral reactivity in preterm infants in the NICU. Pain. 2005 Feb;113(3):293-300.

Grunau RE, Holsti L, Peters JW. Long-term consequences of pain in human neonates. Semin Fetal Neonatal Med. 2006 Aug;11(4):268-75. 
Grunau RE, Linhares MB, Holsti L, Oberlander TF, Whitfield MF. Does prone or supine position influence pain responses in preterm infants at 32 weeks gestational age? Clin $\mathrm{J}$ Pain. 2004 Mar-Apr;20(2):76-82.

Grunau RE, Oberlander TF, Whitfield MF, Fitzgerald C, Lee SK. Demographic and therapeutic determinants of pain reactivity in very low birth weight neonates at 32 Weeks' postconceptional Age. Pediatrics. 2001 Jan;107(1):105-12...

Grunau RE, Tu MT, Whitfield MF, Oberlander TF, Weinberg J, Yu W, Thiessen P, Gosse G, Scheifele D. Cortisol, behavior, and heart rate reactivity to immunization pain at 4 months corrected age in infants born very preterm. Clin J Pain. 2010 Oct;26(8):698-704.

Grunau RE. Neonatal pain in very preterm infants: long-term effects on brain, neurodevelopment and pain reactivity. Rambam Maimonides Med J. 2013;4(4):e0025. Published 2013 Oct 29.

Grunau RV, Craig KD. Pain expression in neonates: facial action and cry. Pain. 1987 Mar;28(3):395-410.

Habiyaremye G, Morales DM, Morgan CD, McAllister JP, CreveCoeur TS, Han RH, Gabir M, Baksh B, Mercer D, Limbrick DD Jr. Chemokine and cytokine levels in the lumbar cerebrospinal fluid of preterm infants with post-hemorrhagic hydrocephalus. Fluids Barriers CNS. 2017 Dec 12;14(1):35.

Hall RW, Shbarou RM. Drugs of choice for sedation and analgesia in the neonatal ICU. Clin Perinatol. 2009 Jun;36(2):215-26, vii.

Hall RW, Anand KJ. Pain management in newborns. Clin Perinatol. 2014 Dec;41(4):895-924. doi: 10.1016/j.clp.2014.08.010. Epub 2014 Oct 7.

Hamilton JL, Nagao M, Levine BR, Chen D, Olsen BR, Im HJ. Targeting VEGF and Its Receptors for the Treatment of Osteoarthritis and Associated Pain. J Bone Miner Res. 2016 May;31(5):911-24. 
Harrison D, Beggs S, Stevens B. Sucrose for procedural pain management in infants. Pediatrics. 2012 Nov;130(5):918-25.

Harrison D, Loughnan P, Johnston L. Pain assessment and procedural pain management practices in neonatal units in Australia. J Paediatr Child Health. 2006 Jan-Feb;42(1-2):6-9.

Harrison D, Reszel J, Bueno M, Sampson M, Shah VS, Taddio A, Larocque C, Turner L. Breastfeeding for procedural pain in infants beyond the neonatal period. Cochrane Database Syst Rev. 2016 Oct 28;10(10):CD011248.

Hartley C, Slater R. Neurophysiological measures of nociceptive brain activity in the newborn infant--the next steps. Acta Paediatr. 2014 Mar;103(3):238-42.

Hartley KA, Miller CS, Gephart SM. Facilitated tucking to reduce pain in neonates: evidence for best practice. Adv Neonatal Care. 2015 Jun;15(3):201-8.

Hatfield LA, Ely EA. Measurement of acute pain in infants: a review of behavioral and physiological variables. Biol Res Nurs. 2015 Jan;17(1):100-11.

Hatfield LA, Murphy N, Karp K, Polomano RC. A Systematic Review of Behavioral and Environmental Interventions for Procedural Pain Management in Preterm Infants. J Pediatr Nurs. 2019 Jan-Feb;44:22-30.

Hatfield LA. Neonatal pain: What's age got to do with it? Surg Neurol Int. 2014 Nov 13;5(Suppl 13):S479-89.

Heim C, Nemeroff CB. Neurobiology of early life stress: clinical studies. Semin Clin Neuropsychiatry. 2002 Apr;7(2):147-59.

Henderson YO, Victoria NC, Inoue K, Murphy AZ, Parent MB. Early life inflammatory pain induces long-lasting deficits in hippocampal-dependent spatial memory in male and female rats. Neurobiol Learn Mem. 2015 Feb;118:30-41. 
Hess A, Axmann R, Rech J, Finzel S, Heindl C, Kreitz S, Sergeeva M, Saake M, Garcia M, Kollias G, Straub RH, Sporns O, Doerfler A, Brune K, Schett G. Blockade of TNF- $\alpha$ rapidly inhibits pain responses in the central nervous system. Proc Natl Acad Sci U S A. 2011 Mar $1 ; 108(9): 3731-6$.

Ho LP, Ho SS, Leung DY, So WK, Chan CW. A feasibility and efficacy randomised controlled trial of swaddling for controlling procedural pain in preterm infants. J Clin Nurs. 2016 Feb;25(3-4):472-82.

Holsti L, Grunau RE. Extremity movements help occupational therapists identify stress responses in preterm infants in the neonatal intensive care unit: a systematic review. Can $\mathbf{J}$ Occup Ther. 2007 Jun;74(3):183-94.

Holsti L, Grunau RE. Considerations for using sucrose to reduce procedural pain in preterm infants. Pediatrics. 2010 May;125(5):1042-7.

Holsti L, Grunau RE, Shany E. Assessing pain in preterm infants in the neonatal intensive care unit: moving to a 'brain-oriented' approach. Pain Manag. 2011 Mar 1;1(2):171-179.

Hong JY, Lim KT. Effect of preemptive epidural analgesia on cytokine response and postoperative pain in laparoscopic radical hysterectomy for cervical cancer. Reg Anesth Pain Med. 2008 Jan-Feb;33(1):44-51.

Hsieh KH, Chen SJ, Tsao PC, Wang CC, Huang CF, Lin CM, Chou YL, Chen WY, Chan IC. The analgesic effect of non-pharmacological interventions to reduce procedural pain in preterm neonates. Pediatr Neonatol. 2018 Feb;59(1):71-76.

Hug L, Alexander M, You D, Alkema L; UN Inter-agency Group for Child Mortality Estimation. National, regional, and global levels and trends in neonatal mortality between 1990 and 2017, with scenario-based projections to 2030: a systematic analysis. Lancet Glob Health. 2019 Jun;7(6):e710-e720. 
Hulse RP, Beazley-Long N, Hua J, Kennedy H, Prager J, Bevan H, Qiu Y, Fernandes ES, Gammons MV, Ballmer-Hofer K, Gittenberger de Groot AC, Churchill AJ, Harper SJ, Brain SD, Bates DO, Donaldson LF. Regulation of alternative VEGF-A mRNA splicing is a therapeutic target for analgesia. Neurobiol Dis. 2014 Nov;71:245-59.

Hummel P, Puchalski M, Creech SD, Weiss MG. Clinical reliability and validity of the NPASS: neonatal pain, agitation and sedation scale with prolonged pain. J Perinatol. 2008 $\operatorname{Jan} ; 28(1): 55-60$.

Imamura M, Targino RA, Hsing WT, Imamura S, Azevedo RS, Boas LS, Tozetto-Mendoza TR, Alfieri FM, Filippo TR, Battistella LR. Concentration of cytokines in patients with osteoarthritis of the knee and fibromyalgia. Clin Interv Aging. 2014 Jun 12;9:939-44.

International Association for the Study of Pain (IASP), 2020.

Ismail AQ, Gandhi A. Non-pharmacological analgesia: effective but underused. Arch Dis Child. 2011 Aug;96(8):784-5.

Jaekel J, Eryigit-Madzwamuse S, Wolke D. Preterm Toddlers' Inhibitory Control Abilities Predict Attention Regulation and Academic Achievement at Age 8 Years. J Pediatr. 2016 Feb;169:87-92.e1.

Jenkins BN, Granger DA, Roemer RJ, Martinez A, Torres TK, Fortier MA. Emotion regulation and positive affect in the context of salivary alpha-amylase response to pain in children with cancer. Pediatr Blood Cancer. 2018 Jun;65(6):e26973.

Johnston C, Barrington KJ, Taddio A, Carbajal R, Filion F. Pain in Canadian NICUs: have we improved over the past 12 years? Clin J Pain. 2011 Mar-Apr;27(3):225-32.

Johnston C, Campbell-Yeo M, Disher T, Benoit B, Fernandes A, Streiner D, Inglis D, Zee R. Skin-to-skin care for procedural pain in neonates. Cochrane Database Syst Rev. 2017 Feb 16;2(2):CD008435. 
Johnston CC, Filion F, Snider L, Majnemer A, Limperopoulos C, Walker CD, Veilleux A, Pelausa E, Cake H, Stone S, Sherrard A, Boyer K. Routine sucrose analgesia during the first week of life in neonates younger than 31 weeks' postconceptional age. Pediatrics. 2002 Sep;110(3):523-8.

Jordão KR, Pinto LA, Machado LR, Costa LB, Trajano ET. Possible stressors in a neonatal intensive care unit at a university hospital. Rev Bras Ter Intensiva. 2016 Sep;28(3):310-314.

Keels E, Sethna NF, Committee on Fetus \& Newborn, Section on Anesthesiology \& Pain Medicine.. Prevention and management of procedural pain in the neonate: an update. Pediatrics 2016; 137: 1-13.

Kraychete DC, Siqueira JT, Garcia JB; Specialists Group. Recommendations for the use of opioids in Brazil: Part II. Use in children and the elderly. Rev Dor. 2014;15(1):65-9.

Krock E, Jurczak A, Svensson CI. Pain pathogenesis in rheumatoid arthritis-what have we learned from animal models? Pain. 2018 Sep;159 Suppl 1:S98-S109.

Krock E, Millecamps M, Anderson KM, Srivastava A, Reihsen TE, Hari P, Sun YR, Jang SH, Wilcox GL, Belani KG, Beebe DS, Ouellet J, Pinto MR, Kehl LJ, Haglund L, Stone LS. Interleukin-8 as a therapeutic target for chronic low back pain: Upregulation in human cerebrospinal fluid and pre-clinical validation with chronic reparixin in the SPARC-null mouse model. EBioMedicine. 2019 May;43:487-500.

Kugelman A, Colin AA. Late preterm infants: near term but still in a critical developmental time period. Pediatrics. 2013 Oct;132(4):741-51.

Kuner R. Central mechanisms of pathological pain. Nat Med. 2010 Nov;16(11):1258-66.

Kurtz DM, Tschetter LK, Allred JB, Geyer SM, Kurtin PJ, Putnam WD, Rowland KM Jr, Wiesenfeld M, Soori GS, Tenglin RC, Bernath AM, Witzig TE. Subcutaneous interleukin-4 (IL-4) for relapsed and resistant non-Hodgkin lymphoma: a phase II trial in the North Central Cancer Treatment Group, NCCTG 91-78-51. Leuk Lymphoma. 2007 Jul;48(7):1290-8. 
Kyololo OM, Stevens B, Gastaldo D, Gisore P. Procedural pain in neonatal units in Kenya. Arch Dis Child Fetal Neonatal Ed. 2014 Nov;99(6):F464-7.

Lages CDR, Sousa JCO, Cunha KJB, Silva NC, Santos TMMG. Fatores preditores para a admissão do recém-nascido na unidade de terapia intensiva. Rev Rene. 2014 jan-fev;15(1):311.

Lago P, Garetti E, Bellieni CV, Merazzi D, Savant Levet P, Ancora G, Pirelli A; Pain Study Group of the Italian Society of Neonatology. Systematic review of nonpharmacological analgesic interventions for common needle-related procedure in newborn infants and development of evidence-based clinical guidelines. Acta Paediatr. 2017 Jun;106(6):864-870.

Lago P, Garetti E, Merazzi D, Pieragostini L, Ancora G, Pirelli A, Bellieni CV; Pain Study Group of the Italian Society of Neonatology. Guidelines for procedural pain in the newborn. Acta Paediatr. 2009 Jun;98(6):932-9.

Lam HS, Ng PC. Biochemical markers of neonatal sepsis. Pathology. 2008 Feb;40(2):141-8.

le Roux CW, Sivakumaran S, Alaghband-Zadeh J, Dhillo W, Kong WM, Wheeler MJ. Free cortisol index as a surrogate marker for serum free cortisol. Ann Clin Biochem. 2002 Jul;39(Pt 4):406-8.

Leal YA, Álvarez-Nemegyei J, Lavadores-May AI, Girón-Carrillo JL, Cedillo-Rivera R, Velazquez JR. Cytokine profile as diagnostic and prognostic factor in neonatal sepsis. J Matern Fetal Neonatal Med. 2019 Sep;32(17):2830-2836.

Lee JH, Espinera AR, Chen D, Choi KE, Caslin AY, Won S, Pecoraro V, Xu GY, Wei L, Yu SP. Neonatal inflammatory pain and systemic inflammatory responses as possible environmental factors in the development of autism spectrum disorder of juvenile rats. $\mathrm{J}$ Neuroinflammation. 2016 May 16;13(1):109.

Lemos NR, Caetano EA, Marques SM, Moreira DS. Management of pain in the newborn: literature review. Rev Enferm UFPE. 2010; 4 (3Esp): 972-9. 
Leviton A, Allred EN, Fichorova RN, Kuban KC, Michael O'Shea T, Dammann O; ELGAN study investigators. Systemic inflammation on postnatal days 21 and 28 and indicators of brain dysfunction 2years later among children born before the 28th week of gestation. Early Hum Dev. 2016 Feb;93:25-32..

Lima SS, Silva SM, Avila PES, Nicolau MV, Neves PFM. Aspectos clínicos de recémnascidos admitidos em Unidade de Terapia Intensiva de hospital de referência da Região Norte do Brasil. ABCS Health Sci. 2015;40(2):62-8

Lin E, Calvano SE, Lowry SF. Inflammatory cytokines and cell response in surgery. Surgery. 2000 Feb;127(2):117-26. doi: 10.1067/msy.2000.101584.

Linsell L, Johnson S, Wolke D, O'Reilly H, Morris JK, Kurinczuk JJ, Marlow N. Cognitive trajectories from infancy to early adulthood following birth before 26 weeks of gestation: a prospective, population-based cohort study. Arch Dis Child. 2018 Apr;103(4):363-370.

Liu L, Oza S, Hogan D, Perin J, Rudan I, Lawn JE, Cousens S, Mathers C, Black RE. Global, regional, and national causes of child mortality in 2000-13, with projections to inform post2015 priorities: an updated systematic analysis. Lancet. 2015 Jan 31;385(9966):430-40.

Lucas-Thompson R, Townsend EL, Gunnar MR, Georgieff MK, Guiang SF, Ciffuentes RF, Lussky RC, Davis EP. Developmental changes in the responses of preterm infants to a painful stressor. Infant Behav Dev. 2008 Dec;31(4):614-23.

Llorián-Salvador M, González-Rodríguez S. Painful Understanding of VEGF. Front Pharmacol. 2018 Nov 6;9:1267.

Luo C, Kuner T, Kuner R. Synaptic plasticity in pathological pain. Trends Neurosci. 2014 Jun;37(6):343-55.

Lyon D, Cheng CY, Howland L, Rattican D, Jallo N, Pickler R, Brown L, McGrath J. Integrated review of cytokines in maternal, cord, and newborn blood: part I--associations with preterm birth. Biol Res Nurs. 2010 Apr;11(4):371-6. 
Maciel HIA, Costa MF, Costa ACL, Marcatto JO, Manzo BF, Bueno M. Pharmacological and nonpharmacological measures of pain management and treatment among neonates. Medidas farmacológicas e não farmacológicas de controle e tratamento da dor em recém-nascidos. Rev Bras Ter Intensiva. 2019;31(1):21-26.

Mainous RO, Looney S. A pilot study of changes in cerebral blood flow velocity, resistance, and vital signs following a painful stimulus in the premature infant. Adv Neonatal Care. 2007 Apr;7(2):88-104. doi: 10.1097/01.anc.0000267914.96844.ce. PMID: 17605449.

Mangat AK, Oei JL, Chen K, Quah-Smith I, Schmölzer GM. A Review of NonPharmacological Treatments for Pain Management in Newborn Infants. Children (Basel). 2018 Sep 20;5(10):130.

Marcatto, Juliana \& Barbosa, José \& Andrade, Marcus \& Machado, Camilla \& Soares da Cunha Castello Branco, Angela \& Viana, Luciana \& Vidigal, Pedro. Cytokines in preterm newborns using blood samples collected on filter paper: correlation with unfavorable clinical outcomes. Revista Médica de Minas Gerais. 2017. 27: [1-7], jan.-dez. 2017.

Martins CF, Fialho FA, Dias IV, Amaral JA, Freitas SC. Unidade de terapia intensiva neonatal: o papel da enfermagem na construção de um ambiente terapêutico. R Enferm Cent Oeste Min. 2011;1(2):268-76.

Matsuda M, Huh Y, Ji RR. Roles of inflammation, neurogenic inflammation, and neuroinflammation in pain. J Anesth. 2019;33(1):131-139.

Maxwell LG, Fraga MV, Malavolta CP. Assessment of Pain in the Newborn: An Update. Clin Perinatol. 2019 Dec;46(4):693-707.

Maxwell LG, Malavolta CP, Fraga MV. Assessment of pain in the neonate. Clin Perinatol. 2013 Sep;40(3):457-69.

McMahon SB, La Russa F, Bennett DL. Crosstalk between the nociceptive and immune systems in host defence and disease. Nat Rev Neurosci. 2015 Jul;16(7):389-402. 
McNamee KE, Alzabin S, Hughes JP, Anand P, Feldmann M, Williams RO, Inglis JJ. IL-17 induces hyperalgesia via TNF-dependent neutrophil infiltration. Pain. 2011 Aug;152(8):183845.

McPherson C, Grunau RE. Neonatal pain control and neurologic effects of anesthetics and sedatives in preterm infants. Clin Perinatol. 2014 Mar;41(1):209-27.

McPherson C, Miller SP, El-Dib M, Massaro AN, Inder TE. The influence of pain, agitation, and their management on the immature brain. Pediatr Res. 2020 Jan 2:1-8.

Meek J, Huertas A. Cochrane review: Non-nutritive sucking, kangaroo care and swaddling/facilitated tucking are observed to reduce procedural pain in infants and young children. Evid Based Nurs. 2012 Jul;15(3):84-5.

Meller S, Bhandari V. VEGF levels in humans and animal models with RDS and BPD: temporal relationships. Exp Lung Res. 2012 May;38(4):192-203.

Mendieta D, De la Cruz-Aguilera DL, Barrera-Villalpando MI, Becerril-Villanueva E, Arreola R, Hernández-Ferreira E, Pérez-Tapia SM, Pérez-Sánchez G, Garcés-Alvarez ME, Aguirre-Cruz L, Velasco-Velázquez MA, Pavón L. IL-8 and IL-6 primarily mediate the inflammatory response in fibromyalgia patients. J Neuroimmunol. 2016 Jan 15;290:22-5.

Mens LJJ, van de Sande MGH, Menegatti S, Chen S, Blijdorp ICJ, de Jong HM, Fluri IA, Latuhihin TE, van Kuijk AWR, Rogge L, Yeremenko NG, Baeten DLP. Brief Report: Interleukin-17 Blockade With Secukinumab in Peripheral Spondyloarthritis Impacts Synovial Immunopathology Without Compromising Systemic Immune Responses. Arthritis Rheumatol. 2018 Dec;70(12):1994-2002.

Miller JR, Flaherman VJ, Schaefer EW, Kuzniewicz MW, Li SX, Walsh EM, Paul IM. Early weight loss nomograms for formula fed newborns. Hosp Pediatr. 2015 May;5(5):263-8. 
Ministério da Saúde (BR), Secretaria de Ciência, Tecnologia e Insumos Estratégicos Comissão Nacional de Incorporação de Tecnologia do SUS. Diretrizes de Atenção à Gestante: a Operação Cesariana. Brasília, DF: Ministério da Saúde; 2018.

Mitchell AJ, Chang J, Yates C, Hall RW. Challenges, guidelines, and systemateic review of salivary cortisol research in preterm infants. EJ Neonatol Res [Internet] 2012;2:44-51.

Mitul AR, Sarin YK. Minimal Access Surgery in Neonates. J Neonatal Surg. 2017 Aug 10;6(3):59.

Moen GH, Moen A, Schistad EI, Gjerstad J. Local up-regulation of interferon- $\gamma$ (IFN- $\gamma$ ) following disc herniation is involved in the inflammatory response underlying acute lumbar radicular pain. Cytokine. 2017 Sep;97:181-186.

Moran CA, Cacho RO, Cacho EWA, Souza KG, Souza JC, Fonseca Filho GC, et al. Use of music during physical therapy intervention in a neonatal intensive care unit: a randomized controlled trial. Journal of Human Growth and Development, 2015; 25(2): 177-181

Morrow CJ, Field TM, Scafidi FA, Roberts J, Eisen L, Hogan AE, Bandstra ES. Transcutaneous oxygen tension in preterm neonates during neonatal behavioral assessments and heelsticks. J Dev Behav Pediatr. 1990 Dec;11(6):312-6.

Motta Gde C, Schardosim JM, Cunha ML. Neonatal Infant Pain Scale: Cross-Cultural Adaptation and Validation in Brazil. J Pain Symptom Manage. 2015 Sep;50(3):394-401.

Mwaniki MK, Atieno M, Lawn JE, Newton CR. Long-term neurodevelopmental outcomes after intrauterine and neonatal insults: a systematic review. Lancet. 2012 Feb $4 ; 379(9814): 445-52$.

Nicolau, Carla \& Modesto, Kiliana \& Nunes, Priscila \& Araújo, Karina \& Amaral, Heloisa \& Mario, Falcao. Avaliação da dor no recém-nascido prematuro: Parâmetros fisiológicos versus comportamentais. Arquivos Brasileiros de Ciências da Saúde. 200833. 10.7322/abcs.v33i3.149. 
Nist MD, Pickler RH. An Integrative Review of Cytokine/Chemokine Predictors of Neurodevelopment in Preterm Infants. Biol Res Nurs. 2019 Jul;21(4):366-376.

Nuseir KQ, Alzoubi KH, Alabwaini J, Khabour OF, Kassab MI. Sucrose-induced analgesia during early life modulates adulthood learning and memory formation. Physiol Behav. 2015 Jun 1;145:84-90.

Nuseir KQ, Alzoubi KH, Alhusban A, Bawaane A, Al-Azzani M, Khabour OF. Sucrose and naltrexone prevent increased pain sensitivity and impaired long-term memory induced by repetitive neonatal noxious stimulation: Role of BDNF and $\beta$-endorphin. Physiol Behav. 2017 Oct 1;179:213-219.

Occhi GM, de Lamare Franco Netto T, Neri MA, Rodrigues EAB, de Lourdes Vieira Fernandes A. Strategic measures to reduce the caesarean section rate in Brazil. Lancet. 2018 Oct 13;392(10155):1290-1291.

Okamura H, Kinoshita M, Saitsu H, Kanda H, Iwata S, Maeno Y, Matsuishi T, Iwata O. Noninvasive surrogate markers for plasma cortisol in newborn infants: utility of urine and saliva samples and caution for venipuncture blood samples. J Clin Endocrinol Metab. 2014 Oct;99(10):E2020-4.

Oliveira CB, Sakata RK, Issy AM, Gerola LR, Salomão R. Cytokines and pain. Rev Bras Anestesiol. 2011 Mar-Apr;61(2):255-9, 260-5, 137-42.

Oliveira CS, Casagrande GA, Grecco LC, Golin MO. Perfil de recém-nascidos pré-termo internados na unidade de terapia intensiva de hospital de alta complexidade. ABCS Health Sci. 2015;40(1):28-32.

Olsen A, Dennis EL, Evensen KAI, Husby Hollund IM, Løhaugen GCC, Thompson PM, Brubakk AM, Eikenes L, Håberg AK. Preterm birth leads to hyper-reactive cognitive control processing and poor white matter organization in adulthood. Neuroimage. 2018 Feb $15 ; 167: 419-428$. 
Orovec A, Disher T, Caddell K, Campbell-Yeo M. Assessment and Management of Procedural Pain During the Entire Neonatal Intensive Care Unit Hospitalization. Pain Manag Nurs. 2019 Oct;20(5):503-511.

Ozaktay AC, Kallakuri S, Takebayashi T, Cavanaugh JM, Asik I, DeLeo JA, Weinstein JN. Effects of interleukin-1 beta, interleukin-6, and tumor necrosis factor on sensitivity of dorsal root ganglion and peripheral receptive fields in rats. Eur Spine J. 2006 Oct;15(10):1529-37.

Ozawa M, Yokoo K. Pain management of neonatal intensive care units in Japan. Acta Paediatr. 2013 Apr;102(4):366-72. doi: 10.1111/apa.12160. Epub 2013 Jan 29.

Pandey M, Chauhan M, Awasthi S. Interplay of cytokines in preterm birth. Indian J Med Res. 2017 Sep;146(3):316-327.

Parkash A, Haider N, Khoso ZA, Shaikh AS. Frequency, causes and outcome of neonates with respiratory distress admitted to Neonatal Intensive Care Unit, National Institute of Child Health, Karachi. J Pak Med Assoc. 2015 Jul;65(7):771-5. PubMed PMID: 26160089.

Peña-Bautista C, Escrig R, Lara I, García-Blanco A, Cháfer-Pericás C, Vento M. Noninvasive monitoring of stress biomarkers in the newborn period. Semin Fetal Neonatal Med. 2019 Aug;24(4):101002.

Pernambuco AP, Schetino LP, Alvim CC, Murad CM, Viana RS, Carvalho LS, Reis DÁ. Increased levels of IL-17A in patients with fibromyalgia. Clin Exp Rheumatol. 2013 NovDec;31(6 Suppl 79):S60-3. Epub 2013 Sep 10.

Perroteau A, Nanquette MC, Rousseau A, Renolleau S, Bérard L, Mitanchez D, Leblanc J. Efficacy of facilitated tucking combined with non-nutritive sucking on very preterm infants' pain during the heel-stick procedure: A randomized controlled trial. Int J Nurs Stud. 2018 Oct;86:29-35.

Perry M, Tan Z, Chen J, Weidig T, Xu W, Cong XS. Neonatal Pain: Perceptions and Current Practice. Crit Care Nurs Clin North Am. 2018 Dec;30(4):549-561. 
Peterson BS, Vohr B, Staib LH, Cannistraci CJ, Dolberg A, Schneider KC, Katz KH, Westerveld M, Sparrow S, Anderson AW, Duncan CC, Makuch RW, Gore JC, Ment LR. Regional brain volume abnormalities and long-term cognitive outcome in preterm infants. JAMA. 2000 Oct 18;284(15):1939-47.

Pillai Riddell RR, Racine NM, Gennis HG, Turcotte K, Uman LS, Horton RE, Ahola Kohut S, Hillgrove Stuart J, Stevens B, Lisi DM. Non-pharmacological management of infant and young child procedural pain. Cochrane Database Syst Rev. 2015 Dec 2;2015(12):CD006275.

Pinho-Ribeiro FA, Verri WA Jr, Chiu IM. Nociceptor Sensory Neuron-Immune Interactions in Pain and Inflammation. Trends Immunol. 2017 Jan;38(1):5-19.

Pinto LG, Cunha TM, Vieira SM, Lemos HP, Verri WA Jr, Cunha FQ, Ferreira SH. IL-17 mediates articular hypernociception in antigen-induced arthritis in mice. Pain. 2010 Feb;148(2):247-56.

Platt MJ. Outcomes in preterm infants. Public Health. 2014 May;128(5):399-403.

Pölkki T, Korhonen A, Laukkala H. Nurses' perceptions of pain assessment and management practices in neonates: a cross-sectional survey. Scand J Caring Sci. 2018 Jun;32(2):725-733.

Prestes AC, Guinsburg R, Balda RC, Marba ST, Rugolo LM, Pachi PR, Bentlin MR. Freqüência do emprego de analgésicos em unidades de terapia intensiva neonatal universitárias [The frequency of pharmacological pain relief in university neonatal intensive care units]. J Pediatr (Rio J). 2005 Sep-Oct;81(5):405-10. Portuguese.

Qiu X, Zhang L, Tong Y, Qu Y, Wang H, Mu D. Interleukin-6 for early diagnosis of neonatal sepsis with premature rupture of the membranes: A meta-analysis. Medicine (Baltimore). 2018 Nov;97(47):e13146.

Raeburn CD, Sheppard F, Barsness KA, Arya J, Harken AH. Cytokines for surgeons. Am J Surg. 2002 Mar;183(3):268-73. 
Raeside L. Physiological measures of assessing infant pain: a literature review. Br J Nurs. 2011 Nov 24-Dec 7;20(21):1370-6.

Ramelet AS, Abu-Saad HH, Bulsara MK, Rees N, McDonald S. Capturing postoperative pain responses in critically ill infants aged 0 to 9 months. Pediatr Crit Care Med. 2006 Jan;7(1):1926

Ranger M, Grunau RE. Early repetitive pain in preterm infants in relation to the developing brain. Pain Manag. 2014 Jan;4(1):57-67.

Ranger M, Johnston CC, Anand KJ. Current controversies regarding pain assessment in neonates. Semin Perinatol. 2007 Oct;31(5):283-8.

Ranger M, Tremblay S, Chau CMY, Holsti L, Grunau RE, Goldowitz D. Adverse Behavioral Changes in Adult Mice Following Neonatal Repeated Exposure to Pain and Sucrose. Front Psychol. 2019 Jan 21;9:2394.

Ren K, Dubner R. Interactions between the immune and nervous systems in pain. Nat Med. 2010 Nov;16(11):1267-76.

Ren X, Li J, Zhou X, Luo X, Huang N, Wang Y, Chen X, Wei Y. Recombinant murine interleukin 4 protein therapy for psoriasis in a transgenic VEGF mouse model. Dermatology. 2009;219(3):232-8.

Ridgley LA, Anderson AE, Pratt AG. What are the dominant cytokines in early rheumatoid arthritis? Curr Opin Rheumatol. 2018 Mar;30(2):207-214.

Romagnoli C, Frezza S, Cingolani A, De Luca A, Puopolo M, De Carolis MP, Vento G, Antinori A, Tortorolo G. Plasma levels of interleukin-6 and interleukin-10 in preterm neonates evaluated for sepsis. Eur J Pediatr. 2001 Jun;160(6):345-50. 
Roué JM, Rioualen S, Gendras J, Misery L, Gouillou M, Sizun J. Multi-modal pain assessment: are near-infrared spectroscopy, skin conductance, salivary cortisol, physiologic parameters, and Neonatal Facial Coding System interrelated during venepuncture in healthy, term neonates? J Pain Res. 2018 Oct 11;11:2257-2267.

Sabzehei MK, Basiri B, Shokouhi M, Fayyazi A. Causes and Outcomes of Respiratory Distress in Neonates Hospitalized in NICU of Be'sat Hospital in Hamadan Province, Iran. Int J Pediatr 2017; 5(12): 6253-60.

Sachs D, Cunha FQ, Poole S, Ferreira SH. Tumour necrosis factor-alpha, interleukin-1beta and interleukin-8 induce persistent mechanical nociceptor hypersensitivity. Pain. 2002 Mar;96(1-2):89-97.

Sack U, Biereder B, Elouahidi T, Bauer K, Keller T, Tröbs RB. Diagnostic value of blood inflammatory markers for detection of acute appendicitis in children. BMC Surg. 2006 Nov 28;6:15.

Santos LM, Pereira MP, dos Santos LF, de Santana RC. Pain assessment in the premature newborn in Intensive Care Unit. Rev Bras Enferm. 2012 Jan-Feb;65(1):27-33.

Schafer CA, Schafer JJ, Yakob M, Lima P, Camargo P, Wong DT. Saliva diagnostics: utilizing oral fluids to determine health status. Monogr Oral Sci. 2014;24:88-98.

Schaible HG. Nociceptive neurons detect cytokines in arthritis. Arthritis Res Ther. 2014;16(5):470.

Schardosim JM, Rodrigues N LA, Rattner D. Parâmetros utilizados na avaliação do bem-estar do bebê no nascimento. Av Enferm. 2018: 36(2):197-208.

Schneider J, Duerden EG, Guo T, Ng K, Hagmann P, Bickle Graz M, Grunau RE, Chakravarty MM, Hüppi PS, Truttmann AC, Miller SP. Procedural pain and oral glucose in preterm neonates: brain development and sex-specific effects. Pain. 2018 Mar;159(3):515525. 
Schwaller F and Fitzgerald M. The consequences of pain in early life: injury-induced plasticity in developing pain pathways. Eur J Neurosci. 2014 Feb;39(3):344-52.

Seaton SE, Barker L, Draper ES, Abrams KR, Modi N, Manktelow BN; UK Neonatal Collaborative. Estimating neonatal length of stay for babies born very preterm. Arch Dis Child Fetal Neonatal Ed. 2019 Mar;104(2):F182-F186.

Serour F, Herman A, Babai I, Gorenstein A, Gershon N, Somekh E, Dalal I. Evaluation of a possible inflammatory response after appendectomy for non-perforated appendicitis in children. Eur J Pediatr Surg. 2010 Jan;20(1):29-34.

Sesso ML, Borges MC, Ferriani VP, Geraldo-Martins VR, Rodrigues DB, Nogueira RD. Prospective evaluation of cytokine in saliva of preterm and fullterm neonates. Immunobiology. 2014 Nov;219(11):830-5.

Shafiekhani M, Mirjalili M, Vazin A. Psychotropic drug therapy in patients in the intensive care unit - usage, adverse effects, and drug interactions: a review. Ther Clin Risk Manag. 2018 Sep 28;14:1799-1812.

Shah PS, Herbozo C, Aliwalas LL, Shah VS. Breastfeeding or breast milk for procedural pain in neonates. Cochrane Database Syst Rev. 2012 Dec 12;12:CD004950.

Shah VS, Ohlsson A. Venepuncture versus heel lance for blood sampling in term neonates. Cochrane Database Syst Rev. 2011 Oct 5;2011(10):CD001452.

Shao Q, Li Y, Wang Q, Zhao J. IL-10 and IL-1 $\beta$ mediate neuropathic-pain like behavior in the ventrolateral orbital cortex. Neurochem Res. 2015 Apr;40(4):733-9.

Silveira RC, Fortes Filho JB, Procianoy RS. Assessment of the contribution of cytokine plasma levels to detect retinopathy of prematurity in very low birth weight infants. Invest Ophthalmol Vis Sci. 2011 Mar 10;52(3):1297-301. 
Simons SH, van Dijk M, Anand KS, Roofthooft D, van Lingen RA, Tibboel D. Do we still hurt newborn babies? A prospective study of procedural pain and analgesia in neonates. Arch Pediatr Adolesc Med. 2003 Nov;157(11):1058-64.

Slater R, Cantarella A, Gallella S, Worley A, Boyd S, Meek J, Fitzgerald M. Cortical pain responses in human infants. J Neurosci. 2006 Apr 5;26(14):3662-6.

Slater R, Cantarella A, Yoxen J, Patten D, Potts H, Meek J, Fitzgerald M. Latency to facial expression change following noxious stimulation in infants is dependent on postmenstrual age. Pain. 2009 Nov;146(1-2):177-82.

Slater R, Cornelissen L, Fabrizi L, Patten D, Yoxen J, Worley A, Boyd S, Meek J, Fitzgerald M. Oral sucrose as an analgesic drug for procedural pain in newborn infants: a randomised controlled trial. Lancet. 2010 Oct 9;376(9748):1225-32..

Soares ACO, Caminha MFC, Coutinho ACFP, Ventura CMU. Dor na Unidade Neonatal: conhecimento, atitude e prática da equipe de enfermagem. Cogitare Enferm. [Internet]. 2016 [Acesso 8 mar 2017];21(2). Disponível em: http://revistas.ufpr.br/cogitare/article/ view/42897/28163

Sommer C and White F. Cytokines, Chemokines, and Pain, em: Beaulieu P, Lussier D, Porreca F et al. - Pharmacology of Pain. 1st Ed, Seattle, IASP Press.2010; 279-302.

Spittle A, Treyvaud K. The role of early developmental intervention to influence neurobehavioral outcomes of children born preterm. Semin Perinatol. 2016 Dec;40(8):542548.

Sposito NPB, Rossato LM, Bueno M, Kimura AF, Costa T, Guedes DMB. Assessment and management of pain in newborns hospitalized in a Neonatal Intensive Care Unit: a crosssectional study. Rev Lat Am Enfermagem. 2017 Sep 12;25:e2931.

Stevens B, Johnston C, Petryshen P, Taddio A. Premature Infant Pain Profile: development and initial validation. Clin J Pain. 1996 Mar;12(1):13-22. 
Stevens B, McGrath P, Gibbins S, Beyene J, Breau L, Camfield C, Finley A, Franck L, Howlett A, Johnston C, McKeever P, O'Brien K, Ohlsson A, Yamada J. Determining behavioural and physiological responses to pain in infants at risk for neurological impairment. Pain. 2007 Jan;127(1-2):94-102.

Stevens B, Yamada J, Lee GY, Ohlsson A. Sucrose for analgesia in newborn infants undergoing painful procedures. Cochrane Database Syst Rev. 2013 Jan 31;(1):CD001069.

Stevens B, Yamada J, Ohlsson A, Haliburton S, Shorkey A. Sucrose for analgesia in newborn infants undergoing painful procedures. Cochrane Database Syst Rev. 2016 Jul 16;7(7):CD001069.

Stevens B, Yamada J, Ohlsson A. Sucrose for analgesia in newborn infants undergoing painful procedures. Cochrane Database Syst Rev. 2010 Jan 20;(1):CD001069.

Stevens BJ, Abbott LK, Yamada J, Harrison D, Stinson J, Taddio A, Barwick M, Latimer M, Scott SD, Rashotte J, Campbell F, Finley GA; CIHR Team in Children's Pain. Epidemiology and management of painful procedures in children in Canadian hospitals. CMAJ. 2011 Apr 19;183(7):E403-10.

Stevens B, Gibbins S, Franck LS. Treatment of pain in the neonatal intensive care unit. Pediatr Clin North Am. 2000 Jun;47(3):633-50.

Taddio A, Shah V, Gilbert-MacLeod C, Katz J. Conditioning and hyperalgesia in newborns exposed to repeated heel lances. JAMA. 2002 Aug 21;288(7):857-61.

Taddio A, Goldbach M, Ipp M, Stevens B, Koren G. Effect of neonatal circumcision on pain responses during vaccination in boys. Lancet. 1995 Feb 4;345(8945):291-2.

Taddio A, Katz J. The effects of early pain experience in neonates on pain responses in infancy and childhood. Paediatr Drugs. 2005;7(4):245-57. 
Takano S, Uchida K, Inoue G, Matsumoto T, Aikawa J, Iwase D, Mukai M, Miyagi M, Takaso M. Vascular endothelial growth factor expression and their action in the synovial membranes of patients with painful knee osteoarthritis. BMC Musculoskelet Disord. 2018 Jun 26;19(1):204.

Teodorczyk-Injeyan JA, Triano JJ, Injeyan HS. Nonspecific Low Back Pain: Inflammatory Profiles of Patients With Acute and Chronic Pain. Clin J Pain. 2019 Oct;35(10):818-825.

Totsch SK, Sorge RE. Immune System Involvement in Specific Pain Conditions. Mol Pain. 2017 Jan-Dec;13:1744806917724559.

Uçeyler N, Valenza R, Stock M, Schedel R, Sprotte G, Sommer C. Reduced levels of antiinflammatory cytokines in patients with chronic widespread pain. Arthritis Rheum. 2006 Aug;54(8):2656-64.

Valeri BO, Holsti L, Linhares MB. Neonatal pain and developmental outcomes in children born preterm: a systematic review. Clin J Pain. 2015 Apr;31(4):355-62.

Vanderwall AG, Milligan ED. Cytokines in Pain: Harnessing Endogenous Anti-Inflammatory Signaling for Improved Pain Management. Front Immunol. 2019 Dec 23;10:3009

Veronez M, Correa, DAM. A dor e o recém-nascido de risco: percepção dos profissionais de enfermagem. Cogitare Enferm 2010;15(2):263-70.

Verri WA Jr, Cunha TM, Parada CA, Poole S, Cunha FQ, Ferreira SH. Hypernociceptive role of cytokines and chemokines: targets for analgesic drug development? Pharmacol Ther. 2006 Oct;112(1):116-38.

Verri WA Jr, Cunha TM, Parada CA, Poole S, Liew FY, Ferreira SH, Cunha FQ. Antigeninduced inflammatory mechanical hypernociception in mice is mediated by IL-18. Brain Behav Immun. 2007 Jul;21(5):535-43. 
Victoria NC, Murphy AZ. Exposure to Early Life Pain: Long Term Consequences and Contributing Mechanisms. Curr Opin Behav Sci. 2016 Feb;7:61-68.

Vignali DA. Multiplexed particle-based flow cytometric assays. J Immunol Methods. 2000 Sep 21;243(1-2):243-55.

Vinall J, Miller SP, Chau V, Brummelte S, Synnes AR, Grunau RE. Neonatal pain in relation to postnatal growth in infants born very preterm. Pain. $2012 \mathrm{Jul}$;153(7):1374-81.

Vining RF, McGinley RA, Maksvytis JJ, Ho KY. Salivary cortisol: a better measure of adrenal cortical function than serum cortisol. Ann Clin Biochem. 1983 Nov;20 (Pt 6):329-35.

Walden M, Gibbins S. Pain assessment and management: guideline for practice. 2nd edition. Glenview (IL): National Association of Neonatal Nurses 2008; p. 1-29.

Walker SM, Melbourne A, O'Reilly H, Beckmann J, Eaton-Rosen Z, Ourselin S, Marlow N. Somatosensory function and pain in extremely preterm young adults from the UK EPICure cohort: sex-dependent differences and impact of neonatal surgery. Br J Anaesth. 2018 Sep;121(3):623-635.

Walker SM. Biological and neurodevelopmental implications of neonatal pain. Clin Perinatol. 2013 Sep;40(3):471-91.

Walker SM. Translational studies identify long-term impact of prior neonatal pain experience. Pain. 2017 Apr;158 Suppl 1:S29-S42.

Wallace DJ. Is there a role for cytokine based therapies in fibromyalgia. Curr Pharm Des. 2006;12(1):17-22.

Wang K, Bao JP, Yang S, Hong X, Liu L, Xie XH, Wu XT. A cohort study comparing the serum levels of pro- or anti-inflammatory cytokines in patients with lumbar radicular pain and healthy subjects. Eur Spine J. 2016 May;25(5):1428-1434. 
Watkins LR, Maier SF. Beyond neurons: evidence that immune and glial cells contribute to pathological pain states. Physiol Rev. 2002 Oct;82(4):981-1011.

Wei SQ, Fraser W, Luo ZC. Inflammatory cytokines and spontaneous preterm birth in asymptomatic women: a systematic review. Obstet Gynecol. 2010 Aug;116(2 Pt 1):393-401.

Wigerblad G, Bas DB, Fernades-Cerqueira C, Krishnamurthy A, Nandakumar KS, Rogoz K, Kato J, Sandor K, Su J, Jimenez-Andrade JM, Finn A, Bersellini Farinotti A, Amara K, Lundberg K, Holmdahl R, Jakobsson PJ, Malmström V, Catrina AI, Klareskog L, Svensson CI. Autoantibodies to citrullinated proteins induce joint pain independent of inflammation via a chemokine-dependent mechanism. Ann Rheum Dis. 2016 Apr;75(4):730-8.

Williams MD, Lascelles BDX. Early Neonatal Pain-A Review of Clinical and Experimental Implications on Painful Conditions Later in Life. Front Pediatr. 2020 Feb 7;8:30.

Wittwer A, Krummenacher P, La Marca R, Ehlert U, Folkers G. Salivary Alpha-Amylase Correlates with Subjective Heat Pain Perception. Pain Med. 2016 Jun;17(6):1131-6.

Wolf G, Livshits D, Beilin B, Yirmiya R, Shavit Y. Interleukin-1 signaling is required for induction and maintenance of postoperative incisional pain: genetic and pharmacological studies in mice. Brain Behav Immun. 2008 Oct;22(7):1072-7.

Wuyts AP, P; Damme, JV. Interleukin-8 and other CXC chemokines. In: Thomson AW, editor. The cytokine handbook. San Diego, Ca: Academic Press. 1998; p. 271-311.

Yung-Weng W, Ying-Ju C. A preliminary study of bottom care effects on premature infants' heart rate and oxygen saturation. J Nurs Res. 2004 Jun;12(2):161-8.

Zhang JH, Huang YG. The immune system: a new look at pain. Chin Med J (Engl). 2006 Jun 5;119(11):930-8. PMID: 16780773.

Zhang JM, An J. Cytokines, inflammation, and pain. Int Anesthesiol Clin. 2007 Spring;45(2):27-37. 
Zhou YQ, Liu Z, Liu ZH, Chen SP, Li M, Shahveranov A, Ye DW, Tian YK. Interleukin-6: an emerging regulator of pathological pain. J Neuroinflammation. 2016 Jun 7;13(1):141.

Zou B., Pan H., Zhang X.J., Yin Z. S. Serum levels of the inflammatory cytokines in patients with radicular pain due to disc herniation. Asian Spine Journal. 2016; 10(5):843-849.

Zwicker JG, Grunau RE, Adams E, Chau V, Brant R, Poskitt KJ, Synnes A, Miller SP. Score for neonatal acute physiology-II and neonatal pain predict corticospinal tract development in premature newborns. Pediatr Neurol. 2013 Feb;48(2):123-129.e1. 


\section{APÊNCIDE A - TERMO DE CONSENTIMENTO LIVRE E ESCLARECIDO TERMO DE CONSENTIMENTO LIVRE E ESCLARECIDO}

ESTUDO: Avaliação da dor em recém-nascidos hospitalizados em unidade de terapia intensiva: aspectos fisiológicos, endócrinos e comportamentais.

Estamos realizando um estudo com objetivo de investigar se há correlação entre as variáveis bioquímicas, fisiológicas, hormonais e escores de dor em recém-nascidos (RNs) admitidos na Unidade de Terapia Intensiva Neonatal (UTIN) de forma a contribuir para a compreensão, avaliação e manejo da dor neonatal.

O documento abaixo contém todas as informações necessárias sobre a pesquisa que estamos (ou estaremos) fazendo. Leia atentamente. Caso tenha dúvidas, teremos prazer em esclarecê-las. Se concordar, o documento será assinado e só então daremos início ao estudo. Este documento está em duas vias, uma delas é sua e a outra é do pesquisador responsável. Sua colaboração será muito importante para nós. Mas, se quiser desistir a qualquer momento, isto não causará nenhum prejuízo, nem a você, nem ao (à) seu (sua) filho(a).

$\mathrm{Eu}$.

RG.

Sexo:

$\mathrm{DN}$ :

Parentesco:

Telefone:

Endereço:

abaixo assinado (a), concordo de livre e espontânea vontade que meu (minha) filho (a)

nascido (a) em , seja voluntário do estudo "Avaliação da dor em recém-nascidos hospitalizados em unidade de terapia intensiva: aspectos fisiológicos, endócrinos e comportamentais". Declaro que obtive todas as informações necessárias e que todas as minhas dúvidas foram esclarecidas.

Estou ciente de que:

I) Neste estudo será investigado a possível correlação entre as variáveis bioquímicas, fisiológicas, hormonais e escores de dor em recém-nascidos (RNs) nos primeiros cinco dias de internação na Unidade de Terapia Intensiva Neonatal.

II) Os RNs serão caracterizados de acordo com os dados obtidos do prontuário: sexo, idade gestacional, peso de nascimento, escore de Apgar no $1^{\circ}$ e $5^{\circ}$ minutos de vida, diagnóstico clínico inicial, tipo de parto e medicamentos em uso. Os dados referentes aos valores da freqüência cardíaca (FC), da saturação do oxigênio no sangue ( $\mathrm{SpO} 2)$ e dos escores de dor serão obtidos dos registros do prontuário de cada RN. Os procedimentos realizados com os RNs serão registrados ao longo de três dias num instrumento previamente desenvolvido. Finalmente, serão 
realizadas coletas de saliva obtidas de forma não invasiva diretamente da boca em intervalos de 8 horas $(8: 00 \mathrm{~h} ; 16: 00 \mathrm{~h}$ e $24: 00 \mathrm{~h})$ num período de 24 horas por três dias consecutivos (1-3) após admissão na UTI Neonatal totalizando nove amostras. As coletas serão feitas por profissional devidamente treinado para tal, com técnica correta, toda a segurança e cuidados necessários. As amostras de saliva serão armazenadas e analisadas no Departamento de Fisiologia do Instituto de Biociências da Universidade de São Paulo. Todos os procedimentos foram previamente aprovados pelos comitês de ética em experimentação em humanos da Escola de Enfermagem da Universidade de São Paulo e do Hospital Universitário da Universidade de São Paulo/SP.

III) A coleta de saliva é um procedimento de risco mínimo que, contudo, pode causar um desconforto leve como agitação ou incômodo. Desta forma, cuidados devem ser empregados para minimizar esses riscos, desconfortos e condições adversas que possam causar danos. Entretanto, na eventualidade de ocorrência de qualquer dano à saúde ou intercorrência com seu filho em decorrência da pesquisa, este tem à sua disposição toda assistência passível de ser oferecida pelo HU/USP e, em casos de maior complexidade, será encaminhado ao SUS.

IV) Este estudo será realizado durante os cinco primeiros dias de permanência de meu (minha) filho (a) na UTIN (Unidade de Terapia Intensiva Neonatal) do Hospital Universitário da Universidade de São Paulo/SP . A participação neste estudo não interfere no tratamento e será sem custo algum para mim;

V) Tenho a liberdade de desistir ou interromper a colaboração neste estudo no momento em que desejar, sem necessidade de dar qualquer explicação;

VI) A desistência não causará nenhum prejuízo a mim, nem (a) meu (minha) filho (a), nem interferirá no atendimento ou tratamento médico a que ele (ela) estiver sendo submetido;

VII) Os resultados obtidos durante este estudo serão mantidos em sigilo, mas concordo em que sejam divulgados em publicações científicas, desde que nem o meu nome, nem o de meu filho sejam mencionados;

VIII) Os resultados deste estudo não trarão qualquer benefício imediato para o paciente ou para a família, mas poderão contribuir para o avanço no conhecimento e na divulgação sobre informações referentes à dor neonatal;

IX) Caso eu deseje, poderei tomar conhecimento dos resultados ao final deste estudo;

$\mathrm{X}) \quad \mathrm{O}$ sujeito de pesquisa ou seu representante, quando for o caso, deverá rubricar todas as folhas do Termo de Consentimento Livre e Esclarecido - TCLE - apondo sua assinatura na última página do referido Termo.

$\mathrm{XI} \quad \mathrm{O}$ pesquisador responsável deverá, da mesma forma, rubricar todas as folhas do Termo de Consentimento Livre e Esclarecido - TCLE- apondo sua assinatura na última página do referido Termo. 
XII) Não haverá nenhuma despesa pessoal para o participante em qualquer fase do estudo. Também não haverá pagamento por participação nesta pesquisa. Há garantia de indenização diante de eventuais danos decorrentes diretamente da pesquisa.

XIII) Esta pesquisa atende todas as especificações da Resolução 466, de 12 de dezembro de 2012 que aprova as diretrizes e normas regulamentadoras de pesquisas envolvendo seres humanos - Estou recebendo uma cópia deste Termo de Consentimento Livre e Esclarecido;

OBS: Assinalar abaixo com (x):

( ) Desejo conhecer os resultados desta pesquisa.

( ) Não desejo conhecer os resultados desta pesquisa.

"Declaro que, após convenientemente esclarecido pelo pesquisador e ter entendido o que me foi explicado, consinto em participar do presente Projeto de Pesquisa".

São Paulo, de. de $20 \ldots . . .$.

Responsável legal

"Declaro que obtive de forma apropriada e voluntária o Consentimento Livre e Esclarecido para a participação neste estudo".

\footnotetext{
Vanderlei Amadeu da Rocha

Enfermeiro - COREN-SP 184224

Responsável pelo Projeto
}

\section{Contatos:}

Escola de Enfermagem da Universidade de São Paulo - EEUSP

Departamento de Enfermagem Materno-Infantil e Psiquiátrica

Responsável pelo projeto: Vanderlei Amadeu da Rocha

E-mail: vanrocha@usp.br (11-99675-9521)

Endereço: Av. Dr. Enéas de Carvalho Aguiar, n 419 - Cerqueira Cesar - CEP: 05403-000- São Paulo - SP - Telefone: (11) 3061-7602

Comissão de Ética em Pesquisa da Escola de Enfermagem da Universidade de São Paulo EEUSP

Endereço: Av. Dr. Enéas de Carvalho Aguiar, 419 - Cerqueira Cesar - CEP: 05403-000 - São Paulo - SP - Telefone: 3061-8858 - E-mail: cepee@usp.br

Comissão de Ética em Pesquisa do Hospital Universitário - USP

Endereço: Av. Prof. Lineu Prestes, 2565 - Cidade Universitária - CEP: 05508-000 São Paulo -SP - Telefone: 3091-9457 - Fax: 3091-9452 - E-mail: cep@hu.usp.br

* Caso o participante (responsável legal) não tenha condições de ler o documento, o mesmo será lido pelo pesquisador na presença de uma testemunha 


\section{APÊNCIDE B - TERMO DE ASSENTIMENTO LIVRE E ESCLARECIDO TERMO DE ASSENTIMENTO LIVRE E ESCLARECIDO}

ESTUDO: Avaliação da dor em recém-nascidos hospitalizados em unidade de terapia intensiva: aspectos fisiológicos, endócrinos e comportamentais.

Estamos realizando um estudo com objetivo de investigar se há correlação entre as variáveis bioquímicas, físiológicas, hormonais e escores de dor em recém-nascidos (RNs) admitidos na Unidade de Terapia Intensiva Neonatal (UTIN) de forma a contribuir para a compreensão, avaliação e manejo da dor neonatal.

O documento abaixo contém todas as informações necessárias sobre a pesquisa que estamos (ou estaremos) fazendo. Leia atentamente. Caso tenha dúvidas, teremos prazer em esclarecê-las. Se concordar, o documento será assinado e só então daremos início ao estudo. Este documento está em duas vias, uma delas é sua e a outra é do pesquisador responsável. Sua colaboração será muito importante para nós. Mas, se quiser desistir a qualquer momento, isto não causará nenhum prejuízo, nem a você, nem ao (à) seu (sua) filho(a).

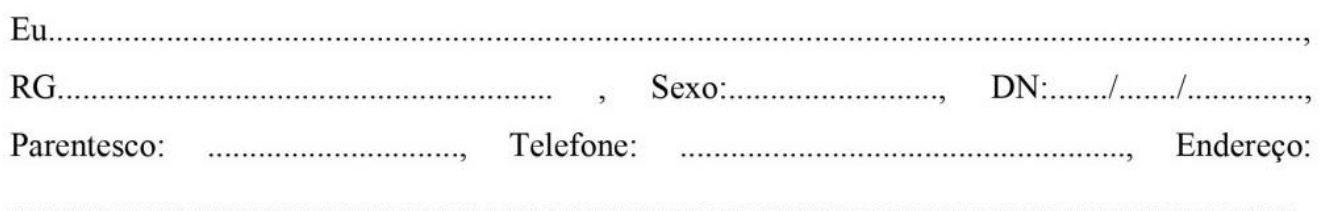

abaixo assinado (a), concordo de livre e espontânea vontade que meu (minha) filho (a)

nascido (a) em ___ _ _ _ _ _ seja voluntário do estudo "Avaliação da dor em recém-nascidos hospitalizados em unidade de terapia intensiva: aspectos fisiológicos, endócrinos e comportamentais". Declaro que obtive todas as informações necessárias e que todas as minhas dúvidas foram esclarecidas.

Estou ciente de que:

I) Neste estudo será investigado a possível correlação entre as variáveis bioquímicas, fisiológicas, hormonais e escores de dor em recém-nascidos (RNs) nos primeiros cinco dias de internação na Unidade de Terapia Intensiva Neonatal.

II) Os RNs serão caracterizados de acordo com os dados obtidos do prontuário: sexo, idade gestacional, peso de nascimento, escore de Apgar no $1^{\circ}$ e $5^{\circ}$ minutos de vida, diagnóstico clínico inicial, tipo de parto e medicamentos em uso. Os dados referentes aos valores da freqüência cardíaca (FC), da saturação do oxigênio no sangue $(\mathrm{SpO} 2)$ e dos escores de dor serão obtidos dos registros do prontuário de cada $\mathrm{RN}$. Os procedimentos realizados com os RNs serão registrados ao longo de três dias num instrumento previamente desenvolvido. Finalmente, serão 
realizadas coletas de saliva obtidas de forma não invasiva diretamente da boca em intervalos de 8 horas $(8: 00 \mathrm{~h} ; 16: 00 \mathrm{~h}$ e 24:00h) num período de 24 horas por três dias consecutivos (1-3) após admissão na UTI Neonatal totalizando nove amostras. As coletas serão feitas por profissional devidamente treinado para tal, com técnica correta, toda a segurança e cuidados necessários. As amostras de saliva serão armazenadas e analisadas no Departamento de Fisiologia do Instituto de Biociências da Universidade de São Paulo. Todos os procedimentos foram previamente aprovados pelos comitês de ética em experimentação em humanos da Escola de Enfermagem da Universidade de São Paulo e do Hospital Universitário da Universidade de São Paulo/SP.

III) A coleta de saliva é um procedimento de risco mínimo que, contudo, pode causar um desconforto leve como agitação ou incômodo. Desta forma, cuidados devem ser empregados para minimizar esses riscos, desconfortos e condições adversas que possam causar danos. Entretanto, na eventualidade de ocorrência de qualquer dano à saúde ou intercorrência com seu filho em decorrência da pesquisa, este tem à sua disposição toda assistência passível de ser oferecida pelo HU/USP e, em casos de maior complexidade, será encaminhado ao SUS.

IV) Este estudo será realizado durante os cinco primeiros dias de permanência de meu (minha) filho (a) na UTIN (Unidade de Terapia Intensiva Neonatal) do Hospital Universitário da Universidade de São Paulo/SP . A participação neste estudo não interfere no tratamento e será sem custo algum para mim;

V) Tenho a liberdade de desistir ou interromper a colaboração neste estudo no momento em que desejar, sem necessidade de dar qualquer explicação;

VI) A desistência não causará nenhum prejuízo a mim, nem (a) meu (minha) filho (a), nem interferirá no atendimento ou tratamento médico a que ele (ela) estiver sendo submetido;

VII) Os resultados obtidos durante este estudo serão mantidos em sigilo, mas concordo em que sejam divulgados em publicações científicas, desde que nem o meu nome, nem o de meu filho sejam mencionados;

VIII) Os resultados deste estudo não trarão qualquer benefício imediato para o paciente ou para a família, mas poderão contribuir para o avanço no conhecimento e na divulgação sobre informações referentes à dor neonatal;

IX) Caso eu deseje, poderei tomar conhecimento dos resultados ao final deste estudo;

X) O sujeito de pesquisa ou seu representante, quando for o caso, deverá rubricar todas as folhas do Termo de Consentimento Livre e Esclarecido - TCLE - apondo sua assinatura na última página do referido Termo.

XI) O pesquisador responsável deverá, da mesma forma, rubricar todas as folhas do Termo de Consentimento Livre e Esclarecido - TCLE- apondo sua assinatura na última página do referido Termo. 
XII) Não haverá nenhuma despesa pessoal para o participante em qualquer fase do estudo. Também não haverá pagamento por participação nesta pesquisa. Há garantia de indenização diante de eventuais danos decorrentes diretamente da pesquisa.

XIII) Esta pesquisa atende todas as especificações da Resolução 466, de 12 de dezembro de 2012 que aprova as diretrizes e normas regulamentadoras de pesquisas envolvendo seres humanos - Estou recebendo uma cópia deste Termo de Consentimento Livre e Esclarecido;

OBS: Assinalar abaixo com (x):

( ) Desejo conhecer os resultados desta pesquisa.

( ) Não desejo conhecer os resultados desta pesquisa.

"Declaro que, após convenientemente esclarecido pelo pesquisador e ter entendido o que me foi explicado, consinto em participar do presente Projeto de Pesquisa".

São Paulo, de. de $20 \ldots . . .$.

Responsável legal

"Declaro que obtive de forma apropriada e voluntária o Consentimento Livre e Esclarecido para a participação neste estudo".

\footnotetext{
Vanderlei Amadeu da Rocha

Enfermeiro - COREN-SP 184224

Responsável pelo Projeto
}

\section{Contatos:}

Escola de Enfermagem da Universidade de São Paulo - EEUSP

Departamento de Enfermagem Materno-Infantil e Psiquiátrica

Responsável pelo projeto: Vanderlei Amadeu da Rocha

E-mail: vanrocha@usp.br (11-99675-9521)

Endereço: Av. Dr. Enéas de Carvalho Aguiar, nº 419 - Cerqueira Cesar - CEP: 05403-000- São Paulo - SP - Telefone: (11) 3061-7602

Comissão de Ética em Pesquisa da Escola de Enfermagem da Universidade de São Paulo EEUSP

Endereço: Av. Dr. Enéas de Carvalho Aguiar, 419 - Cerqueira Cesar - CEP: 05403-000 - São Paulo - SP - Telefone: 3061-8858 - E-mail: cepee@usp.br

Comissão de Ética em Pesquisa do Hospital Universitário - USP

Endereço: Av. Prof. Lineu Prestes, 2565 - Cidade Universitária - CEP: 05508-000 São Paulo - SP - Telefone: 3091-9457 - Fax: 3091-9452 - E-mail: cep@hu.usp.br

* Caso o participante (responsável legal) não tenha condições de ler o documento, o mesmo será lido pelo pesquisador na presença de uma testemunha 
APÊNCIDE C - INSTRUMENTO DE COLETA DE DADOS - PROCEDIMENTOS DOLOROSOS E ANALGESIA

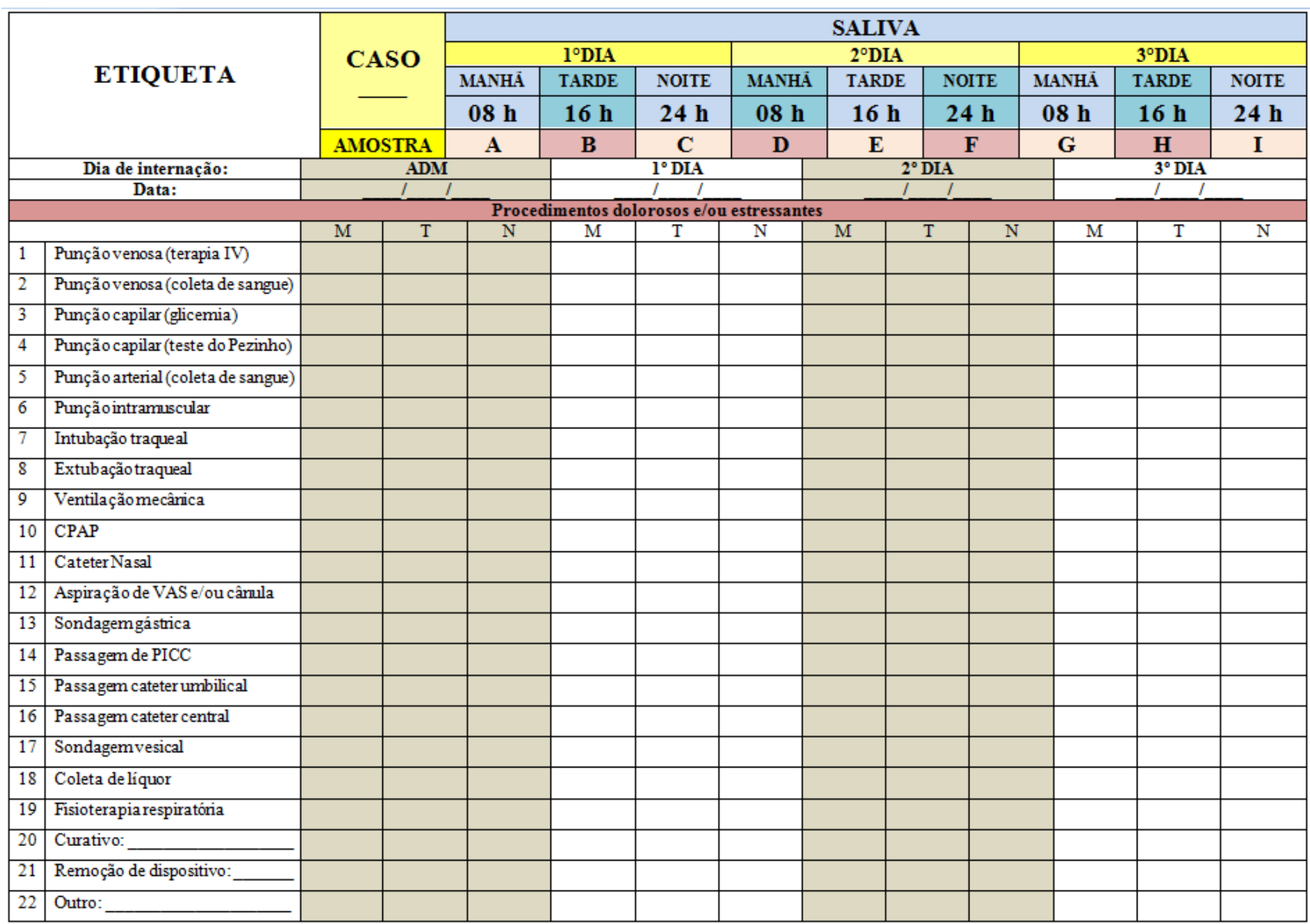




\begin{tabular}{|c|c|c|c|c|c|c|c|c|c|c|c|c|}
\hline Dia de internação: & & ADM & & & $1^{\circ} \mathrm{DL}$ & & & $2^{\circ} \mathrm{DIA}$ & & & $3^{\circ} \mathrm{DIA}$ & \\
\hline Data: & & = & & & $=$ & $I$ & & 1 & & & 1 & \\
\hline & & & ratégias nã & armac & gicas $\mathrm{e}$ & ou medidas d & conforto & & & & & \\
\hline & $\mathrm{M}$ & $\mathrm{T}$ & $\mathrm{N}$ & $\mathrm{M}$ & $\mathrm{T}$ & $\mathrm{N}$ & $\mathrm{M}$ & $\mathrm{T}$ & $\mathrm{N}$ & $\mathrm{M}$ & $\mathrm{T}$ & $\mathrm{N}$ \\
\hline Solução adocicada & & & & & & & & & & & & \\
\hline Sucçãonão-nutritiva & & & & & & & & & & & & \\
\hline Aleitamentomatemo & & & & & & & & & & & & \\
\hline Leite matemo/humano ordenhado & & & & & & & & & & & & \\
\hline Contato pele a pele (canguru) & & & & & & & & & & & & \\
\hline Contenção facilita da & & & & & & & & & & & & \\
\hline Aconchegono leito/ aninhamento & & & & & & & & & & & & \\
\hline Redução de luminosidade & & & & & & & & & & & & \\
\hline Manipulação mírima & & & & & & & & & & & & \\
\hline Outra:__ & & & & & & & & & & & & \\
\hline & & & Estratégias & armace & icas de & analgesia es & dação & & & & & \\
\hline & $\mathrm{M}$ & $\mathrm{T}$ & $\mathrm{N}$ & M & $\mathrm{T}$ & $\mathrm{N}$ & M & $\mathrm{T}$ & $\mathrm{N}$ & $\mathrm{M}$ & $\mathrm{T}$ & $\mathrm{N}$ \\
\hline Dipirona intermitente & & & & & & & & & & & & \\
\hline $\begin{array}{l}\text { Paracetamol intemitente } \\
\end{array}$ & & & & & & & & & & & & \\
\hline Fentaril intermitente & & & & & & & & & & & & \\
\hline Fentaril contínuo & & & & & & & & & & & & \\
\hline Morfina intemitente & & & & & & & & & & & & \\
\hline Morfina contínua & & & & & & & & & & & & \\
\hline Midazolamintemitente & & & & & & & & & & & & \\
\hline Midazolam contínuo & & & & & & & & & & & & \\
\hline Outra: & & & & & & & & & & & & \\
\hline & & & egenda $-P$ & cedi & sdolor & rosos e/ou estr & issantes & & & & & \\
\hline \begin{tabular}{l|l}
1 & Punçãovenosa (terapia IV)
\end{tabular} & 7 & Intubaçã̃ & raqueal & & 13 & Sondagemgá & & & 19 & Fisioterapiare & iratónia & \\
\hline \begin{tabular}{|l|l|}
2 & Punçãovenosa (coleta de sangue) \\
\end{tabular} & 8 & Extubaçã & raqueal & & 14 & Passagem de & & & 20 & Curativo:__ & - & \\
\hline Punção capilar (glicemia) & 9 & Ventilaçẫ & mecârica & & 15 & Passagem cat & ter umbilical & & 21 & Remoção de c & positivo:_ & \\
\hline Punção capilar (teste do Pezinho) & 10 & CPAP & & & 16 & Passagem cat & ter central & & 22 & Outro: & & \\
\hline Punção arterial (coleta de sangue) & 11 & Cateter $\mathrm{N}$ & & & 17 & Sondagemve & & & 23 & Outro:_ & & \\
\hline Punçãointramuscular & 12 & Aspiraçã & leVAS e/ou & inula & 18 & \begin{tabular}{|l} 
Coleta de líqu \\
\end{tabular} & & & 24 & Outro: & & \\
\hline
\end{tabular}


APÊNCIDE D - INSTRUMENTO DE COLETA DE DADOS - CARACTERIZAÇÃO DOS RECÉM-NASCIDOS

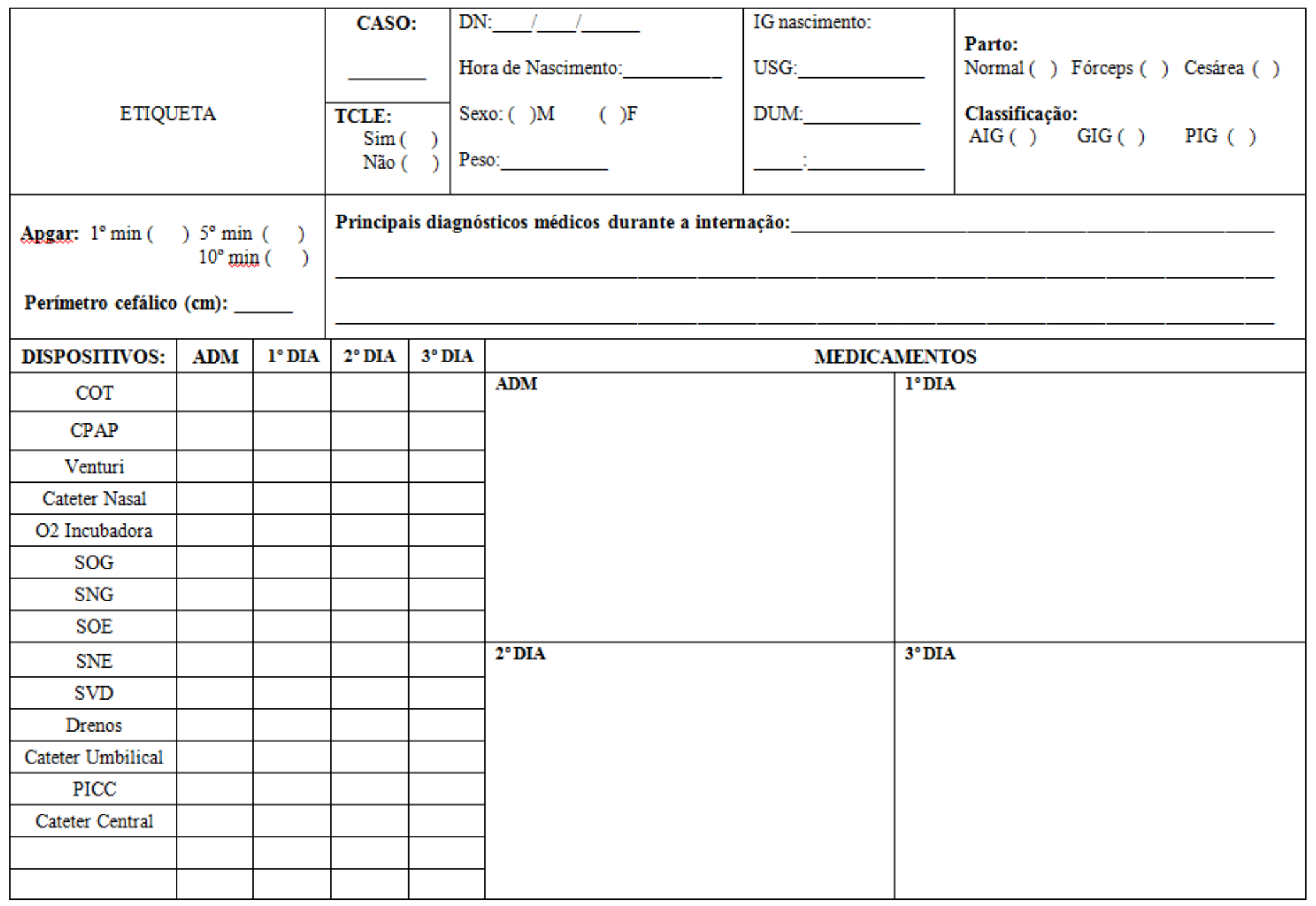




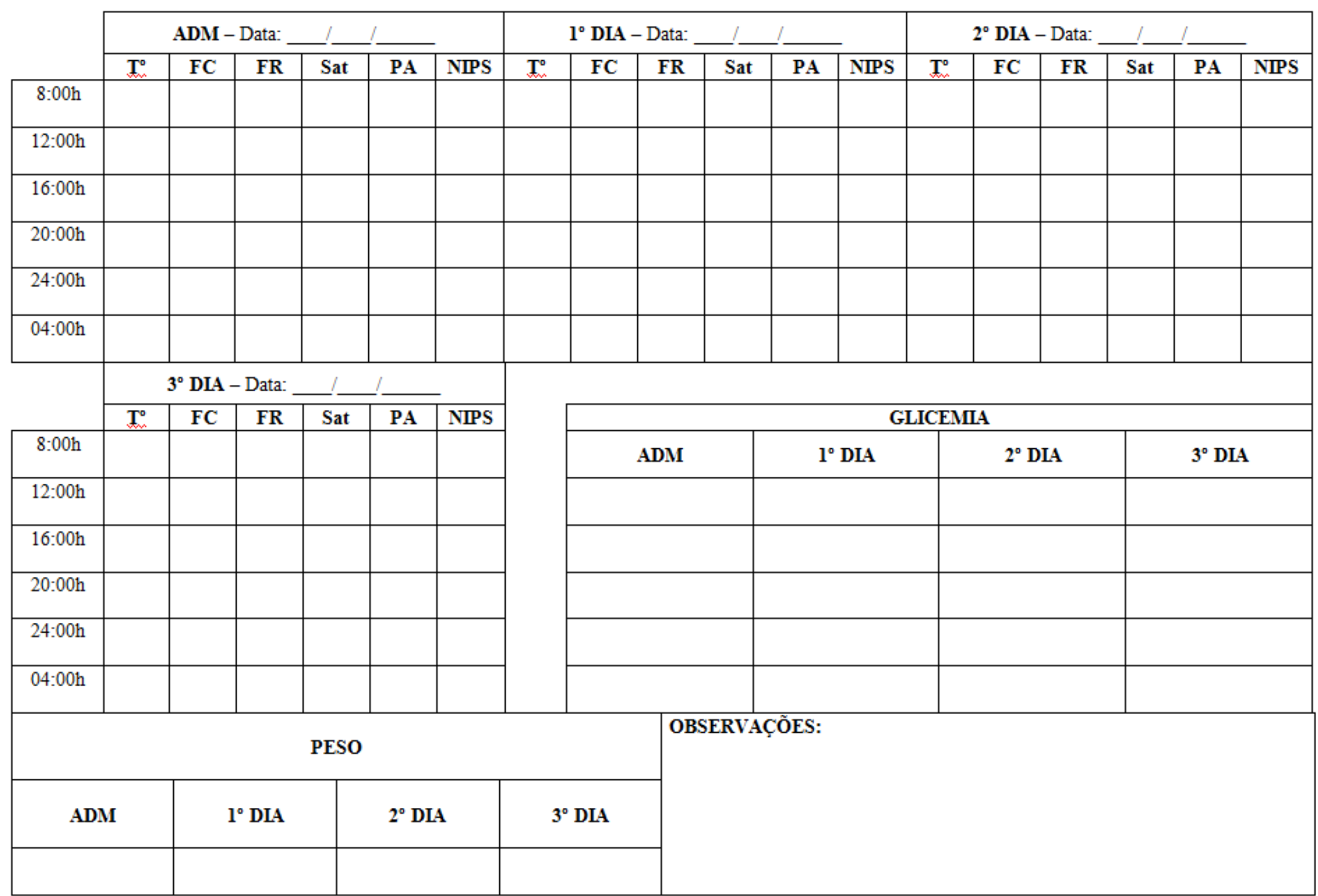


ANEXO 1 - PARECER CONSUBSTANCIADO DO CEP- EEUSP

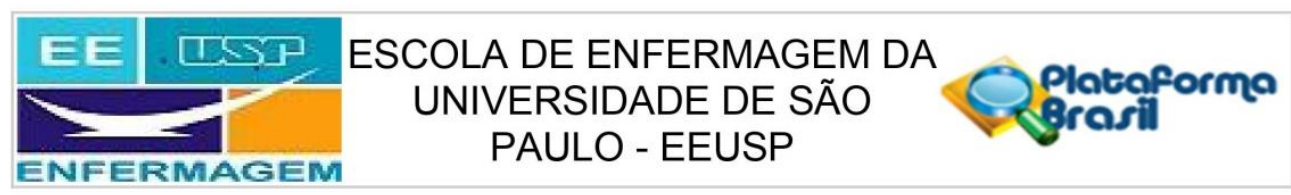

PARECER CONSUBSTANCIADO DO CEP

\section{DADOS DO PROJETO DE PESQUISA}

Título da Pesquisa: AVALIAÇÃO DA DOR EM RECÉM-NASCIDOS HOSPITALIZADOS EM UNIDADE DE TERAPIA INTENSIVA: ASPECTOS FISIOLÓGICOS, ENDÓCRIONOS E COMPORTAMENTAIS

Pesquisador: MARIANA BUENO

Área Temática:

Versão: 2

CAAE: 59994116.0 .0000 .5392

Instituição Proponente: Escola de Enfermagem da Universidade de São Paulo - EEUSP

Patrocinador Principal: Financiamento Próprio

\section{DADOS DO PARECER}

Número do Parecer: 1.833 .194

\section{Apresentação do Projeto:}

Trata-se de um projeto de pesquisa de doutorado, observacional, clínico, prospectivo e de seguimento, no qual serão investigados os procedimentos invasivos, dolorosos e repetitivos a que são expostos nos primeiros cinco dias de hospitalização, além de identificar as intervenções farmacológicas e não farmacológicas empregadas no alívio da dor neonatal e suas possíveis correlações com parâmetros fisiológicos, endócrinos e comportamentais.

Objetivo da Pesquisa:

Geral

Avaliar padrões hormonais, fisiológicas e escores de dor nos primeiros cinco dias de vida em recémnascidos hospitalizados em Unidade de Terapia Intensiva Neonatal.

Específicos

Caracterizar o número e o tipo de procedimentos dolorosos realizados nos primeiros cinco dias de vida de recém-nascidos hospitalizados em Unidade Terapia Intensiva Neonatal;

Caracterizar os registros dos valores de frequência cardiaca e saturação periférica de oxigênio nos primeiros cinco dias de vida de recém-nascidos hospitalizados em Unidade de Terapia Intensiva Neonatal;

Caracterizar os registros de escores de dor mensurados pela escala Neonatal Infant Pain Scale

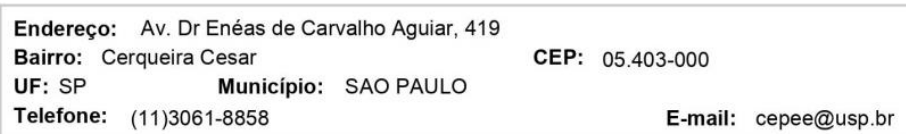




\section{EE UNIVERSIDADE DE SÃO
PAULO - EEUSP}

Continuação do Parecer: 1.833 .194

(NIPS) nos primeiros cinco dias de vida de recém-nascidos hospitalizados em Unidade de Terapia Intensiva Neonatal;

Caracterizar os níveis de cortisol, alfa-amilase e das citocinas pró-inflamatórias (IL-6, IL-8 e TNF) na saliva nos primeiros cinco dias de vida de recém-nascidos hospitalizados em Unidade de Terapia Intensiva Neonatal;

Verificar a correlação entre os registros dos escores de dor com os indicadores fisiológicos (frequência cardíaca e saturação periférica) e os niveis de cortisol salivar, alfa amilase e das citocinas pró-inflamatórias; Determinar e avaliar a correlação dos níveis de cortisol, alfa-amilase e das citocinas pró-inflamatórias associadas à dor (IL-6, IL-8 e TNF) na saliva de recém-nacidos durante os cinco primeiros dias de hospitalização na Unidade de Terapia Intensiva Neonatal;

Correlacionar as variáveis hormonais, fisiológicas e escores de dor com o tipo e número de procedimentos dolorosos realizados nos primeiros cinco dias de vida de recém-nascidos hospitalizados em Unidade de Terapia Intensiva Neonatal.

\section{Avaliação dos Riscos e Benefícios:}

A coleta de saliva é um procedimento de risco mínimo que, contudo, pode causar um desconforto leve como agitação ou incômodo. Desta forma, cuidados serão empregados para minimizar esses riscos, desconfortos e condições adversas que possam causar danos.

Os resultados deste estudo não trarão qualquer benefício imediato para o paciente ou para a família, mas poderão contribuir para o avanço no conhecimento e na divulgação sobre informações referentes à dor neonatal.

\section{Comentários e Considerações sobre a Pesquisa:}

Estudo importante para a área de enfermagem e da saúde, que contibuirá para o manejo da dor em RN e permitirá ampliar o conhecimento existente sobre os efeitos da dor em parâmetros fisiológicos, endócrinos e comportamentais de RN internados em UTI. Serão considerados elegiveis neonatos provenientes do $\mathrm{CO}$ e admitidos na unidade de terapia intensiva, independente da idade gestacional. O estudo será desenvolvido na Unidade de Terapia Intensiva Pediátrica e Neonatal do Hospital Universitário da Universidade de São Paulo. O número e o tipo de procedimentos realizados (o que inclui tentativas sem sucesso) com os RN, assim como possiveis intervenções (estratégias não farmacológicas e/ou medidas de conforto e estratégias farmacológicas de analgesia e sedação) serão registradas pelo profissional de enfermagem responsável pelos cuidados do RN em instrumento/impresso que ficará no prontuário clínico do RN. Os dados referentes aos valores da freqüência cardíaca e da saturação de

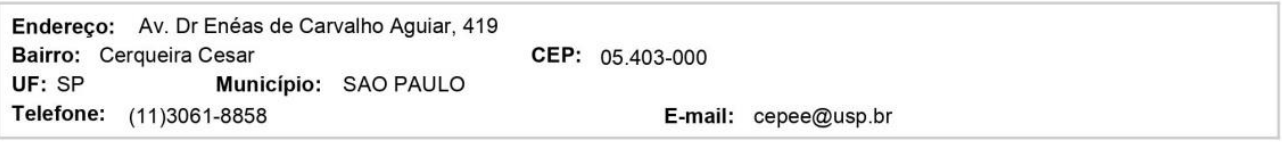




\section{ESCOLA DE ENFERMAGEM DA
UNIVERSIDADE DE SÃO
PAULO - EEUSP}

Continuação do Parecer: 1.833 .194

oxigênio são registrados periodicamente a cada 4 horas para todos os RN internados na unidade e serão obtidos pelo pesquisador a partir de impresso específico que compõe o prontuário de cada RN. A escala de dor (Neonatal Infant Pain Scale - NIPS) é aplicada pelo profissional de enfermagem responsável pelos cuidados do RN a cada 4 horas rotineiramente e registrada em impresso próprio da UTIN, que permanece no prontuário do RN. Posteriormente o pesquisador responsável coletará os dados do prontuário do RN. As coletas de saliva serão realizadas por profissional de enfermagem responsável pelos cuidados do RN devidamente treinado para tal. $O$ treinamento da equipe de enfermagem

será realizado antes do projeto piloto e abordará aspectos teóricos e práticos relacionados avaliação da dor, preenchimento do impresso do número e tipo de procedimentos dolorosos realizados e, sobre a técnica para coletada, identificação e armazenamento da saliva dos RNs. As dosagens da saliva serão realizadas pelo pesquisador responsável. O processamento das amostras de saliva será realizado em colaboração com o Laboratório de Neuroimunoendocrinologia do Departamento de Fisiologia do Instituto de Biociências da Universidade de São Paulo.

\section{Considerações sobre os Termos de apresentação obrigatória:}

Todos são apresentados adequadamente.

\section{Recomendações:}

Não há.

Conclusões ou Pendências e Lista de Inadequações:

Não há.

Considerações Finais a critério do CEP:

Este CEP informa a necessidade de registro dos resultados parciais e finais na Plataforma Brasil.

Esta aprovação não substitui a autorização da instituição coparticipante, antes do início da coleta de dados.

Este parecer foi elaborado baseado nos documentos abaixo relacionados:

\begin{tabular}{|l|l|c|c|c|}
\hline \multicolumn{1}{|c|}{ Tipo Documento } & \multicolumn{1}{|c|}{ Arquivo } & Postagem & Autor & Situação \\
\hline $\begin{array}{l}\text { Informações Básicas } \\
\text { do Projeto }\end{array}$ & PB_INFORMAÇŌES_BÁSICAS_DO_P & $06 / 11 / 2016$ & & Aceito \\
\hline
\end{tabular}

Endereço: Av. Dr Enéas de Carvalho Aguiar, 419

Bairro: Cerqueira Cesar

UF: SP Município: SAO PAULO

CEP: $\quad 05.403-000$

Telefone: (11)3061-8858

E-mail: cepee@usp.br 


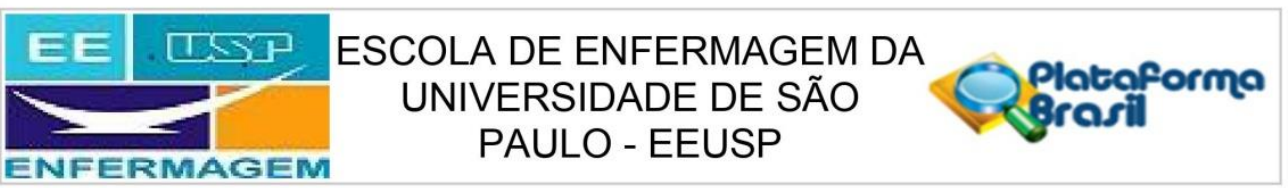

Continuação do Parecer: 1.833.194

\begin{tabular}{|c|c|c|c|c|}
\hline $\begin{array}{l}\text { Projeto Detalhado / } \\
\text { Brochura } \\
\text { Investigador }\end{array}$ & Projeto_doutorado_v11_correcoes.doc & $\begin{array}{c}06 / 11 / 2016 \\
12: 22: 35\end{array}$ & $\begin{array}{l}\text { Vanderlei Amadeu da } \\
\text { Rocha }\end{array}$ & Aceito \\
\hline $\begin{array}{l}\text { TCLE / Termos de } \\
\text { Assentimento / } \\
\text { Justificativa de } \\
\text { Ausência }\end{array}$ & TCLE_v6_correcoes.pdf & $\begin{array}{c}06 / 11 / 2016 \\
12: 21: 06\end{array}$ & $\begin{array}{l}\text { Vanderlei Amadeu da } \\
\text { Rocha }\end{array}$ & Aceito \\
\hline Outros & Carta_anuencia_IBUSP.pdf & $\begin{array}{c}06 / 11 / 2016 \\
12: 18: 08 \\
\end{array}$ & $\begin{array}{l}\begin{array}{l}\text { Vanderlei Amadeu da } \\
\text { Rocha }\end{array} \\
\end{array}$ & Aceito \\
\hline Folha de Rosto & Folha_de_Rosto_VRocha_nova.pdf & $\begin{array}{c}06 / 11 / 2016 \\
12: 14: 39\end{array}$ & $\begin{array}{l}\text { Vanderlei Amadeu da } \\
\text { Rocha }\end{array}$ & Aceito \\
\hline $\begin{array}{l}\text { Projeto Detalhado / } \\
\text { Brochura } \\
\text { Investigador }\end{array}$ & Projeto_doutorado_v11.doc & $\begin{array}{c}12 / 09 / 2016 \\
19: 57: 35\end{array}$ & $\begin{array}{l}\text { Vanderlei Amadeu da } \\
\text { Rocha }\end{array}$ & Aceito \\
\hline Outros & $\begin{array}{l}\text { Carta_anuencia_da_area_envolvida_no } \\
\text { estudo.pdf }\end{array}$ & $\begin{array}{c}03 / 09 / 2016 \\
13: 15: 47\end{array}$ & $\begin{array}{l}\text { Vanderlei Amadeu da } \\
\text { Rocha }\end{array}$ & Aceito \\
\hline Outros & Anuencia_CPesq_Vanderlei.pdf & $\begin{array}{c}03 / 09 / 2016 \\
13: 14: 47 \\
\end{array}$ & \begin{tabular}{|l|} 
Vanderlei Amadeu da \\
Rocha
\end{tabular} & Aceito \\
\hline Outros & $\begin{array}{l}\text { VRocha_Declaracao_Risco_Beneficios. } \\
\text { pdf }\end{array}$ & $\begin{array}{c}03 / 09 / 2016 \\
13: 13: 11 \\
\end{array}$ & $\begin{array}{l}\text { Vanderlei Amadeu da } \\
\text { Rocha }\end{array}$ & Aceito \\
\hline $\begin{array}{l}\text { Declaração de } \\
\text { Pesquisadores } \\
\end{array}$ & VRocha_Declaracao_Compromisso.pdf & $\begin{array}{c}03 / 09 / 2016 \\
13: 11: 20 \\
\end{array}$ & $\begin{array}{l}\text { Vanderlei Amadeu da } \\
\text { Rocha }\end{array}$ & Aceito \\
\hline Outros & Instrumento_coleta_dados_v3.pdf & $\begin{array}{c}03 / 09 / 2016 \\
13: 06: 05 \\
\end{array}$ & $\begin{array}{l}\text { Vanderlei Amadeu da } \\
\text { Rocha }\end{array}$ & Aceito \\
\hline $\begin{array}{l}\text { Declaração de } \\
\text { Instituição e } \\
\text { Infraestrutura } \\
\end{array}$ & Decl_Infraestrutura_Vanderlei.pdf & $\begin{array}{c}03 / 09 / 2016 \\
13: 04: 14\end{array}$ & $\begin{array}{l}\text { Vanderlei Amadeu da } \\
\text { Rocha }\end{array}$ & Aceito \\
\hline Orçamento & VRocha_Orcamento.pdf & $\begin{array}{c}03 / 09 / 2016 \\
13: 01: 29 \\
\end{array}$ & \begin{tabular}{|l|} 
Vanderlei Amadeu da \\
Rocha
\end{tabular} & Aceito \\
\hline $\begin{array}{l}\text { Projeto Detalhado / } \\
\text { Brochura } \\
\text { Investigador }\end{array}$ & Projeto_doutorado_v11.pdf & $\begin{array}{c}03 / 09 / 2016 \\
13: 00: 04\end{array}$ & $\begin{array}{l}\text { Vanderlei Amadeu da } \\
\text { Rocha }\end{array}$ & Aceito \\
\hline $\begin{array}{l}\text { TCLE / Termos de } \\
\text { Assentimento / } \\
\text { Justificativa de } \\
\text { Ausência } \\
\end{array}$ & TCLE_v6.pdf & $\begin{array}{c}03 / 09 / 2016 \\
12: 58: 45\end{array}$ & $\begin{array}{l}\text { Vanderlei Amadeu da } \\
\text { Rocha }\end{array}$ & Aceito \\
\hline Outros & VRocha_cadastrover2016.pdf & $\begin{array}{c}03 / 09 / 2016 \\
12: 57: 21 \\
\end{array}$ & \begin{tabular}{|l|} 
Vanderlei Amadeu da \\
Rocha
\end{tabular} & Aceito \\
\hline Cronograma & VRocha_Cronograma.pdf & $\begin{array}{c}03 / 09 / 2016 \\
12: 55: 56 \\
\end{array}$ & \begin{tabular}{|l|} 
Vanderlei Amadeu da \\
Rocha
\end{tabular} & Aceito \\
\hline
\end{tabular}

Situação do Parecer:

Aprovado

Necessita Apreciação da CONEP:

Não

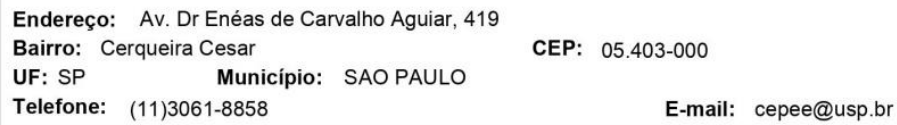




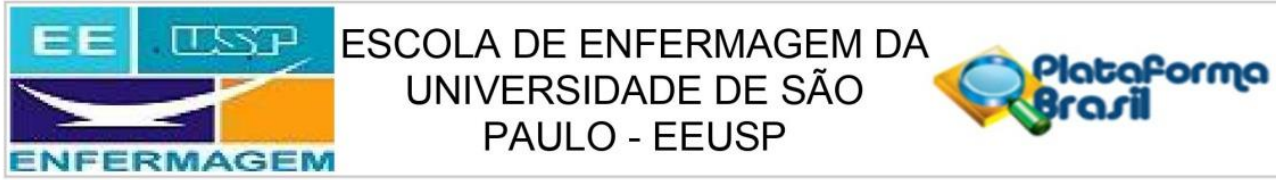

Continuação do Parecer: 1.833.194

SAO PAULO, 23 de Novembro de 2016

Assinado por:

Marcelo José dos Santos

(Coordenador)

Endereço: Av. Dr Enéas de Carvalho Aguiar, 419 
ANEXO 2 - PARECER CONSUBSTANCIADO DO CEP- HU/USP

USP - HOSPITAL
UNIVERSITÁRIO DA
UNIVERSIDADE DE SÃO

\section{PARECER CONSUBSTANCIADO DO CEP}

Elaborado pela Instituição Coparticipante

DADOS DO PROJETO DE PESQUISA

Título da Pesquisa: AVALIAÇÃO DA DOR EM RECÉM-NASCIDOS HOSPITALIZADOS EM UNIDADE DE TERAPIA INTENSIVA: ASPECTOS FISIOLÓGICOS, ENDÓCRIONOS E COMPORTAMENTAIS

Pesquisador: MARIANA BUENO

Área Temática:

Versão: 1

CAAE: 59994116.0 .3001 .0076

Instituição Proponente: Escola de Enfermagem da Universidade de São Paulo - EEUSP

Patrocinador Principal: Financiamento Próprio

DADOS DO PARECER

Número do Parecer: 1.870 .943

Apresentação do Projeto:

Avaliação da dor em RN hospitalizados em UTIN é de importância vital devido ao grande número de procedimentos dolorosos a que são expostos. Embora a compreensão da dor tenha avançado, muitos aspectos relacionados à avaliação e manejo da dor neonatal permanecem inexplorados. O desenvolvimento do presente estudo permitirá traçar um perfil dos RN hospitalizados em UTIN, bem como descrever os procedimentos invasivos, dolorosos e repetitivos a que são expostos nos primeiros cinco dias de hospitalização, além de identificar as intervenções farmacológicas e não farmacológicas empregadas no alívio da dor neonatal e suas possíveis correlações com parâmetros fisiológicos, endócrinos e comportamentais. Neste estudo, a avaliação da dor será fundamentada nas variáveis fisiológicas, comportamentais e nas dosagens salivares dos níveis de cortisol,

alfa amilase e de citocinas pró-inflamatórias, proposta que se justifica pelo ineditismo e que apresenta grande relevância, pois fornecerá fundamentação científica que poderá contribuir para avaliação e manejo da dor, aprimorando a assistência ao neonato e possibilitando análises futuras acerca dos impactos imediatos ou mesmo tardios decorrentes da exposição do RN a procedimentos dolorosos.

\section{Objetivo da Pesquisa:}

Objetivo Primário: - Descrever as variáveis hormonais, fisiológicas e escores de dor nos primeiros

\begin{tabular}{|c|c|c|c|}
\hline \multicolumn{4}{|c|}{ Endereço: Av. Prof ${ }^{\circ}$ Lineu Prestes, 2565} \\
\hline Bairro: & Cidade Universitária & CEP: & $05.508-000$ \\
\hline UF: SP & Município: & SAO PAULO & \\
\hline Telefone & e: (11)3091-9457 & Fax: (11)3091-9452 & E-mail: \\
\hline
\end{tabular}




\section{USP - HOSPITAL UNIVERSITÁRIO DA UNIVERSIDADE DE SÃO

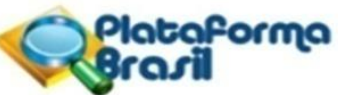

Continuação do Parecer: 1.870 .943

cinco dias de vida em recém-nascidos hospitalizados em Unidade de Terapia Intensiva Neonatal.

Objetivo Secundário: - - Caracterizar o número e o tipo de procedimentos dolorosos realizados nos primeiros cinco dias de vida de recém-nascidos hospitalizados em

Unidade Terapia Intensiva Neonatal; - - Caracterizar os registros dos valores de frequência cardíaca e saturação periférica de oxigênio nos primeiros cinco dias de vida de recém-nascidos hospitalizados em Unidade de Terapia Intensiva Neonatal; - - Caracterizar os registros de escores de dor mensurados pela escala Neonatal Infant Pain Scale (NIPS) nos primeiros cinco dias de vida de recém nascidos hospitalizados em Unidade de Terapia Intensiva Neonatal; - • Caracterizar os níveis de cortisol, alfa-amilase e das citocinas pró-inflamatórias (IL-6, IL-8 e TNF) na saliva nos primeiros cinco dias de vida de recém-nascidos hospitalizados em Unidade de Terapia Intensiva Neonatal; - • Verificar a correlação entre os registros dos escores de dor com os indicadores fisiológicos (frequência cardíaca e saturação periférica) e os níveis de cortisol salivar, alfa amilase e das citocinas pró-inflamatórias; - • Determinar e avaliar a correlação dos níveis de cortisol, alfa-amilase e das citocinas pró-inflamatórias associadas à dor (IL-6, IL-8 e TNF) na saliva de recém-nascidos durante os cinco primeiros dias de hospitalização na Unidade de Terapia Intensiva Neonatal; - - Correlacionar as variáveis hormonais, fisiológicas e escores de dor com o tipo e número de procedimentos dolorosos realizados nos primeiros cinco dias de vida de recém-nascidos hospitalizados em Unidade de Terapia Intensiva Neonatal;

Critério de Inclusão: - Serão considerados elegíveis neonatos provenientes do co e admitidos na unidade de terapia intensiva, independente da idade gestacional.

Critério de Exclusão: - Serão excluídos deste estudo RN com qualquer tipo de malformação grave (estrutura, função ou metabolismo), anomalias congênitas (físicas ou

mentais), hemorragia intraventricular grau III ou IV, hidrocefalia, microcefalia, síndromes genéticas e que tiverem alta ou que morrerem antes do término do período de coleta.

\section{Avaliação dos Riscos e Benefícios:}

Riscos: - A coleta de saliva é um procedimento de risco mínimo que, contudo, pode causar um desconforto leve como agitação ou incômodo. Desta forma,cuidados serão empregados para minimizar esses riscos, desconfortos e condições adversas que possam causar danos.

Benefícios: - Os resultados deste estudo não trarão qualquer benefício imediato para o paciente ou para a família, mas poderão contribuir para o avanço no conhecimento e na divulgação sobre informações referentes à dor neonatal.

Comentários e Considerações sobre a Pesquisa:

Desfecho Primário: -Estabelecer possível correlação entre as variáveis bioquímicas, fisiológicas,

Endereço: Av. Profo Lineu Prestes, 2565

Bairro: Cidade Universitária

UF: SP Município: SAOPAULO

Telefone: (11)3091-9457 Fax: (11)3091-9452 E-mail: cep@hu.usp.br 


\section{USP - HOSPITAL UNIVERSITÁRIO DA UNIVERSIDADE DE SÃO}

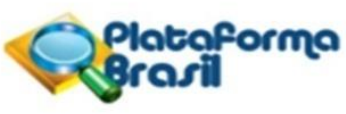

Continuação do Parecer: 1.870 .943

hormonais e escores de dor em recém-nascidos (RNs) admitidos na

Unidade de Terapia Intensiva Neonatal (UTIN). Pretende-se um N de 100 participantes.

Considerações sobre os Termos de apresentação obrigatória:

Em conformidade com as normas.

Recomendações:

Não existem recomendações para o projeto em tela.

Conclusões ou Pendências e Lista de Inadequações:

Não existem.

Considerações Finais a critério do CEP:

O projeto foi apresentado e aprovado na reunião de hoje.Lembramos que cabe ao pesquisador elaborar e apresentar a este Comitê, relatórios parciais e final, de acordo com a Resolução n 466/2012 do Conselho Nacional de Saúde, inciso XI.2, letra "d".

Este parecer foi elaborado baseado nos documentos abaixo relacionados:

\begin{tabular}{|c|c|c|c|c|}
\hline Tipo Documento & Arquivo & Postagem & Autor & Situação \\
\hline $\begin{array}{l}\text { Informações Básicas } \\
\text { do Projeto }\end{array}$ & $\begin{array}{l}\text { PB_INFORMAÇÕES_BÁSICAS_DO_P } \\
\text { ROJETO 766440.pdf }\end{array}$ & $\begin{array}{c}06 / 11 / 2016 \\
12: 24: 34 \\
\end{array}$ & & Aceito \\
\hline $\begin{array}{l}\text { Projeto Detalhado / } \\
\text { Brochura } \\
\text { Investigador }\end{array}$ & Projeto_doutorado_v11_correcoes.doc & $\begin{array}{l}06 / 11 / 2016 \\
12: 22: 35\end{array}$ & $\begin{array}{l}\text { Vanderlei Amadeu da } \\
\text { Rocha }\end{array}$ & Aceito \\
\hline $\begin{array}{l}\text { TCLE / Termos de } \\
\text { Assentimento / } \\
\text { Justificativa de } \\
\text { Ausência }\end{array}$ & TCLE_v6_correcoes.pdf & $\begin{array}{c}06 / 11 / 2016 \\
12: 21: 06\end{array}$ & $\begin{array}{l}\text { Vanderlei Amadeu da } \\
\text { Rocha }\end{array}$ & Aceito \\
\hline Outros & Carta_anuencia_IBUSP.pdf & $\begin{array}{c}06 / 11 / 2016 \\
12: 18: 08 \\
\end{array}$ & \begin{tabular}{|l|} 
Vanderlei Amadeu da \\
Rocha
\end{tabular} & Aceito \\
\hline Folha de Rosto & Folha_de_Rosto_VRocha_nova.pdf & $\begin{array}{c}06 / 11 / 2016 \\
12: 14: 39 \\
\end{array}$ & $\begin{array}{l}\text { Vanderlei Amadeu da } \\
\text { Rocha }\end{array}$ & Aceito \\
\hline $\begin{array}{l}\text { Informações Básicas } \\
\text { do Projeto }\end{array}$ & $\begin{array}{l}\text { PB_INFORMAÇÕES_BÁSICAS_DO_P } \\
\text { ROJETO 766440.pdf }\end{array}$ & $\begin{array}{c}12 / 09 / 2016 \\
19: 58: 39 \\
\end{array}$ & & Aceito \\
\hline $\begin{array}{l}\text { Projeto Detalhado / } \\
\text { Brochura } \\
\text { Investigador }\end{array}$ & Projeto_doutorado_v11.doc & $\begin{array}{c}12 / 09 / 2016 \\
19: 57: 35\end{array}$ & $\begin{array}{l}\text { Vanderlei Amadeu da } \\
\text { Rocha }\end{array}$ & Aceito \\
\hline $\begin{array}{l}\text { Informações Básicas } \\
\text { do Projeto }\end{array}$ & \begin{tabular}{|l|} 
PB_INFORMAÇÕES_BÁSICAS_DO_P \\
ROJETO 766440.pdf \\
\end{tabular} & $\begin{array}{c}03 / 09 / 2016 \\
13: 20: 49 \\
\end{array}$ & & Aceito \\
\hline Outros & $\begin{array}{l}\text { Carta_anuencia_da_area_envolvida_no } \\
\text { estudo.pdf }\end{array}$ & $\begin{array}{c}03 / 09 / 2016 \\
13: 15: 47\end{array}$ & \begin{tabular}{|l|} 
Vanderlei Amadeu da \\
Rocha
\end{tabular} & Aceito \\
\hline Outros & Anuencia_CPesq_Vanderlei.pdf & $03 / 09 / 2016$ & Vanderlei Amadeu & Aceito \\
\hline
\end{tabular}

Endereço: Av. Profo Lineu Prestes, 2565

Bairro: Cidade Universitária

CEP: $05.508-000$

UF: SP Município: SAO PAULO

Telefone: (11)3091-9457 Fax: (11)3091-9452 E-mail: cep@hu.usp.br 


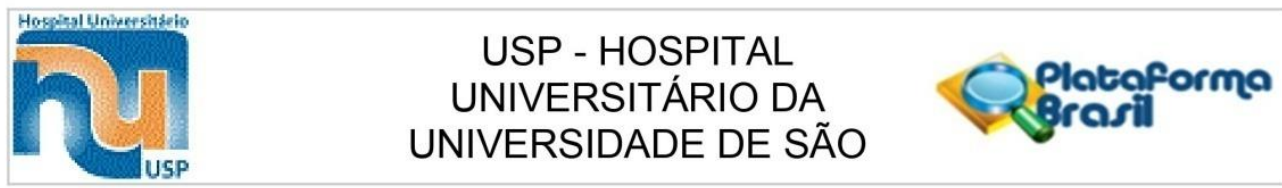

Continuação do Parecer: 1.870 .943

\begin{tabular}{|c|c|c|c|c|}
\hline Outros & Anuencia_CPesq_Vanderlei.pdf & $13: 14: 47$ & da Rocha & Aceito \\
\hline Outros & $\begin{array}{l}\text { VRocha_Declaracao_Risco_Beneficios. } \\
\text { pdf }\end{array}$ & $\begin{array}{c}03 / 09 / 2016 \\
13: 13: 11\end{array}$ & $\begin{array}{l}\text { Vanderlei Amadeu da } \\
\text { Rocha }\end{array}$ & Aceito \\
\hline $\begin{array}{l}\text { Declaração de } \\
\text { Pesquisadores }\end{array}$ & VRocha_Declaracao_Compromisso.pdf & $\begin{array}{c}03 / 09 / 2016 \\
13: 11: 20 \\
\end{array}$ & $\begin{array}{l}\text { Vanderlei Amadeu da } \\
\text { Rocha }\end{array}$ & Aceito \\
\hline Outros & Instrumento_coleta_dados_v3.pdf & $\begin{array}{c}03 / 09 / 2016 \\
13: 06: 05\end{array}$ & $\begin{array}{l}\text { Vanderlei Amadeu da } \\
\text { Rocha }\end{array}$ & Aceito \\
\hline $\begin{array}{l}\text { Declaração de } \\
\text { Instituição e } \\
\text { Infraestrutura }\end{array}$ & Decl_Infraestrutura_Vanderlei.pdf & $\begin{array}{l}03 / 09 / 2016 \\
13: 04: 14\end{array}$ & $\begin{array}{l}\text { Vanderlei Amadeu da } \\
\text { Rocha }\end{array}$ & Aceito \\
\hline Orçamento & VRocha_Orcamento.pdf & $\begin{array}{c}03 / 09 / 2016 \\
13: 01: 29\end{array}$ & $\begin{array}{l}\text { Vanderlei Amadeu da } \\
\text { Rocha }\end{array}$ & Aceito \\
\hline $\begin{array}{l}\text { Projeto Detalhado / } \\
\text { Brochura } \\
\text { Investigador }\end{array}$ & Projeto_doutorado_v11.pdf & $\begin{array}{l}\text { 03/09/2016 } \\
13: 00: 04\end{array}$ & $\begin{array}{l}\text { Vanderlei Amadeu da } \\
\text { Rocha }\end{array}$ & Aceito \\
\hline $\begin{array}{l}\text { TCLE / Termos de } \\
\text { Assentimento / } \\
\text { Justificativa de } \\
\text { Ausência }\end{array}$ & TCLE_v6.pdf & $\begin{array}{c}03 / 09 / 2016 \\
12: 58: 45\end{array}$ & $\begin{array}{l}\text { Vanderlei Amadeu da } \\
\text { Rocha }\end{array}$ & Aceito \\
\hline Outros & VRocha_cadastrover2016.pdf & $\begin{array}{c}03 / 09 / 2016 \\
12: 57: 21 \\
\end{array}$ & $\begin{array}{l}\text { Vanderlei Amadeu da } \\
\text { Rocha }\end{array}$ & Aceito \\
\hline Cronograma & VRocha_Cronograma.pdf & $\begin{array}{c}03 / 09 / 2016 \\
12: 55: 56\end{array}$ & $\begin{array}{l}\text { Vanderlei Amadeu da } \\
\text { Rocha }\end{array}$ & Aceito \\
\hline Folha de Rosto & Folha_rosto_VRocha.pdf & $\begin{array}{c}03 / 09 / 2016 \\
12: 52: 27\end{array}$ & $\begin{array}{l}\text { Vanderlei Amadeu da } \\
\text { Rocha }\end{array}$ & Aceito \\
\hline
\end{tabular}

Situação do Parecer:

Aprovado

Necessita Apreciação da CONEP:

Não

SAO PAULO, 16 de Dezembro de 2016

Assinado por:

Mauricio Seckler

(Coordenador)

Endereço: Av. Prof ${ }^{\circ}$ Lineu Prestes, 2565

Bairro: Cidad Univineu Pre

CEP: $\quad 05.508-000$

UF: SP Município: SAOPAULO

Telefone: (11)3091-9457 Fax: (11)3091-9452 E-mail: cep@hu.usp.br 